NATIONAL LABORATORY

\title{
Design Study for a Low-Enriched Uranium Core for the High Flux Isotope Reactor, Annual Report for FY 2010
}

February 2011

Prepared by

R. T. Primm III

D. H. Cook

J. D. Freels

G. Ilas

B. C. Jolly

J. H. Miller

D. L. Pinkston

D. G. Renfro

J. D. Sease
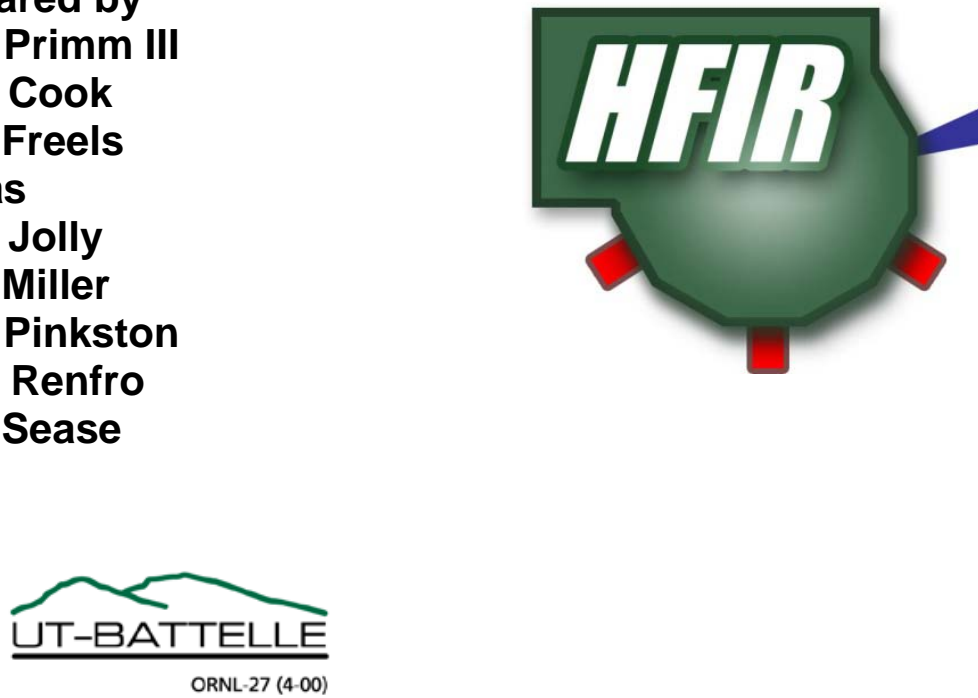


\title{
DOCUMENT AVAILABILITY
}

Reports produced after January 1, 1996, are generally available free via the U.S. Department of Energy (DOE) Information Bridge.

Web site http://www.osti.gov/bridge

Reports produced before January 1, 1996, may be purchased by members of the public from the following source.

\author{
National Technical Information Service \\ 5285 Port Royal Road \\ Springfield, VA 22161 \\ Telephone 703-605-6000 (1-800-553-6847) \\ TDD 703-487-4639 \\ Fax 703-605-6900 \\ E-mail info@ntis.fedworld.gov \\ Web site http://www.ntis.gov/support/ordernowabout.htm
}

Reports are available to DOE employees, DOE contractors, Energy Technology Data Exchange (ETDE) representatives, and International Nuclear Information System (INIS) representatives from the following source.

Office of Scientific and Technical Information

P.O. Box 62

Oak Ridge, TN 37831

Telephone 865-576-8401

Fax 865-576-5728

E-mail reports@osti.gov

Web site http://www.osti.gov/contact.html

This report was prepared as an account of work sponsored by an agency of the United States Government. Neither the United States government nor any agency thereof, nor any of their employees, makes any warranty, express or implied, or assumes any legal liability or responsibility for the accuracy, completeness, or usefulness of any information, apparatus, product, or process disclosed, or represents that its use would not infringe privately owned rights. Reference herein to any specific commercial product, process, or service by trade name, trademark, manufacturer, or otherwise, does not necessarily constitute or imply its endorsement, recommendation, or favoring by the United States Government or any agency thereof. The views and opinions of authors expressed herein do not necessarily state or reflect those of the United States Government or any agency thereof. 


\title{
DESIGN STUDY FOR A LOW-ENRICHED URANIUM CORE FOR THE HIGH FLUX ISOTOPE REACTOR, ANNUAL REPORT FOR FY 2010
}

\author{
R. T. Primm III \\ D. H. Cook \\ J. D. Freels \\ G. Ilas \\ B. C. Jolly \\ J. H. Miller \\ D. L. Pinkston \\ D. G. Renfro \\ J. D. Sease
}

Date Published: February 2011

\footnotetext{
Prepared by

OAK RIDGE NATIONAL LABORATORY

Oak Ridge, Tennessee 37831-6283

managed by

UT-BATTELLE, LLC

for the

U.S. DEPARTMENT OF ENERGY

under contract DE-AC05-00OR22725
} 



\section{CONTENTS}

Page

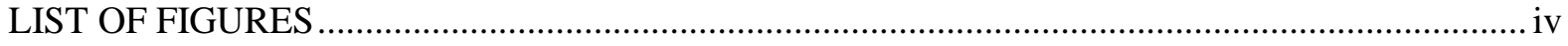

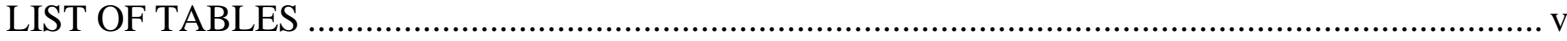

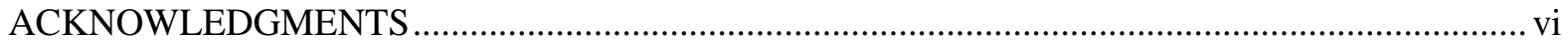

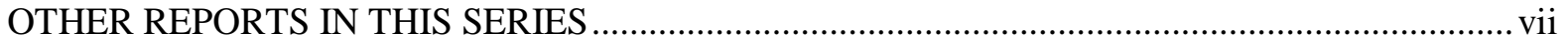

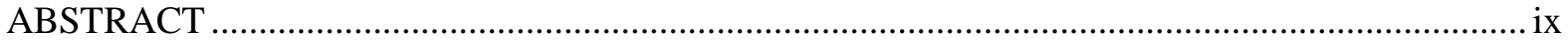

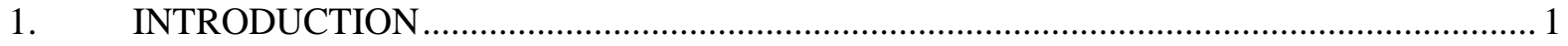

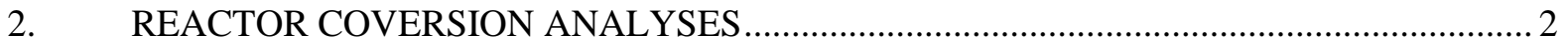

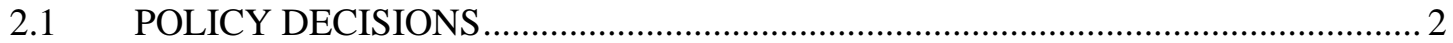

2.2 QUALITY ASSURANCE OPERATIONS OUTSIDE HFIR SITE .......................... 2

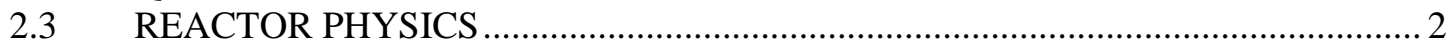

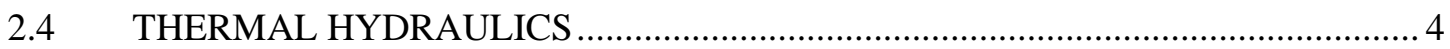

2.5 OREGON STAE UNIVERSITY (OSU) TEST LOOP PARTICIPATION.................. 6

2.5.1 Isothermal Measurements Required to Support HFIR Conversion................... 9

2.5.2 Preconceptual Design of OSU HMFTF HFIR Test Pieces ............................. 11

2.6 ACHIEVING 100 MW: FUEL QUALIFICATION TESTS FOR LEU FUEL ........ 13

2.6.1 Review of Thermal Hydraulic Testing for the HFIR Design and Safety Analysis................................................................................ 13

2.6.2 Proposed Involute Plate Thermal Deflection Separate Effects Testing ........ 14

2.7 ACHIEVING 100 MW: INFRASTRUCTURE UPGRADES/ANALYSES ............ 17

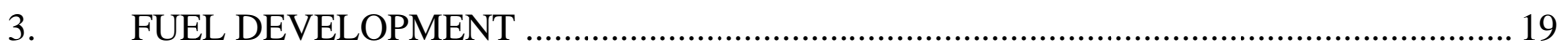

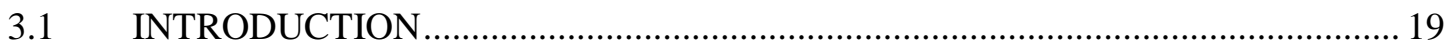

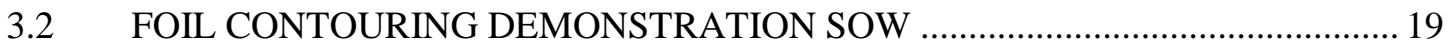

3.3 CONTOURED ROLLING FEASIBILITY RESULTS ........................................ 20

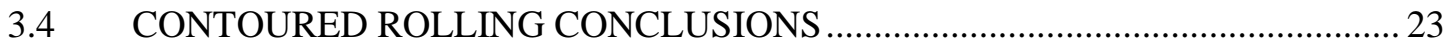

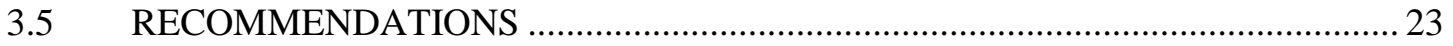

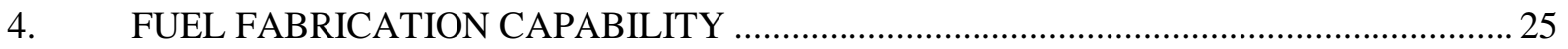

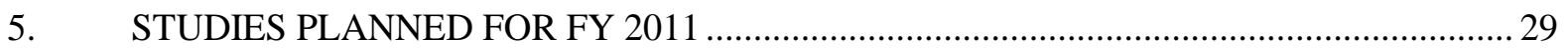

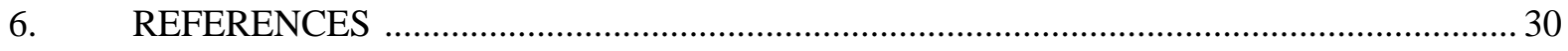

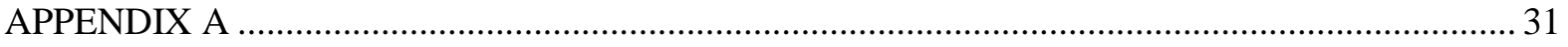

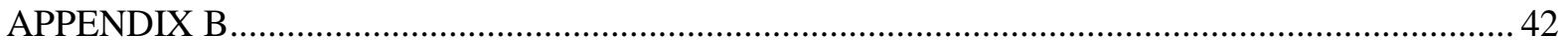





\section{LIST OF FIGURES}

Page

$1 \quad$ Radial fuel thickness profiles inside HFIR fuel plates .......................................................... 3

2. Axial grading profile for LEU fuel $(0-3 \mathrm{~cm}$ from the bottom of each fuel element plate)........ 3

3. Photograph of HFIR fuel plate hydraulic test assemblies - flat plates.................................. 7

4. $\quad$ Photograph of HFIR fuel plate hydraulic test assemblies — involute plates ............................ 7

5. Original involute hydraulic test assembly detailed design drawings — flow inlet end ............ 8

6. Original involute hydraulic test assembly detailed design drawings — side view ................... 8

7. Original involute hydraulic test assembly detailed design drawings — flow exit end ............. 9

8. Isometric view of Preconceptual HFIR test assembly for use in HMFTF ............................. 11

9. Isometric view of Preconceptual HFIR plate subassembly for use in HMFTF....................... 12

10. End view of Preconceptual HFIR single plate and nine plate subassemblies ........................ 13

11. Photographs of Cheverton-Kelly test apparatus — side and end views ................................. 15

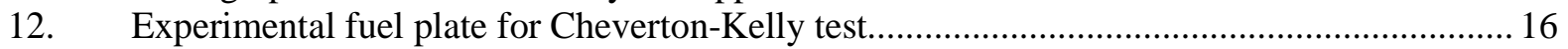

13. Excerpt from assembly drawing for Cheverton-Kelly test apparatus..................................... 17

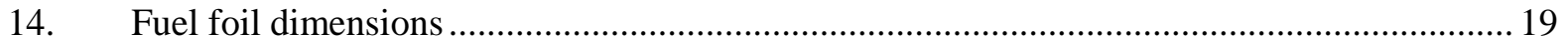

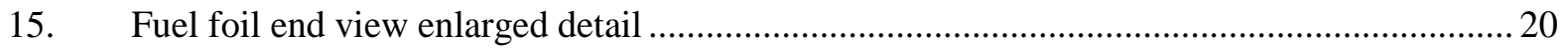

16. Photograph "A" of the first contoured rolling attempt (photo provided by IRM).................. 21

17. Double strip symmetrical contoured rolling profile schematic used in the second

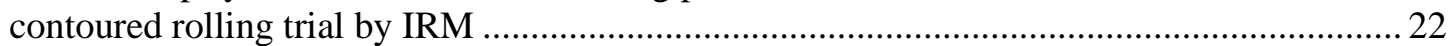

18. Photograph "A" of the second contoured rolling attempt (photo provided by IRM) .............. 22

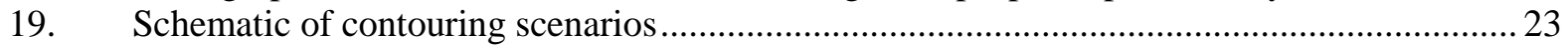

20. Revised, proposed, LEU fuel fabrication flowsheet.............................................................. 26 



\section{LIST OF TABLES}

Page

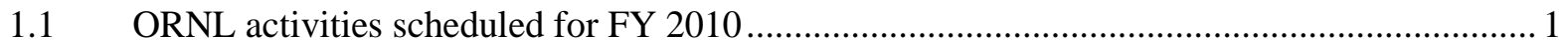

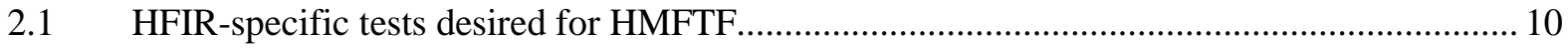

2.2 Operating conditions for HFIR LEU testing ..................................................................... 10

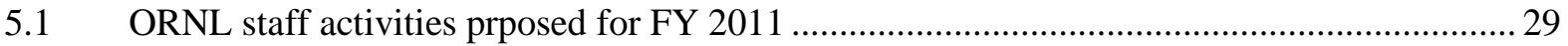





\section{ACKNOWLEDGMENTS}

The authors would like to acknowledge that the support for this project was provided by the Global Threat Reduction Initiative, Reduced Enrichment for Research and Test Reactors program (RERTR), Nuclear National Security Administration, U. S. Department of Energy (DOE). The DOE program manager was Dr. Parrish Staples and the Argonne National Laboratory RERTR reactor conversion program manager was Dr. John Stevens. The authors also acknowledge the technical review of this document performed by Dr. K. A. Smith, Research Reactors Division, Oak Ridge National

Laboratory. Finally, the authors wish to thank Mary Wells for document preparation and editing of this report. 



\section{OTHER REPORTS IN THIS SERIES}

R. T. Primm III, R. J. Ellis, J. C. Gehin, D. L. Moses, J. L. Binder, and N. Xoubi, Assumptions and Criteria for Performing a Feasibility Study of the Conversion of the High Flux Isotope Reactor Core to Use Low-Enriched Uranium Fuel, ORNL/TM-2005/269, February 2006.

R. T. Primm III, R. J. Ellis, J. C. Gehin, K. T. Clarno, K. A. Williams, and D. L. Moses, Design Study for a Low-Enriched Uranium Core for the High Flux Isotope Reactor, Annual Report for FY 2006, ORNL/TM-2006/136, November 2006.

J. D. Sease, R. T. Primm III, and J. H. Miller, Conceptual Process for the Manufacture of Lowenriched Uranium/Molybdenum Fuel for the High Flux Isotope Reactor, ORNL/TM-2007/39, September 2007.

R. T. Primm III, R. J. Ellis, J. C. Gehin, G. Ilas, J. H. Miller, and J. D. Sease, Design Study for a LowEnriched Uranium Core for the High Flux Isotope Reactor, Annual Report for FY 2007, ORNL/TM2007/45, November 2007.

D. Chandler, R. T. Primm, III, and G. I. Maldonado, Validating MCNP for LEU Fuel Design via Power Distribution Comparisons, ORNL/TM-2008/126, November 2008.

Lee Tschaepe, Arthur E. Ruggles, James D. Freels, and R. T. Primm, III, Evaluation of HFIR LEU Fuel Using the COMSOL Multiphysics Platform, ORNL/TM-2008/188, March 2009.

C. Galvez Velit, R. T. Primm III, and J. C. Gehin, Partial Safety Analysis for a Reduced Uranium Enrichment Core for the High Flux Isotope Reactor, ORNL/TM-2007/226, April 2009.

R. T. Primm III, D. Chandler, G. Ilas, B. C. Jolly, J. H. Miller, and J. D. Sease, Design Study for a Low-Enriched Uranium Core for the High Flux Isotope Reactor, Annual Report for FY 2008, ORNL/TM-2009/87, March 2009.

D. Chandler, R. T. Primm, III, and G. I. Maldonado, Validation of a Monte Carlo Based Depletion Methodology with HFIR Post-Irradiation Examination Data, ORNL/TM-2009/123, July 2009.

G. Ilas and R. T. Primm, III, Fuel Grading Study on a Low-Enriched Uranium Fuel Design for the High Flux Isotope Reactor, ORNL/TM-2009/223, November 2009, revised and reissued as ORNL/TM-2009/223/R1, March 2010.

Tracey Guida and R. T. Primm, III, Establishing a Cost Basis for Converting the High Flux Isotope Reactor from High Enriched to Low Enriched Uranium Fuel, ORNL/TM-2009/311, February 2010.

R. T. Primm, III, D. Chandler, J. D. Freels, T. Guida, G. Ilas, B. C. Jolly, J. H. Miller, and J. D. Sease, Design Study for a Low-Enriched Uranium Core for the High Flux Isotope Reactor, Annual Report for FY 2009, ORNL/TM-2009/313, February 2010.

J. D. Freels, I. T. Bodey, R. V. Arimilli, and K. T. Lowe, Two Dimensional Thermal Hydraulic Analysis and Benchmark in Support of HFIR LEU Conversion Using COMSOL, ORNL/TM-2010/18, September 2010. 
G. Ilas and R. T. Primm, III, Low Enriched Uranium Fuel Design with Two-Dimensional Grading for the High Flux Isotope Reactor, ORNL/TM-2010/318, expected publication February 2011.

R. T. Primm, III, D. L. Pinkston, J. D. Sease, and D. G. Renfro, Establishing Specifications for Low Enriched Uranium Fuel Operations Conducted Outside the High Flux Isotope Reactor Site, ORNL/TM-2010/241, September 2010. 


\begin{abstract}
This report is documentation of progress made during FY 2010 in studies of converting the High Flux Isotope Reactor (HFIR) from high enriched uranium (HEU) fuel to low enriched uranium (LEU) fuel. Conversion from HEU to LEU will require a change in fuel form from uranium oxide to a uraniummolybdenum alloy. With axial and radial grading of the fuel foil and an increase in reactor power to $100 \mathrm{MW}$, calculations indicate that the HFIR can be operated with LEU fuel with no degradation in performance to users from the current levels achieved with HEU fuel. Studies are reported of support to a thermal hydraulic test loop design, the implementation of finite element, thermal hydraulic analysis capability with the goal of simplifying the LEU fuel plate design, and infrastructure tasks at HFIR to upgrade the facility for operation at $100 \mathrm{MW}$. A discussion of concerns regarding preparation of a fuel specification for the uranium-molybdenum alloy is provided. Continuing development in the definition of the fuel fabrication process is described.
\end{abstract}





\section{INTRODUCTION}

Design studies for a low-enriched uranium (LEU) core for the High Flux Isotope Reactor (HFIR) were conducted according to the plan documented in ref. 1. A list of the studies that had been planned for fiscal year (FY) 2010 - published in ref. 1 - are shown in Table 1.1. Progress in reactor analysis studies, fuel fabrication capability, and material development are presented in separate sections of this report. The final section of this report is devoted to a discussion of tasks planned for FY 2011.

Table 1.1. ORNL activities scheduled for FY 2010

\begin{tabular}{|c|c|c|}
\hline $\begin{array}{l}\text { Report } \\
\text { section }\end{array}$ & Subtask & Comments \\
\hline 2.1 & Policy decisions & $\begin{array}{l}\text { There has been little communication directly between HFIR staff and Office of } \\
\text { Science staff. It is anticipated that at least one meeting will be required to inform } \\
\text { SC staff of work conducted at HFIR over the past four years. Likely several } \\
\text { interested parties both inside and outside ORNL will wish to participate in this } \\
\text { discussion. The HFIR staff believes that several policy issues - enumerated in } \\
\text { ref. } 2 \text { - must be understood by all participants in the conversion of HFIR. }\end{array}$ \\
\hline 2.2, 4.1 & $\begin{array}{l}\text { Quality assurance } \\
\text { operations outside } \\
\text { HFIR site }\end{array}$ & $\begin{array}{l}\text { Quality assurance for the reactor fuel is a joint responsibility of the reactor owner } \\
\text { and the fuel vendor. The reactor owner is responsible for approving the quality } \\
\text { assurance plans of the fuel vendor and for auditing the vendor to ensure that the } \\
\text { plans are followed. Facilities outside the HFIR site include LANL, Y-12, and } \\
\text { BWXT Lynchburg. }\end{array}$ \\
\hline 2.3, 2.4 & $\begin{array}{l}\text { Neutronics/thermal } \\
\text { hydraulics }\end{array}$ & $\begin{array}{l}\text { ORNL has developed a reference, LEU U-10/Mo fuel design that is believed to be } \\
\text { feasible provided adequate fuel qualification data are supplied. This design } \\
\text { requires radial and axial grading. Current HEU fuel is only graded in the radial } \\
\text { direction, not the axial direction. The HFIR staff believes that with additional } \\
\text { analyses using state-of-the-art methods, the requirement for axial grading could be } \\
\text { removed. }\end{array}$ \\
\hline 2.5 & $\begin{array}{c}\text { Oregon State } \\
\text { University test loop } \\
\text { participation }\end{array}$ & $\begin{array}{l}\text { OSU has stated that their loop could be engineered to provide electrical heating of } \\
\text { the fuel. It is likely that this will be required but more study/assessment is needed. } \\
\text { This task will include the following: } \\
\text { (1) Investigate/review/describe tests related to hydraulics and thermal hydraulics } \\
\text { that were done for HFIR for HEU fuel. Document the configuration of the } \\
\text { experimental apparatus used for HEU fuel and provide a brief summary of } \\
\text { measurements scheduled by OSU to be taken. } \\
\text { (2) Receive description of LEU fuel plates from neutronics/thermal hydraulics } \\
\text { task. } \\
\text { (3) Discuss which data from 1) are still applicable and which are not. } \\
\text { (4) If some data are not applicable and thus new tests needed, develop a test plan. } \\
\text { Define conditions in experiments, how many tests should be done, what } \\
\text { should be measured. }\end{array}$ \\
\hline 3.1 & $\begin{array}{l}\text { Materials science } \\
\text { support }\end{array}$ & To provide support to the fuel development task led by INL. \\
\hline 2.6 & $\begin{array}{l}\text { Operation at } 100 \\
\text { MW: (1) fuel } \\
\text { qualification tests } \\
\text { for LEU fuel } \\
\end{array}$ & $\begin{array}{l}\text { In cooperation with staff at INL and LANL, HFIR staff will prepare a report on } \\
\text { HFIR fuel qualification identifying measurements needed to support operations } \\
\text { and safety analyses and development of an LEU fuel specification. }\end{array}$ \\
\hline 2.7 & $\begin{array}{l}\text { Operation at } 100 \\
\text { MW: (2) } \\
\text { infrastructure } \\
\text { upgrades/ analyses } \\
\text { to achieve } 100 \mathrm{MW}\end{array}$ & $\begin{array}{l}\text { HFIR staff will identify components of the reactor plant and infrastructure that are } \\
\text { impacted by an increase in operating power; assess level of effort needed to } \\
\text { upgrade and certify these elements and develop a preliminary schedule for } \\
\text { implementation }\end{array}$ \\
\hline
\end{tabular}





\section{REACTOR CONVERSION ANALYSES}

The goal of reactor conversion analyses in FY 2010 was to document that High Flux Isotope Reactor (HFIR) performance with a reactor fuel based on low enriched (19.75 wt \%) uranium-molybdenum alloy (90 wt \% uranium, $10 \mathrm{wt} \%$ molybdenum; termed U-10Mo) could be maintained at the same level as with the current, high enriched (HEU) fuel. Having achieved a reference LEU fuel design, attention was focused on those actions needed to be taken to implement conversion of HFIR.

Verified and validated neutronics methods were used to develop a reference U-10Mo design. Safety and performance studies of an advanced, simplified U-10Mo fuel plate continued with three dimensional, finite-element based methods with the goal of replacing the capabilities available from an existing, one dimensional heat conduction computer program. Other activities included consideration of fuel qualification issues and further refinement of a schedule for conversion of the HFIR to LEU fuel.

\section{$2.1 \quad$ POLICY DECISIONS}

ORNL staff met with Office of Science, Oak Ridge Site Office staff in March of 2010 and discussed the status of the LEU conversion program at HFIR. A Department of Energy, Office of Science staff member has been assigned to monitor HFIR LEU conversion. In April 2010, ORNL staff also briefed the safety basis member of the Office of Science's Deputy Director of Field Operations staff on the status of HFIR LEU conversion. In June of 2010, RERTR Program Office staff requested that ORNL consider creating a sole-source contract with the Babcock and Wilcox Company for the purpose of developing LEU fuel fabrication capability for HFIR and for the NIST reactor. (In early FY 2011, NNSA determined that staff at the Idaho National Laboratory would be responsible for creating a startup contract.) Policy issues (documented in ref. 2) continue to be considered by the Office of Science.

\subsection{QUALITY ASSURANCE OPERATIONS OUTSIDE HFIR SITE}

While quality assurance of the LEU fuel is the responsibility of the Fuel Development and Fuel Fabrication Capability tasks, the reactor operator becomes responsible for the quality of the fuel once ownership is passed from the fabricator. Quality is assured via fuel specifications that, for the current HEU fuel, were created by the reactor operator. Since the LEU fuel development environment is different from that which existed at the time the current, HEU fuel was designed, ORNL staff developed and documented a procedure for insuring the to-be-developed LEU fuel specifications will satisfy the Department of Energy regulations to which HFIR operations must adhere (ref. 3). The conclusions of the study were:

- quality assurance for fuel is implemented through fuel specifications,

- ORNL expects safety-related fuel development and fabrication work to comply with NQA-1,

- the initial stage of fuel production - creation of U/Mo alloy - has been prototyped and a specification can be created,

- a prototype, LEU HFIR fuel plate must be fabricated as part of, i.e. prior to, developing a fuel specification for the plate and should be developed with ORNL staff input as well as members of the fuel development (FD) and fuel fabrication capability (FFC) tasks, and

- fuel specification creation should follow an ISO-identified process; a team should be formed including reps from FD, FFC, and reactor operators.

\subsection{REACTOR PHYSICS}

Reference 4 was revised to include peak power density, local burnup and peak local heat flux values, and reissued under the same report number with R1 appended. Models presented in ref. 4 were revised to 
include a 25.4 micron (1 mil) thick layer of Zr surrounding the U/Mo fuel. Calculations in ref. 4 were re-executed using the new model. Safety related reactivity co-efficients not reported in ref. 4 were calculated. Results for FY 2010 studies are reported in ref. 5.

The fuel grading profiles that minimize local power peaking in the reactor core are shown in Fig. 1. To maintain flux parity with the current HEU fuel cycle, reactor power must be increased from the current value of $85 \mathrm{MW}$ to $100 \mathrm{MW}$. To maintain safety margin (margin to incipient boiling) at the higher power, LEU fuel regions must be axially tapered at the base of the plates. (HFIR employs down-flow of coolant and thus the minimum margin to incipient boiling occurs at the base of the core.) A schematic of this tapering is shown in Fig. 2. The minimum fuel thickness shown in Fig. 2 is 75 microns (3 mils).
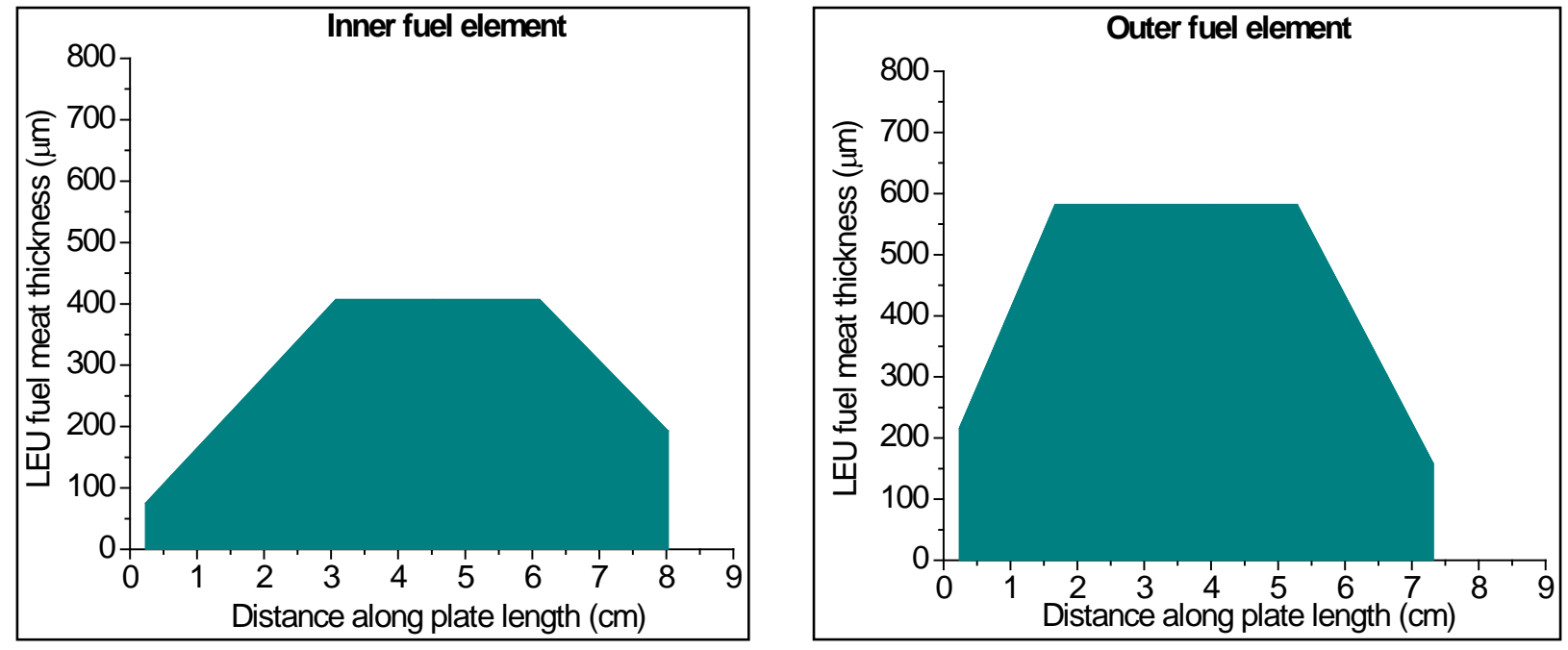

Fig. 1. Radial fuel thickness profiles inside HFIR fuel plates.

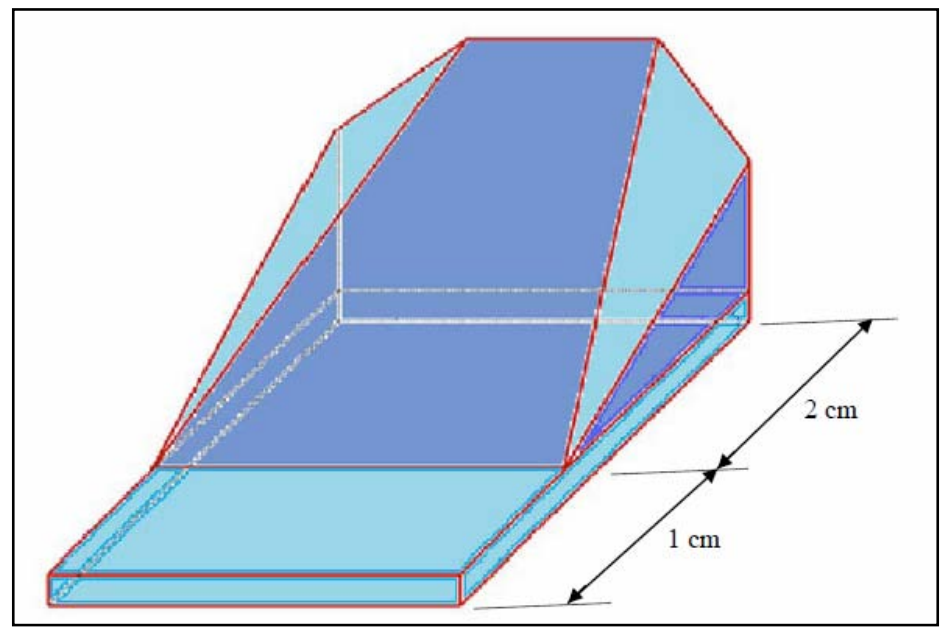

Fig. 2. Axial grading profile for LEU fuel (0-3 cm from the bottom of each fuel element plate).

Benchmark studies for the physics models used to determine LEU power profiles continued during FY 2010. Studies included modeling the depletion of control and safety plates that occurs during irradiation (ref. 6) and confirmation of the ability to predict Cf-252 production in the central target region of HFIR (ref. 7). 


\section{$2.4 \quad$ THERMAL HYDRAULICS}

During the original design of HFIR, the design engineers and analysts at the time wrote an original computer code that has come to be known at HFIR as the "steady-state heat transfer code" (SSHTC, ref. 8). The SSHTC includes most of the physics required to analyze the thermal hydraulics, structural mechanics, and other phenomena related to the normal and abnormal operation of the HFIR HEU fuel plates and fuel elements. The analysis is carried out in a conservative manner such that safe operation of the HFIR is assured with large margins of safety. The code source is available, but it is not well documented or source-commented. Furthermore, many of the correlations and empirical relationships embedded in the SSHTC are based on tests and experiments that will not be repeated again with LEU fuel.

The input for the SSHTC is structured specifically for the HFIR HEU fuel. Some of the inputs to the code can be changed from HEU fuel to LEU fuel such as power distributions. However, some of the most important parameters are the uncertainty factors (U factors as they are called in the SSHTC input) applied to the local heat generation used to generate a conservatively high wall temperature adjacent to the coolant. These factors are unknown for the LEU counterpart but have been assumed to be unchanged from the values for the current, HEU fuel. Therefore, it is not known if the analysis produces conservatively high temperature or non-conservatively low temperature. In the absence of a better way, the SSHTC is used with HEU assumptions and with best engineering judgment of LEU fuel properties to interpret the results of the analysis and meet program goals.

The result of this LEU-based SSHTC analysis has indicated that an axially-graded fuel along with radially-graded fuel (also in the present HEU fuel, but a different contour design) will produce a sufficient margin in the clad surface temperature to allow for $100 \mathrm{Mw}$ operation of the HFIR. The axial-grading adds even more complexity to an already difficult task of manufacturing the fuel. Therefore, in order to simplify the design, an alternative calculation with a new code is needed. COMSOL was chosen for many reasons. The investment in a COMSOL-based analysis tool is justifiable because at least 20 years of operation with an LEU element will occur after the conversion, necessitating over 75,000 individual fuel plates to be manufactured. Operation of the reactor requires a high quality and superior fuel at a reasonable cost. This will ultimately mean a migration from the accepted (by the regulator) conservatism of the SSHTC to the increased accuracy but more complex modeling and as-yet-unreviewed (by the regulator) modern analysis methods included in the COMSOL code.

This section of the report documents progress that has been made in the thermal-hydraulic (T-H) technical area during FY 2010. A significant amount of the research reported here was performed by a group from the University of Tennessee, Knoxville Department of Mechanical, Aerospace, Biomedical Engineering (UTK-MABE) on a contract that started at the beginning of the calendar year (CY) 2010. Therefore, the reporting period of some of the material may span periods of time across the contracting period and/or fiscal years.

The purpose of this research is to develop an accurate and robust simulation capability that will encompass essentially all of the physics associated with thermal effects of a HFIR LEU fuel element. The primary tool to be used is "COMSOL-Multiphysics", or COMSOL, which is commercially available from COMSOL, Inc. The developed COMSOL models are anticipated to be used to simulate both normal operation and accident (or abnormal) conditions to the extent possible given the capabilities of the COMSOL code. 
The need for a thermal simulation capability is driven by the difficulty in performing tests to the extent that the HEU fuel was tested during the original design and construction of the HFIR facility. Therefore, many of the phenomena that were measured or witnessed directly by testing in the original HEU fuel development will now be simulated by a computer for the development of the HFIR LEU fuel. There are several reasons for this modified approach to fuel design: (1) the simulation capabilities brought about by improved computer hardware and software allows for precise estimates of the fuel thermal performance that were not possible at the time of the HEU fuel design, (2) the costs associated with testing a major facility of any kind, particular a nuclear-related facility, have become prohibitively high relative to the costs of computer simulation, and (3) the regulatory requirements that exist today for operating a nuclear facility demand thorough and rigorous quality assurance for both testing and analytical approaches such that testing alone will not be sufficient to develop a new fuel. If it is sufficient to achieve the desired goals without testing, then it is more cost effective to only perform computer simulations of the thermal effects in some cases. However, it is emphasized that there are some phenomena that must also be tested since validation data supporting the computer simulation may not be available. Hence, the quality assurance issues will dictate whether testing is required in addition to the computer simulation.

The thermal-related physics being addressed in this research and documented to some extent in this report are: (1) thermal heat conduction in both fuel and coolant materials and associated structures, (2) thermal convection between the fuel and coolant and advection to and from the fuel regions by the coolant, (3) the thermal expansion and contraction of all the materials modeled within the fuel element domain (i.e., thermal-structure interaction or TSI), and (4) the movement of the structures relative to the coolant caused by the forces of the coolant acting on the structures (i.e., fluid-structure interaction or FSI). There are additional physics that are being considered for investigation under this project and/or coupled with this work at a later time. These include reactor kinetics (space-time), radiation-induced material damage, and corrosion buildup during a cycle. Indeed, the entire question of material properties changing during the fuel cycle will need to be included in this multiple-physics approach to fuel design.

This report summarizes the thermal-hydraulic research performed during FY 2010. The research is divided into two-dimensional (2D) and three-dimensional (3D) parts in the discussion. The goal is to consider only the 3D geometry, but much can be learned about methods and techniques in the 2D framework such that significant resource savings can occur. Therefore, it is judicious to always study in 2D to the extent possible before exploring the 3D details.

The research from CY 2009 was completed during FY 2010 and documented by the following publications:

ORNL/TM-2010/018 , 2D Thermal Hydraulic Analysis and Benchmark in Support of HFIR LEU Conversion using COMSOL, 09/18/2010, http://info.ornl.gov/sites/publications/Files/Pub23015.pdf.

Two papers related to this research were submitted and presented at the COMSOL Conference 2010 Boston, October 7-9, 2010. Copies of the full conference proceedings are available from COMSOL which include these two papers. The papers are also publically available:

http://info.ornl.gov/sites/publications/Files/Pub26121.pdf

Upgrading the HFIR Thermal-Hydraulic Legacy Code Using COMSOL

http://info.ornl.gov/sites/publications/Files/Pub26110.pdf -- paper

http://info.ornl.gov/sites/publications/Files/Pub26490.pdf -- presentation

Exploiting New Features of COMSOL Version 4 on Conjugate Heat Transfer Problems 
A presentation was made to the Joint Meeting of TRTR and IGORR in Knoxville, Tennessee, on September 20, 2010. The presentation was entitled Multiphysics Modeling to Support HFIR LEU Fuel Conversion, and is available here http://info.ornl.gov/sites/publications/Files/Pub24478.pdf .

A presentation was made to the U.S. High-Performance Reactors Working Group Thermal-Hydraulics Experts Meeting on June 10, 2010, at the campus of Oregon State University, Corvallis, Oregon. The presentation was entitled Status of Multiphysics Modeling for the Conversion of HFIR Fuel Elements to $L E U$, and is available here http://info.ornl.gov/sites/publications/Files/Pub24483.pdf .

An invited presentation was made at a CFD Colloquium in honor of the retirement of Professor A. J. Baker of UT-Knoxville on May 27, 2010 at the UTK campus. The presentation was entitled Recent CFD-Related Activities at the High Flux Isotope Reactor of ORNL, and includes a considerable amount of discussion related to this LEU conversion project. The presentation is available at:

http://info.ornl.gov/sites/publications/Files/Pub24235.pdf and

http://cfdlab.utk.edu/html/colloquium/colloq.htm .

A report documenting the research results for CY 2010 will be published early in CY 2011. This report will include the results from the UTK-MABE contract and other research from ORNL staff. A summary of these results to date is included in Appendix A.

\subsection{OREGON STATE UNIVERSITY (OSU) TEST LOOP PARTICIPATION}

Proposed testing to support the design and safety analysis efforts for conversion of the HFIR to U-Mo based fuel involves hydraulic tests to verify the hydraulic similitude of U-Mo foil-core plates to the Al$\mathrm{U}_{3} \mathrm{O}_{8}$ dispersion-core plates. These tests are envisioned as comparison experiments to gather flow, pressure drop, coolant velocity, plate deflection, and plate vibration information to verify that the new plate design performs favorably in comparison to the old plate design. In addition, the hydraulic experiments are expected to gather detailed fuel performance data that can be used to benchmark the new computational fluid dynamics and structural mechanics multiphysics codes being used for the updated HFIR thermal/hydraulics analysis. This part of the proposed testing is planned for performance at the OSU HMFTF facility is described here. Additional tests, currently not possible to be performed at the OSU facility, are described in Section 2.6.

Numerous hydraulic tests were performed early in the development process for the HFIR fuel elements. These tests involved prototypic single channel experiments that were performed as part of fuel plate heat transfer coefficient and plate friction factor measurements, large scale individual hydraulic tests on prototypic inner and outer fuel elements to develop flow-pressure drop correlations, full scale testing in a hydraulic mockup of the vessel and core region (including fuel, mockup target, reflector, control plates, and selected experiments), and preoperational testing in the installed reactor pressure vessel and primary coolant system. The information from these historic tests are still applicable and will be useful for the LEU fuel element design because the fuel geometry, cladding material, primary coolant pressure and primary coolant flow are not envisioned to change, and the primary coolant temperature will only change to a small extent.

In addition to these hydraulics tests that supported the fuel plate and element development, some work was performed during the early operational cycles of the HFIR to investigate the effectiveness of wire spacers between the fuel plates to control plate deflections. As part of this work, hydraulic testing was performed on flat plate-geometry assemblies with HFIR-specific plate and coolant channel dimensions and with prototypic involute plate-geometry assemblies. In both cases, assemblies of 9 plates were tested with wires inserted in the coolant channels. Figure 3 shows a photograph of the flat plate-geometry hydraulic test piece and Fig. 4 shows an end view of the involute plate-geometry hydraulic test piece. 


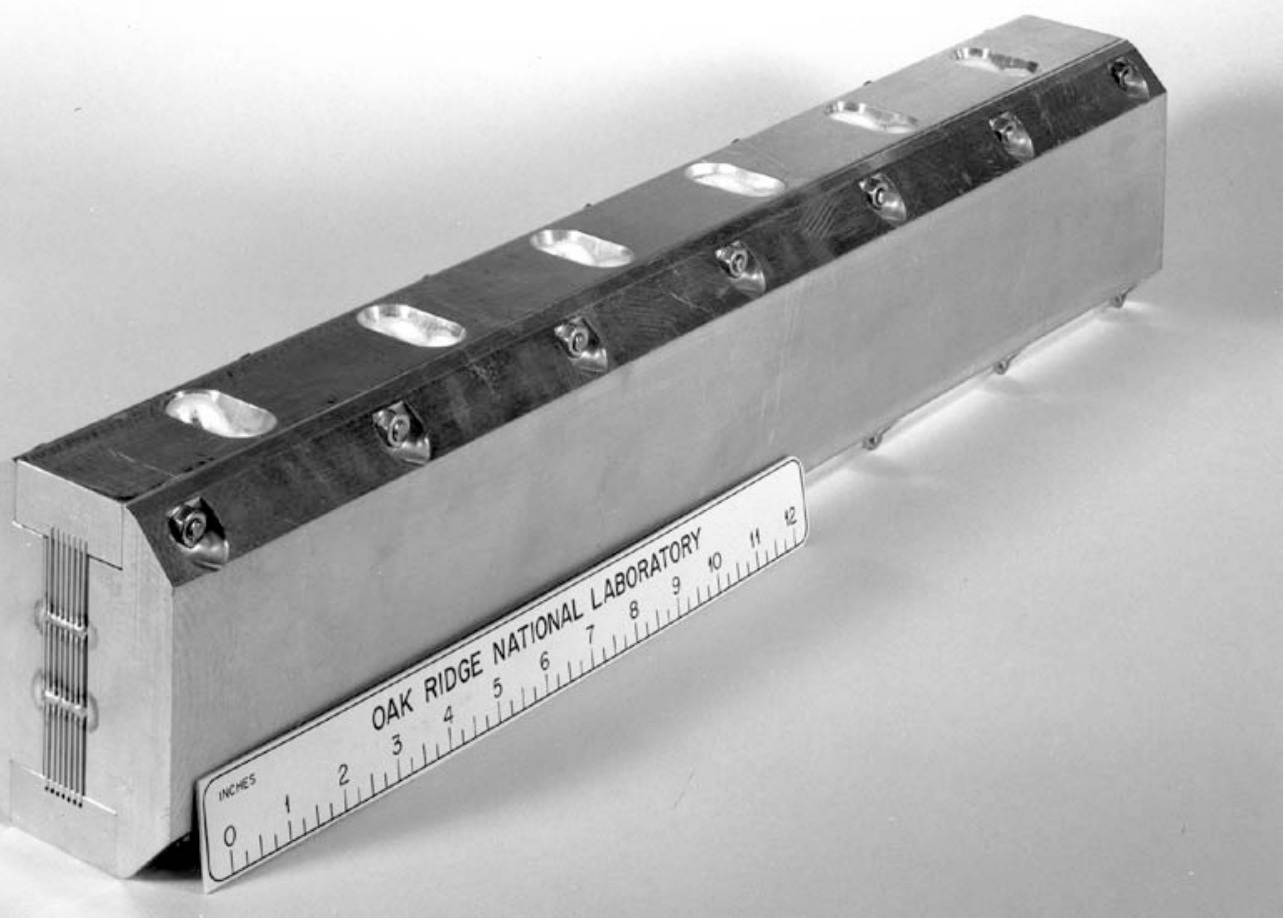

Fig. 3. Photograph of HFIR fuel plate hydraulic test assemblies — flat plates.

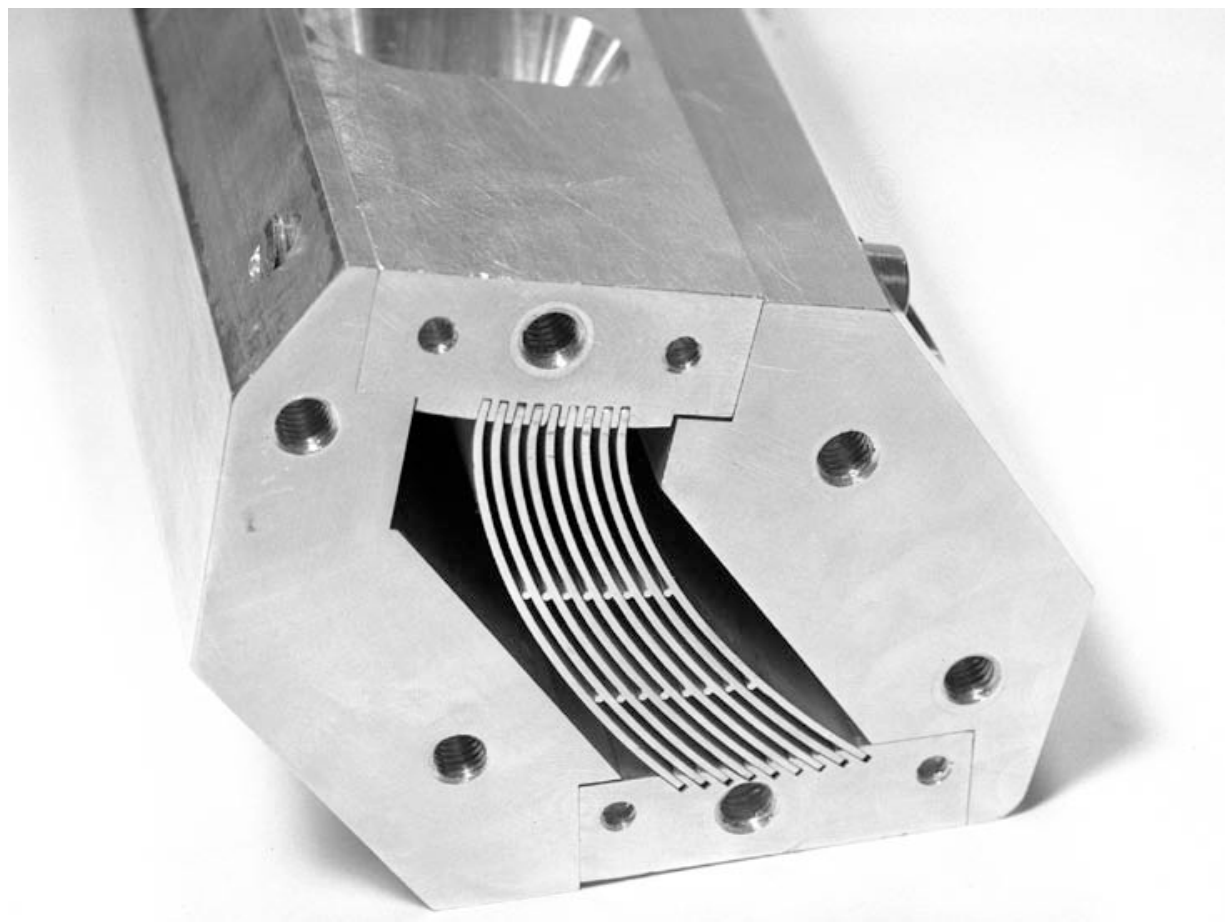

Fig. 4. Photograph of HFIR fuel plate hydraulic test assemblies - involute plates. 
The reports, drawings, and some working files are still available from this early work to form a beginning point for new hydraulic test piece design to support conversion to the new U-Mo fuel plate design. Figures 5 through 7 show portions of the drawing from the test piece shown in Fig. 4. These old drawings were converted to the current RRD drawing architecture and then used in the preconceptual HMFTF test piece sketches discussed in Section 2.5.1.

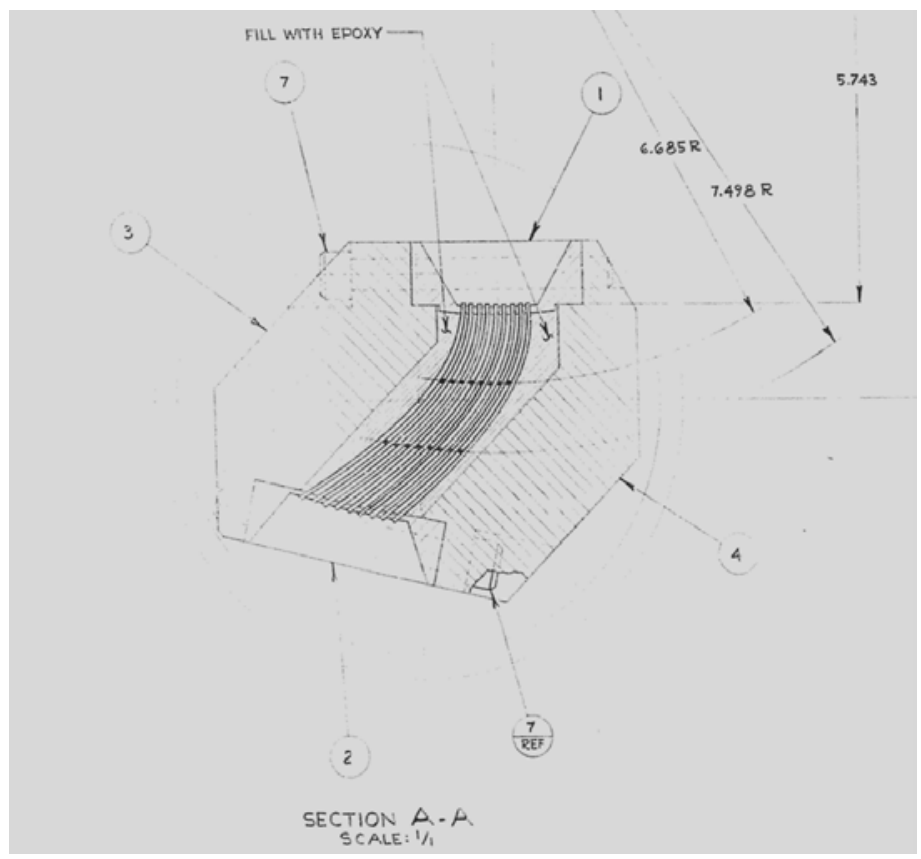

Fig. 5. Original involute hydraulic test assembly detailed design drawings — flow inlet end.

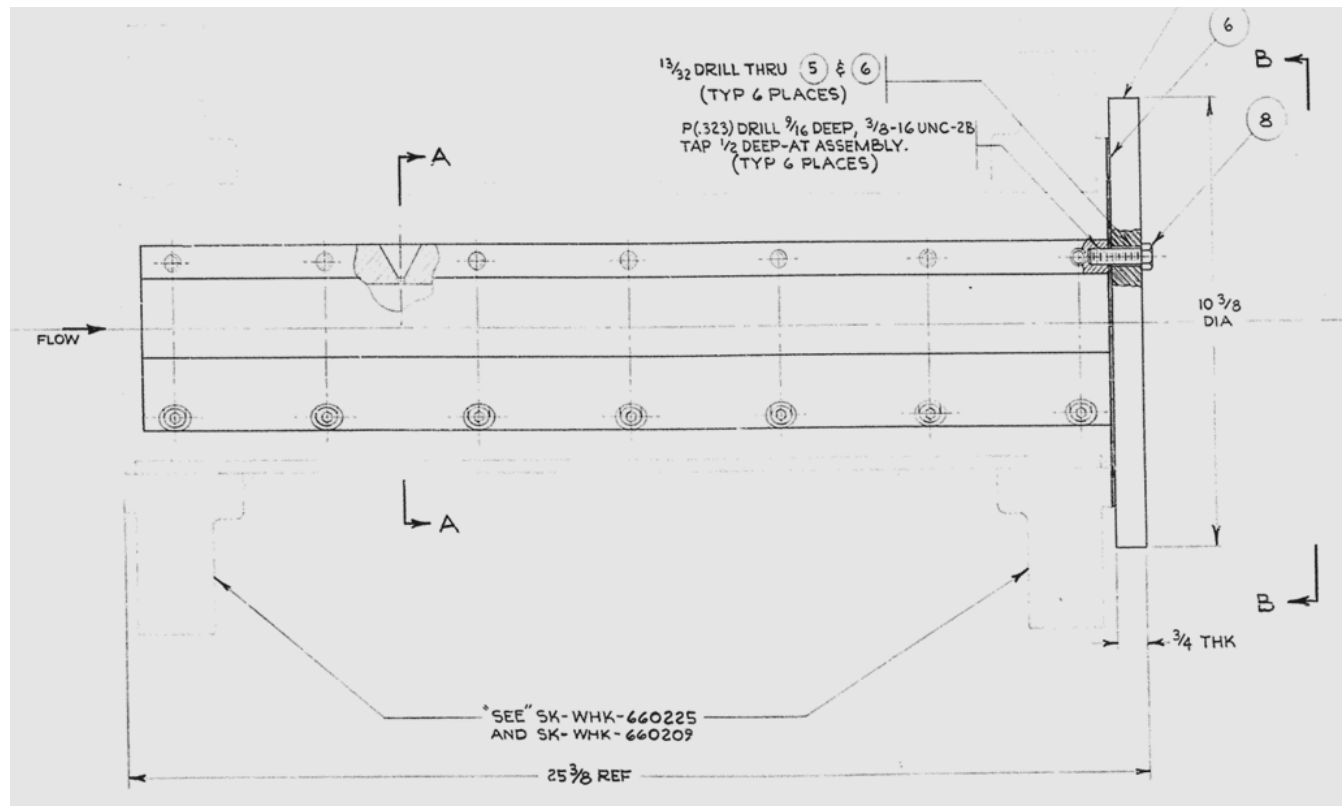

Fig. 6. Original involute hydraulic test assembly detailed design drawings — side view. 


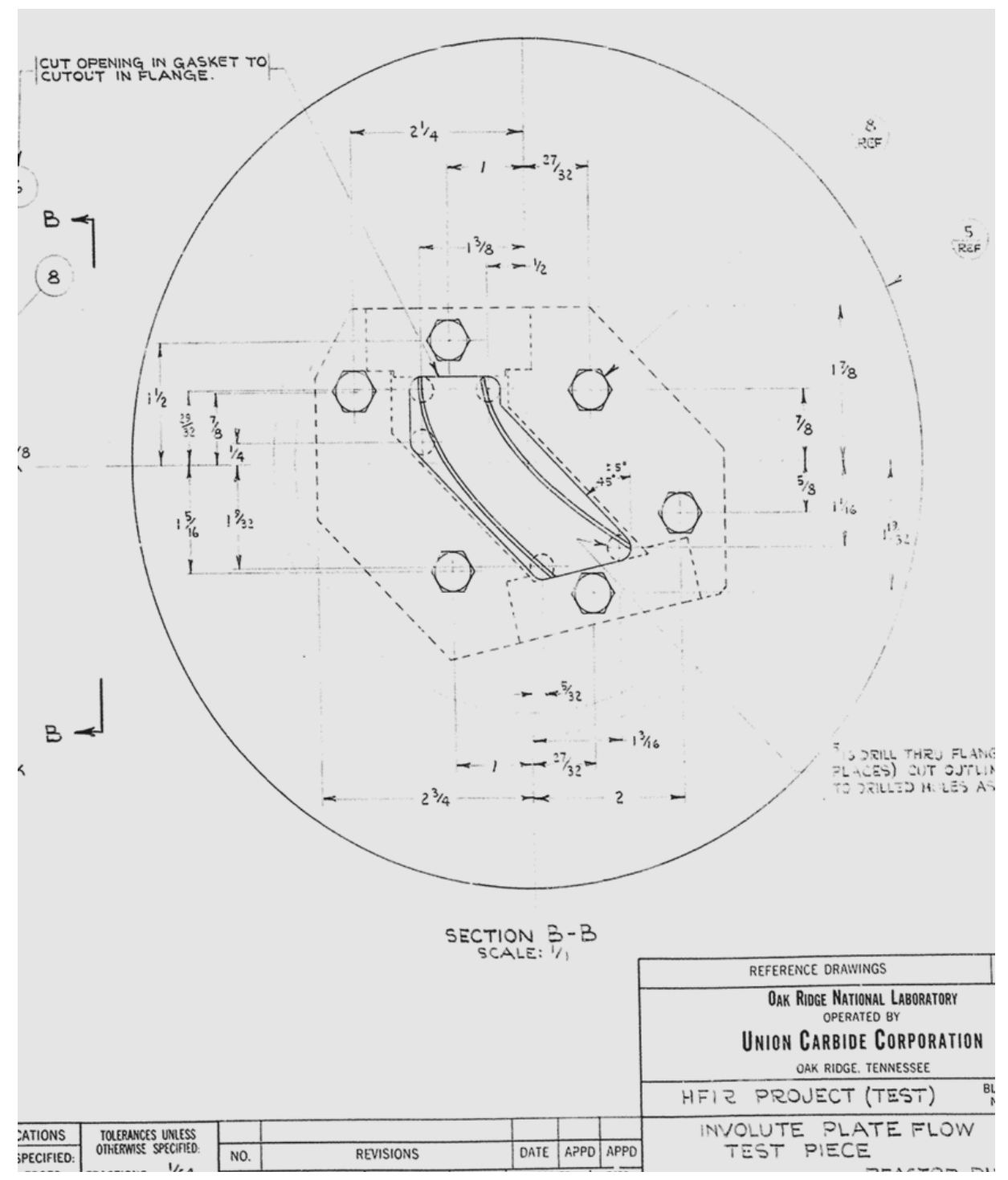

Fig. 7. Original involute hydraulic test assembly detailed design drawings — flow exit end.

\subsubsection{Isothermal Measurements Required to Support HFIR Conversion}

The proposed HMFTF testing to support HFIR involves isothermal testing of single plate and multi-plate assemblies. The single plate tests are intended to establish contrast between the flat plate geometry and involute plate geometry and the multi-plate tests are intended to provide benchmarking data to support multiphysics code calculations of the overall velocity and pressure distribution of a fuel element assembly. The multi-plate tests are also envisioned to provide benchmark data for narrow-wide channel code calculations. Table 2.1 describes the series of tests that are desired.

The operating conditions envisioned for the testing are provided in Table 2.2. This table was presented at Summer, 2010 meeting of the HPRR group, which was held at OSU. 
Table 2.1. HFIR-Specific tests desired for HMFTF

\begin{tabular}{|c|c|c|c|c|c|c|}
\hline $\begin{array}{l}\text { Series } \\
\text { No. }\end{array}$ & Description & $\begin{array}{l}\text { HFIR hydraulic } \\
\text { segment type }\end{array}$ & $\begin{array}{l}\text { All } \\
\text { aluminu } \\
\text { m plates }\end{array}$ & $\begin{array}{l}\text { Depleted U } \\
\text { dispersion } \\
\text { plates }\end{array}$ & $\begin{array}{l}\text { Depleted } \\
\text { U-Mo foil- } \\
\text { plates }\end{array}$ & $\begin{array}{c}\text { Channel flow: } \\
\text { full=full power } \\
\text { steady state design } \\
\text { flow }\end{array}$ \\
\hline 1 & $\begin{array}{l}\text { Single plate-2 } \\
\text { channels }\end{array}$ & $\begin{array}{l}\text { Flat plate - data } \\
\text { could be provided } \\
\text { by generic test } \\
\text { assembly. }\end{array}$ & $\mathbf{X}$ & & $\mathbf{X}$ & Full \\
\hline 2 & $\begin{array}{c}\text { Single plate-2 } \\
\text { channels }\end{array}$ & Involute plate & $\mathbf{X}$ & $\mathbf{X}$ & $\mathbf{X}$ & Full \\
\hline 3 & $\begin{array}{c}\text { Multiple } \\
\text { Involute-9 plates }\end{array}$ & $\begin{array}{c}\text { Involute plate: } 9 \\
\text { plate pack with } 8 \\
\text { normal channels }\end{array}$ & $\mathbf{X}$ & & $\mathbf{X}$ & Full \\
\hline 4 & $\begin{array}{c}\text { Multiple } \\
\text { Involute-9 plates }\end{array}$ & $\begin{array}{l}\text { Involute plate: } 9 \\
\text { plate pack with } 7 \\
\text { normal channels } \\
\text { and one wide } \\
\text { channel }\end{array}$ & $\mathbf{X}$ & & $\mathbf{X}$ & Full \\
\hline
\end{tabular}

Table 2.2. Operating conditions for HFIR LEU testing

\begin{tabular}{|c|c|c|c|c|c|}
\hline Variable & Min., TSR & Max., TSR & $\begin{array}{c}\text { Nominal full } \\
\text { power }\end{array}$ & $\begin{array}{c}\text { Nominal } \\
\text { shutdown }\end{array}$ & Testing \\
\hline Pressure, psia & 325 (fuel inlet) & $\begin{array}{c}650 \\
\text { (reliefs) } \\
\end{array}$ & $\begin{array}{c}475 \\
\text { (fuel inlet) }\end{array}$ & $\begin{array}{l}\text { 475-down to- } 10 \\
\text { (fuel inlet) }\end{array}$ & $\begin{array}{c}\text { 475-down to- } 10 \\
\text { (fuel inlet) }\end{array}$ \\
\hline Temperature, ${ }^{\circ} \mathrm{F}$ & 90 (vessel) & $\begin{array}{l}140 \text { (opr.) } \\
200 \text { (dsgn.) }\end{array}$ & 120 & 120 & $90-200$ \\
\hline $\begin{array}{c}\text { Flow-whole } \\
\text { core, gpm }\end{array}$ & $\begin{array}{l}1100 \text { (opr.) } \\
750 \text { (Shtd.) }\end{array}$ & 14200 & 13000 & 2072 & $750-14200$ \\
\hline $\begin{array}{l}\text { Inner element } \\
\text { flow (total/per } \\
\text { channel), gpm }\end{array}$ & $\begin{array}{c}\text { (396/2.3)- } \\
\text { operating } \\
(270 / 1.6)- \\
\text { shutdown }\end{array}$ & $5112 / 29.9$ & $4680 / 27.4$ & $746 / 4.4$ & $\begin{array}{c}270 / 1.6- \\
5112 / 29.9\end{array}$ \\
\hline $\begin{array}{l}\text { Outer element } \\
\text { flow (total/per } \\
\text { channel), gpm }\end{array}$ & $\begin{array}{l}\text { (704/1.9)- } \\
\text { operating } \\
(480 / 1.3)- \\
\text { shutdown }\end{array}$ & $9088 / 24.6$ & $8320 / 22.5$ & 1326/3.6 & $\begin{array}{c}480 / 1.6- \\
9088 / 24.6\end{array}$ \\
\hline
\end{tabular}




\subsubsection{Preconceptual design of OSU HMFTF HFIR test pieces}

Figure 8 shows a 3D view of a hydraulic test assembly that is based on the original HFIR drawings described earlier. The flow inlet end is shown in the foreground of Fig. 8. The yellow-colored mockup sideplates and fuel plates in Fig. 8. would change for each test series listed in Table 2.1. The parts shown in dark blue in Fig. 8 are envisioned to be reusable side supports that are made from stainless steel and are held together by stainless steel fasteners. The large diameter flange at the exit end would mate with HMFTF support structures and interface with HMFTF pitot tube assemblies to ensure exit channel flow velocities can be measured. The red filler material between the outermost plates and the side supports would be epoxy as in the early HFIR tests, which would direct flow into the channels and support any instruments or instrument leads that come in from the side.

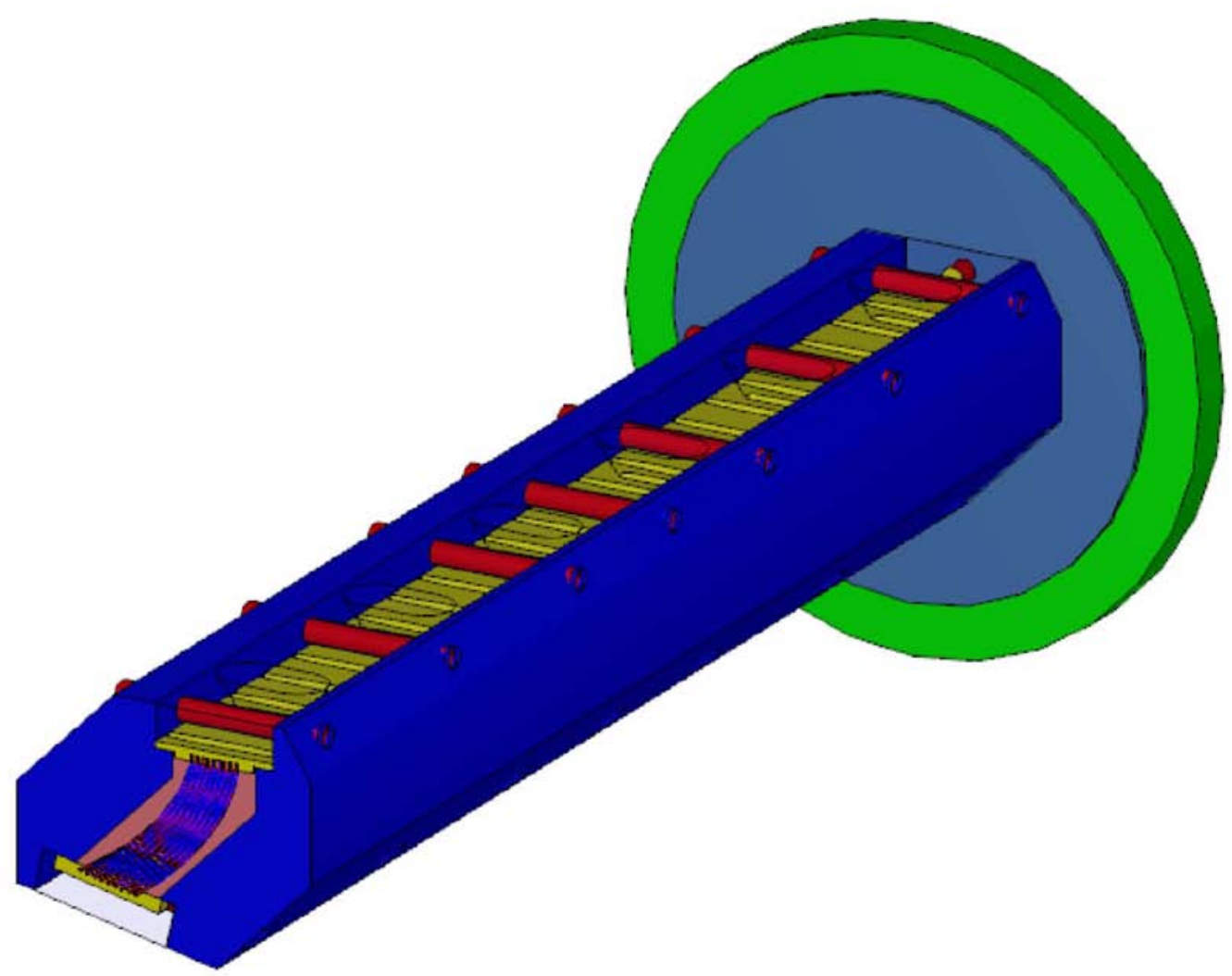

Fig. 8. Isometric view of preconceptual HFIR test assembly for use in HMFTF. 
Figure 9 shows a fuel plate subassembly. The sideplates have prototypic HFIR plate welds at each inch along the axial length of the plates and if desired, instrument access slots can be added to gain access to the edge of the plates along the axial length. If U-Mo plate welds to the sideplate become a design variable to be adjusted, this subassembly could be used to investigate and optimize the number of sideplate welds. Figure 10 shows end views of a single plate subassembly to support series 2 in Table 2.1 and a nine-plate subassembly to support series 3 and 4, respectively. For series 4, one of the innermost coolant channels would be made significantly wider than the others to acquire benchmark data for wide channel calculations.

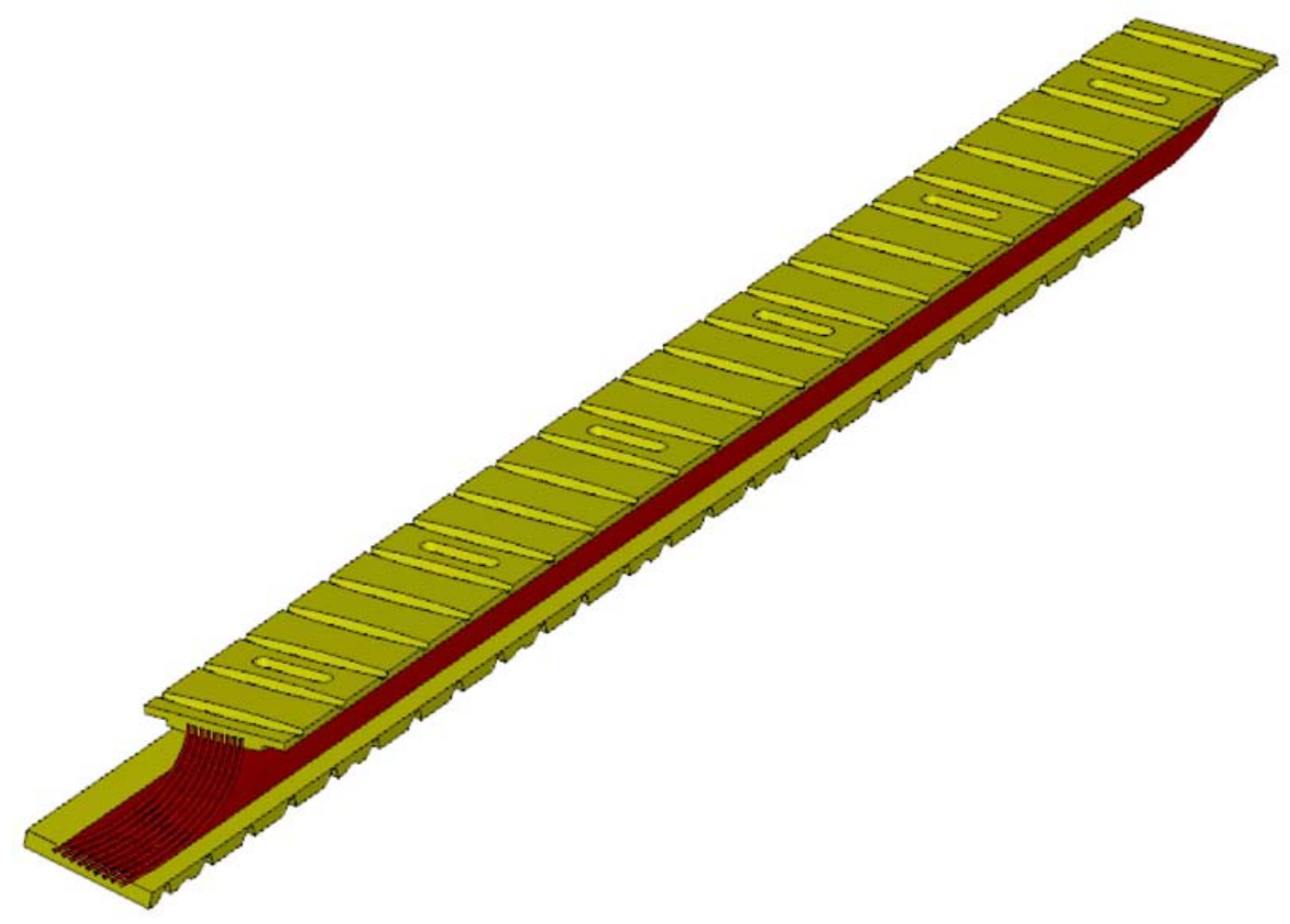

Fig. 9. Isometric view of preconceptual HFIR plate subassembly for use in HMFTF. 

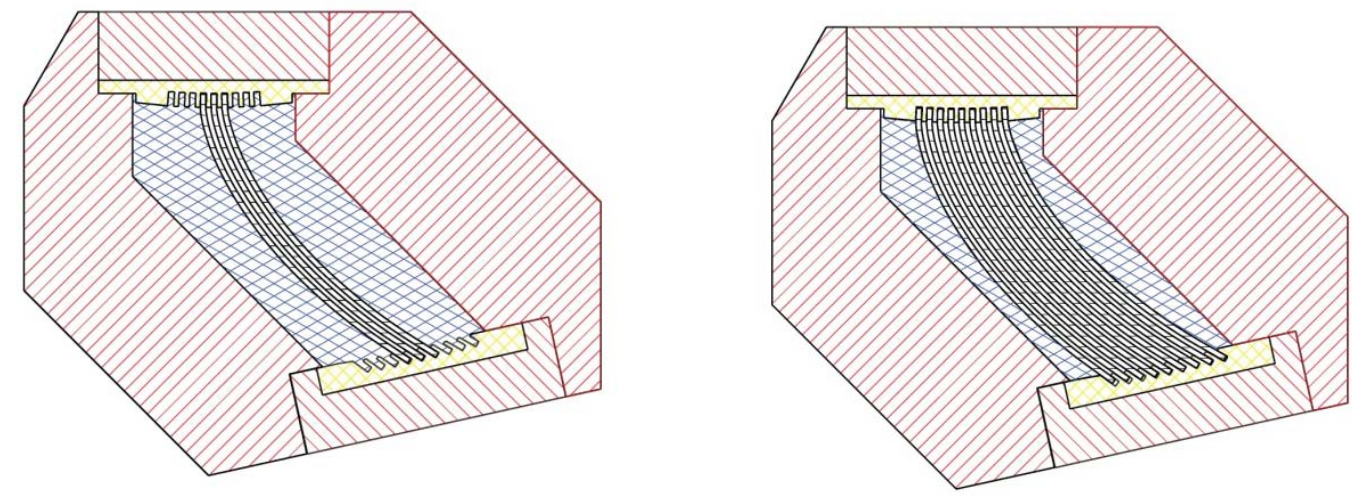

Fig. 10. End view of preconceptual HFIR single plate and nine plate subassemblies.

\subsection{ACHIEVING 100 MW: FUEL QUALIFICATION TESTS FOR LEU FUEL}

\subsubsection{Review of Thermal Hydraulic Testing for the HFIR design and Safety Analysis}

The thermal and hydraulic (T/H) design analysis for the High Flux Isotope Reactor (HFIR) has utilized a steady-state heat transfer analysis of the core design that was originally performed in the early 1960's for $100 \mathrm{MW}$ operation of the reactor. The T/H design analysis was used in the design and development of the fuel elements and core components and was the basis for the original reactor safety limits (SLs) and limiting safety system settings (LSSSs). The T/H design analysis has undergone several revisions over the years since the HFIR first attained criticality, but the basic approach, primary assumptions, key input parameters, and experimental bases are still used as the safety basis for the reactor. Details on the background, description, and current thermal limits calculations using the steady state heat transfer analysis are described in Chapter 4 of the HFIR Safety Analysis Report.

The high performance characteristics of the nuclear design involved a high power density combined with light water cooling of aluminum-based fuel plates, which necessitated high coolant velocities, narrow coolant channels, thin fuel plates, and high fuel temperatures. This challenging combination of fuel geometry and process conditions created problems associated with fuel plate heat transfer, fuel plate hydraulic loads and deflections, corrosion of the fuel cladding during operation, and tight fabrication tolerances. An extensive experimental program was used in the development of the original T/H design analysis in order to guide the fuel system design and to control the uncertainties associated with the heat transfer-related variables. Some of the key experiments were performed in the following categories:

1. fuel heat transfer coefficient related analysis and testing;

2. fuel plate deflection related analysis and testing;

3. fuel cladding oxide layer analysis and testing;

4. fabrication related analysis and testing.

The change from HEU to LEU fuel will involve a change to the fuel form (grading profile) and composition that will affect the $\mathrm{T} / \mathrm{H}$ design analysis. The approach being used for the conversion is to maintain the fuel element external geometry and basic plant thermal hydraulic process conditions, except for the reactor power which is expected to increase from the current value of $85 \mathrm{MW}$ to $100 \mathrm{MW}$. To support the conversion, the original $\mathrm{T} / \mathrm{H}$ design analysis is being updated and upgraded to more current methods (see Section 2.4 and Appendix A). To support the new T/H analysis it is thought that many of 
the original experiments and tests can still be used as a basis, particularly in the area of steady state and transient heat transfer coefficients and fuel element corrosion since the choice of clad and thickness remains unchanged from HEU and the heat flux will be no greater than previously achieved. In addition, some of the information generated during the lifetime of the HFIR may be used and technical information that was generated as part of the Advanced Neutron Source Reactor (ANSR) design may also be used (because of the similarity of the ANSR fuel to the HFIR fuel). New testing to address changes associated with U-Mo based fuel may be necessary to support the revised T/H design bases for LEU fuel.

The purpose of this work (still on-going) is to review the original $\mathrm{T} / \mathrm{H}$ testing that was performed for HFIR and to provide an overview of design and testing information developed during the HFIR lifetime (including ANSR related information) that could be used to support changes to the T/H analysis. An additional purpose of this work is to evaluate testing and analysis needed to support the safety design strategy for conversion of the reactor to LEU fuel to be operated at $100 \mathrm{MW}$, and to provide preconceptual input to specific tests envisioned to support the new $\mathrm{T} / \mathrm{H}$ analysis.

\subsubsection{Proposed Involute Plate Thermal Deflection Separate Effects Testing}

One of the most significant inputs to the original HFIR T/H design analysis was that regarding the deflection of the fuel plates due to the difference in temperature between the operating fuel plates and colder sideplates. The deflections of importance are axial deflections that tend to buckle the plates and affect the channel spacing. Radial deflections are not significant because the fuel elements are designed to rotate slightly relative to one another. This issue was resolved by experiments performed by Cheverton and Kelly that were essentially separate effects thermal-structural deflection experiments designed to understand the nature of the plate deflections and produce a correlation for use in the T/H analysis. Side issues of lesser importance were also addressed by the Cheverton-Kelly tests and included: (1) verification of the analytical model for plate deflection as a result of pressure differences across the plate (between adjacent coolant channels of differing thicknesses), (2) creep performance of the plates, and (3) thermal cycling performance of the plates.

Figure 11 shows photographs of the Cheverton-Kelly experimental apparatus, which consisted of a single fuel plate mounted on a carriage and instrumented with high temperature position sensors across the span of the fuel plate. The apparatus was inserted into an oven and the differential thermal expansion between the aluminum plate and the steel plate base subassembly is used to mimic the differential thermal expansion between the hot fuel plate and the cold sideplate of the reactor. Figure 12 shows the test plate, which was clamped into the base subassembly at the tabs along the side sufficiently tight to avoid slippage. The tabs mimic the axial welds between the fuel plate and sideplate. 

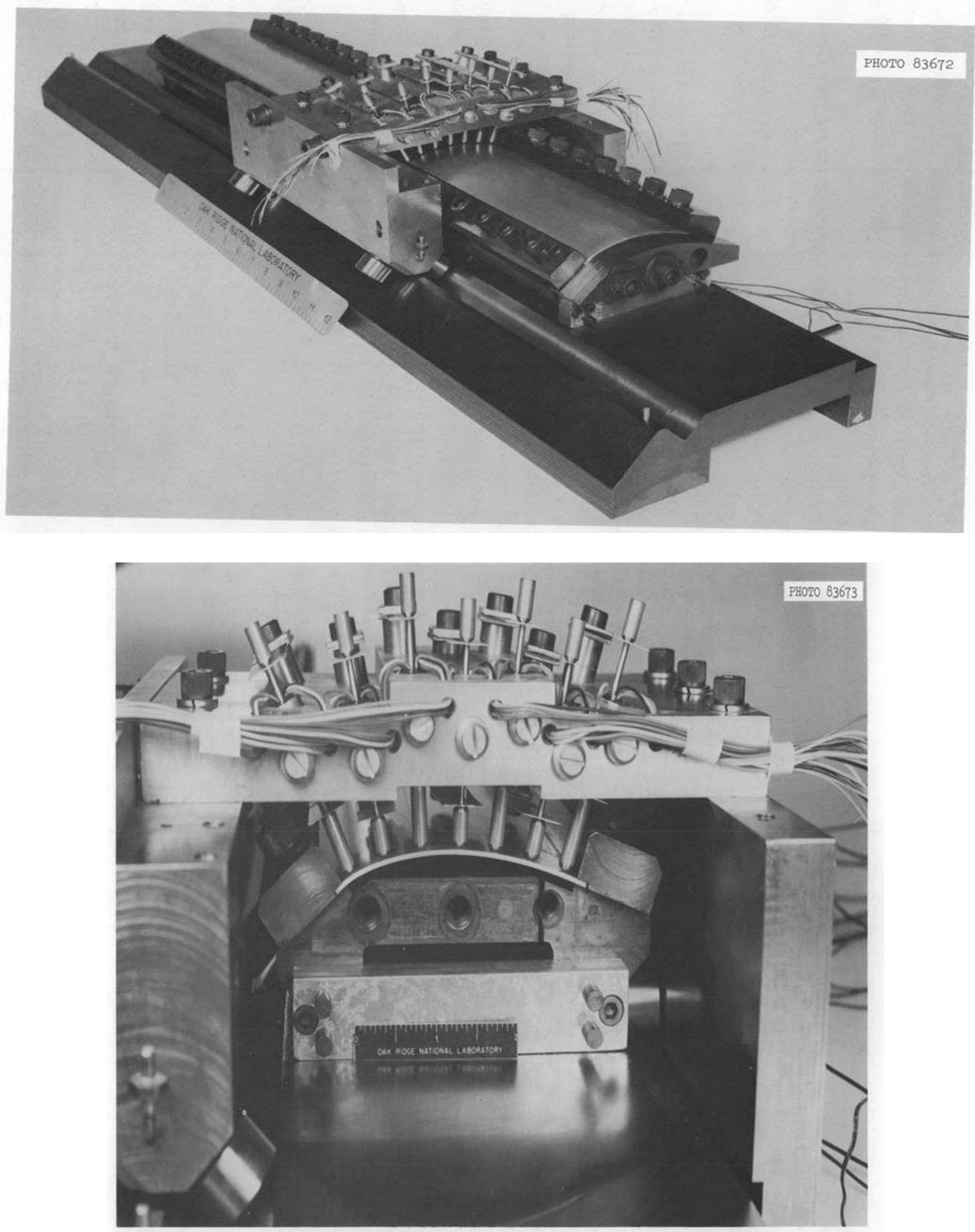

Fig. 11. Fnd View of HFIR Fuel Plate Deflection Experimental Apparatus.

Fig. 11. Photographs of Cheverton-Kelly test apparatus — side and end views. 


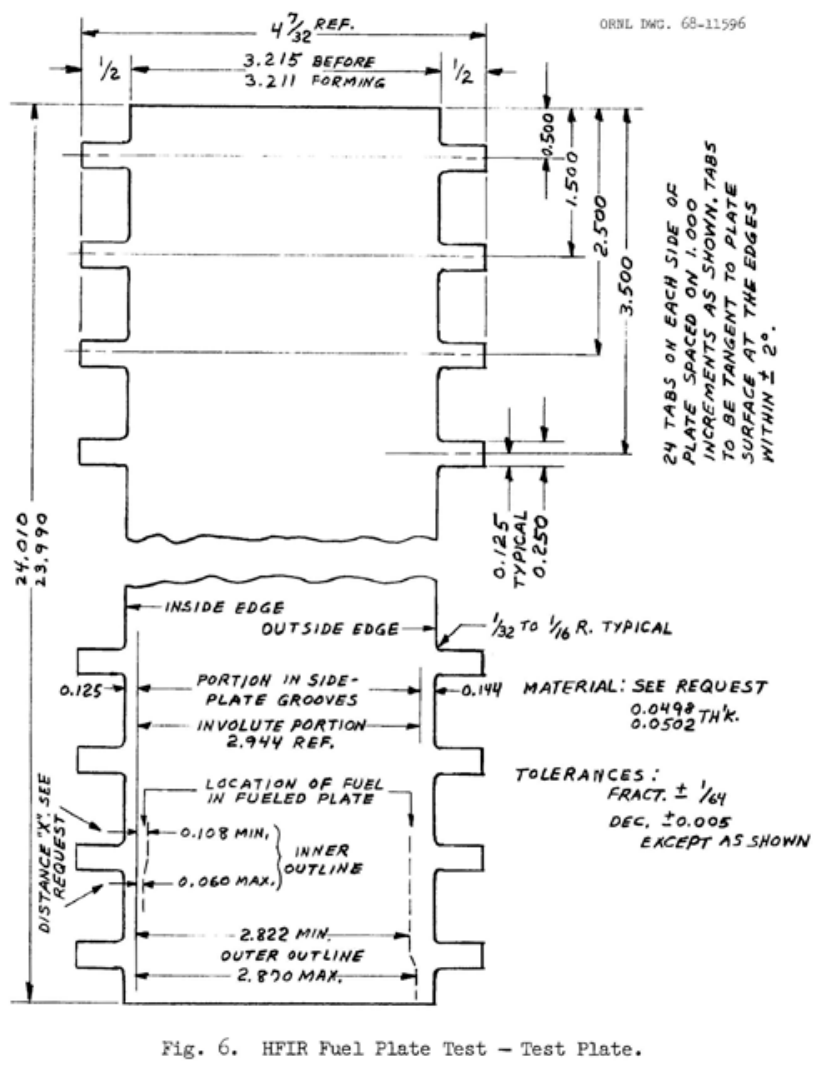

Fig. 12. Experimental fuel plate for Cheverton-Kelly test.

The ORNL Research Reactors Division retains original design drawings of the apparatus and subassembly parts so that if testing is approved and funded, the apparatus can be rebuilt and used to replicate the original data and then acquire new data for the U-Mo plates. Figure 12 is an excerpt from the assembly drawing which shows end and side views of the apparatus. The carriage, base subassembly, and clamping bars would be built identical to the original apparatus and the carriage top assembly would change to accommodate modern high-temperature position sensors. Figure 13 is a drawing of the experimental apparatus. 


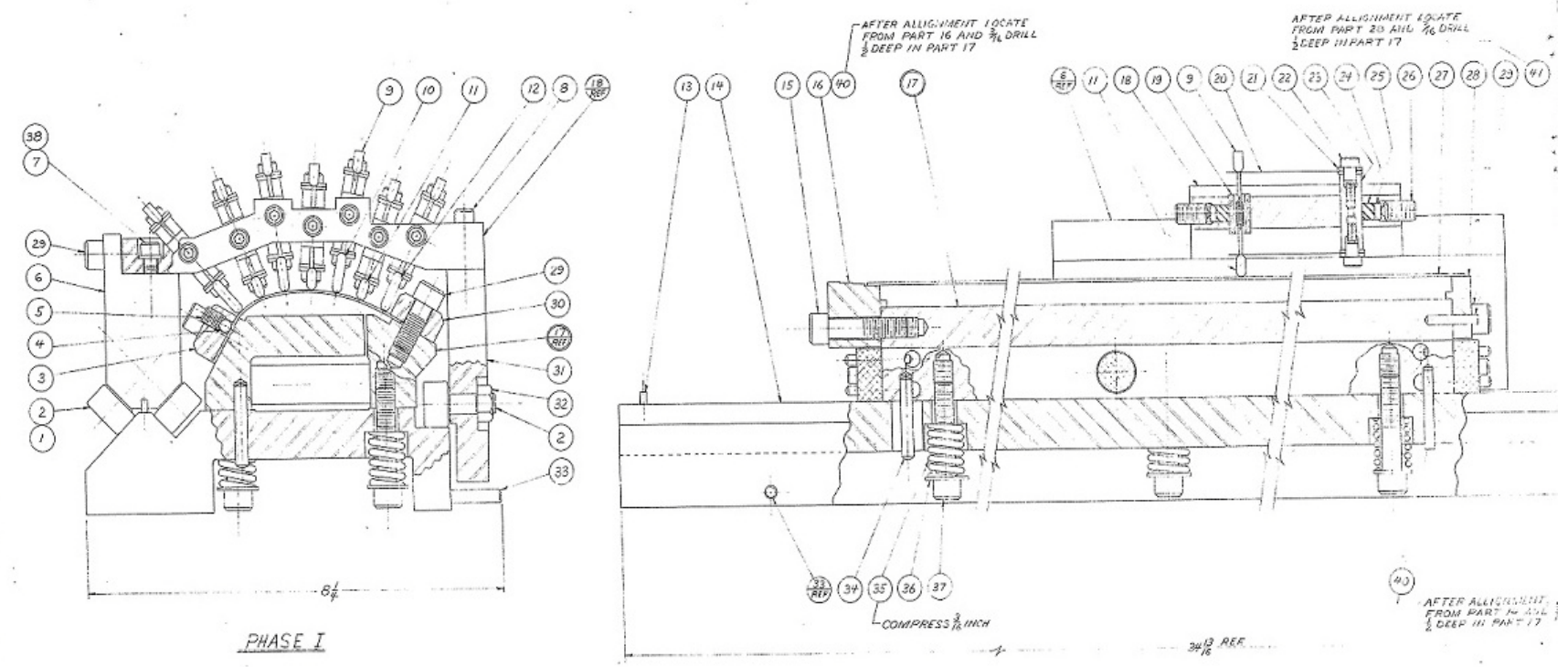

Fig. 13. Excerpt from assembly drawing for Cheverton-Kelly test apparatus.

It is proposed that the Cheverton-Kelly test apparatus be rebuilt using the original drawings to the maximum extent possible. Minor modifications are expected to enable the use of modern high temperature plate deflection instruments. A small oven and $\mathrm{Al}$ test plates made to the original drawings would be used to replicate the original tests. New plates made with depleted U-Mo foils would be fabricated and then testing would be performed with the new plate design. This modern data would be verified by the original work and would be used as benchmark data for validating the thermal-structural deflection calculations in the multiphysics codes used for the new design and safety analysis. In addition to addressing the main issue of thermally induced deflections, the other issues (pressure deflection, creep, and thermal cycling) may be addressed as needed.

\subsection{ACHIEVING 100 MW: INFRASTRUCTURE UPGRADES/ ANALYSES}

To provide a basis for an updated schedule and budget estimate to convert HFIR to LEU fuel, an activity was undertaken by a multi-disciplinary team to identify items impacted by the conversion - in particular, the increase in reactor power from 85 to $100 \mathrm{MW}$ and the increase in fuel weight by $30 \%$. The team included mechanical and instrument and control (I\&C) system engineers, structural/seismic engineers, nuclear safety analysts, operators, and trainers representing both the reactor and the cold neutron source. The team identified hardware (structures, systems, and components) and infrastructure (performance analyses, safety analyses, Technical Safety Requirements, probabilistic risk assessment, design documents, drawings, procedures, and training) impacted by the conversion. For each item, a form was used to capture a description of the impact and an estimate of the manhours by discipline, equipment cost, and duration required to implement. Emphasis was placed on the breadth and completeness of the items and issues being identified rather than the precision of the cost and schedule estimates. The activity was begun in the latter half of FY 2010 and will continue into FY 2011.

Key impacts identified to date include the need to:

- Increase the heat removal capacity of the cooling tower for the increased heat load. 
- Increase the heat removal capacity of the cold neutron source helium refrigerator for the increased heat load.

- Modify the I\&C in several of the control systems and the reactor safety system for the increased heat load and change in flux profile including upgrading the current hard-wired controls to programmable logic controllers for flexibility as HFIR transitions through LEU testing and conversion, revising setpoints and ranges or procuring new instruments, and adjusting fission and ion chambers.

- Evaluate decay heat removal requirements on primary coolant pump run time and availability and refueling scheduling for the change in fission product inventory.

- Revise a suite of other nuclear engineering analyses (shielding, criticality, and dose) for the change in fission product inventory.

- Modify fuel handling tools for the increased fuel weight.

- Evaluate structural and seismic analyses of reactor vessel internals, reactor vessel and supports, spent fuel racks, and spent fuel pool for the increased fuel weight.

- Evaluate spent fuel drop analysis and spent fuel up-righting provisions for the increased fuel weight and revised fission product inventory.

- Procure new fresh fuel shipping containers for increased fuel weight and relicense the spent fuel shipping container for the increased fuel weight and the change in fission product inventory.

- Confirm a spent fuel disposal site for the change in spent fuel material composition. 



\section{FUEL DEVELOPMENT}

\subsection{INTRODUCTION}

Fuel development activities conducted by ORNL in FY 2010 consisted of a fuel foil roll contouring feasibility determination effort. The feasibility determination involved modifying a rolling mill by machining the negative of the desired fuel foil radial contour into the rolls of the mill and then using the modified rolling mill to produce contoured foil strips from flat sheet surrogate (non-radioactive) stock of representative thickness. International Rolling Mills (IRM) of Pawtucket Rhode Island was contracted to perform the roll contouring feasibility study using equipment that was in place in their facility. The statement of work (SOW) provided to IRM was as follows.

\subsection{FOIL CONTOURING DEMONSTRATION SOW}

The development and demonstration of a technique to produce thin sheet metal strips with tapered edges is requested. The geometry desired is shown in Figs. 14 and 15. As shown in the figures, the sheet metal strips (also referred to as foils) are nominally three inches wide by 20 inches long, with a thickness that varies from a minimum of 0.003 inches to a maximum of 0.016 inches with a profile as shown in Fig. 15. The material of these strips is to be commercially available 316L stainless steel. 20 foil samples of the dimensions provided are requested and are to be supplied to ORNL for dimensional inspection.
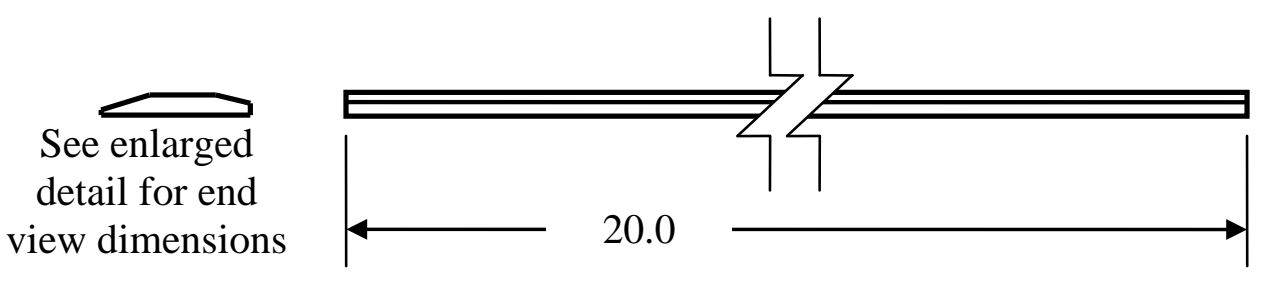

Not to scale

Fig. 14. Fuel foil dimensions. 


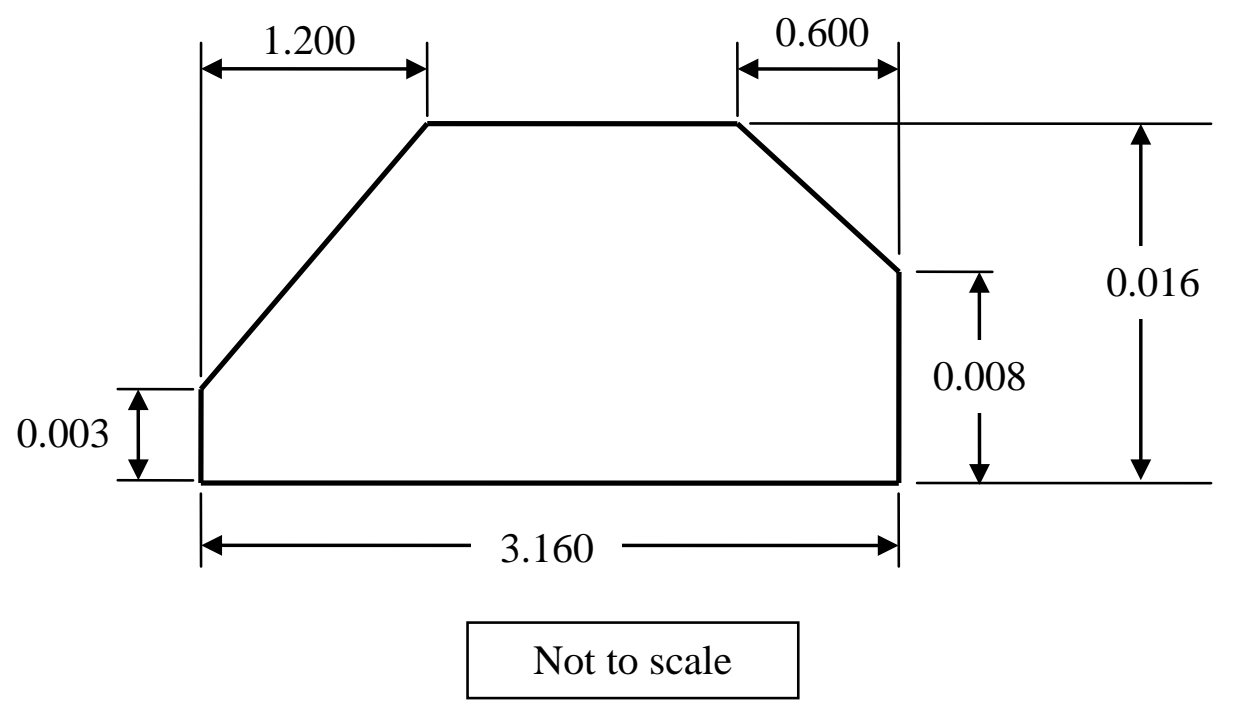

Fig. 15. Fuel foil end view enlarged detail.

The purpose of this activity is (1) to demonstrate the ability to produce foils with the contoured shape provided, and (2) to determine the dimensional control and repeatability of the contoured foil production process.

Since this is a development and demonstration activity, and the base variation of the production process is not yet known, tolerances on the foil dimensions are not provided. However, desirable dimensional tolerances are provided for informational purposes as follows. The profile dimensions (those given in Fig. 14) are desired to be \pm 0.0005 inch (five ten-thousandths of an inch). The preferable length tolerance (Fig. 14) is \pm 0.050 inch. The flatness in the width by length (3.160 inch by 20.0 inch) plane of the foil is desired to be \pm 0.030 inch. The straightness or variation of all foil edges along the 20 -inch length of the foil is desired to be within \pm 0.020 inch.

It is understood that dedicated tooling (likely a custom machined set of dedicated mill rolls) will be required for this demonstration, and that this tooling will represent a significant fraction of the cost of this activity. It is further recognized that tool design is likely an iterative process. In order to minimize the cost of custom tooling, it is requested that tooling design be limited to one best-effort iteration, even if the first iteration of tool design does not produce foils possessing the target dimensions provided. It is assumed that additional iterations on tooling geometry would bring the dimensions of the contoured profile to the desired values, but that the dimensional control and repeatability of the process itself would not change with the additional iterations of tooling design. As stated above, the determination of the dimensional control and repeatability of the contouring process from one foil to the next is more important than the absolute dimensions of the foil itself.

\subsection{CONTOURED ROLLING FEASIBILITY RESULTS}

The results of the contoured rolling investigation were not promising. The statement of work requested samples to be produced by IRM and sent to ORNL for dimensional inspection in hopes of demonstrating 
the feasibility of the contoured rolling process, and beginning to establish the repeatability of the process. Unfortunately, the initial trials at IRM were not successful and demonstration samples for measurement could not be produced.

IRM conducted two contoured rolling trials. The first trial involved machining male and female halves of the profile provided (Fig. 15) into a dedicated set of mill rolls and then using those rolls in an attempt to roll-form the desired cross section profile into flat sheet stock. The results of this first attempt were discouraging. As shown in Fig. 16, and as expected, the contoured roll profile produced excessive material flow in the rolling direction in areas of the thinnest portions of the contoured profile. This uneven flow of material during forming could not be accommodated within the part and resulted in unacceptable distortion of the sheet sample. At the time that this work was planned, it was thought that hot rolling this profile under axial tension (holding the rolled strip under tension in the rolling direction similar to that produced if the rolling were done in a reel to reel configuration) might allow the uneven flow of the contoured rolling profile to be accommodated by the strip sample. The results of this initial trial, done without applied axial tension, indicated that the uneven distortion was too great to be accommodated by hot rolling under tension, therefore it was not attempted.

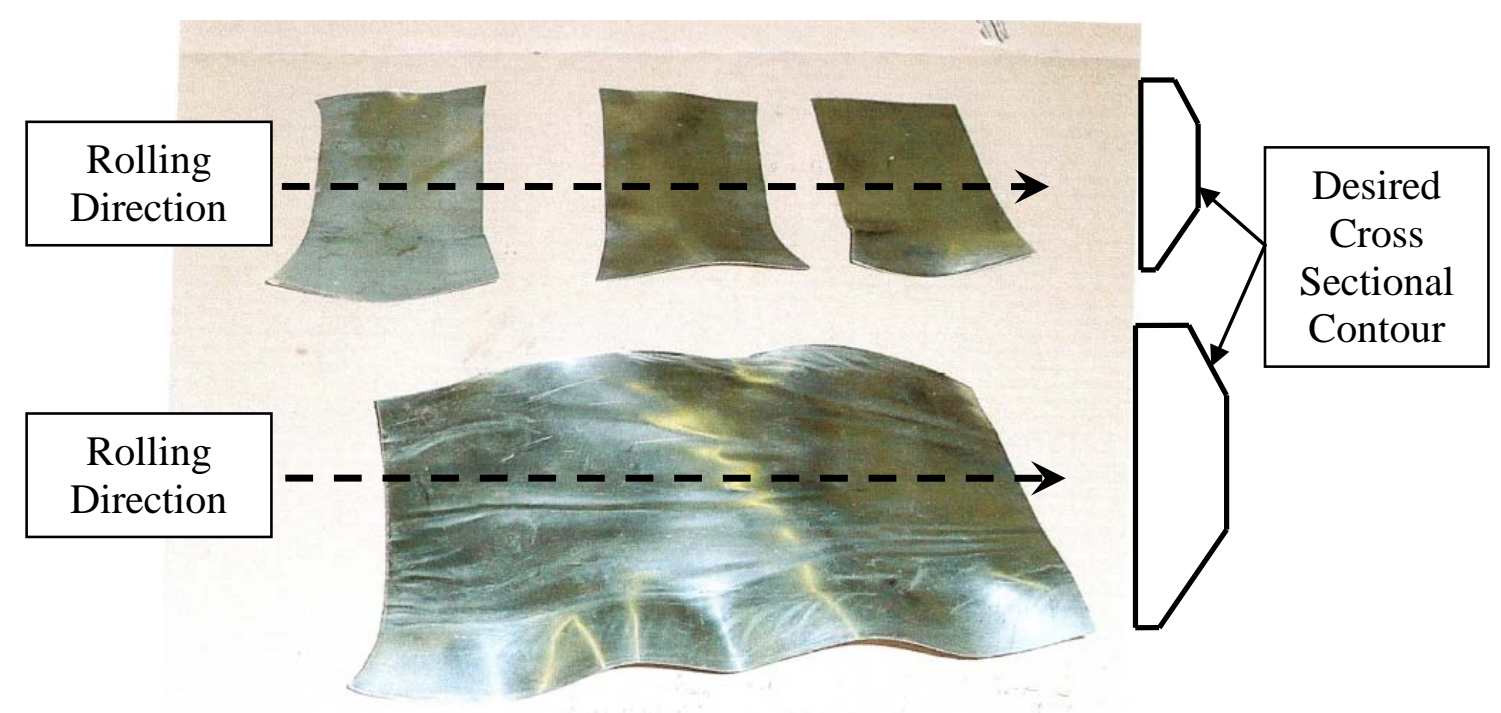

Fig. 16. Photograph “ $A$ ” of the first contoured rolling attempt (photo provided by IRM).

A second contoured rolling scheme was attempted in the second trial. In an effort to produce more symmetric plastic flow requirements, the mill rolls were modified such that the rolling profile consisted of two fuel foil profiles positioned back to back in such a way that there was symmetry about the rolling direction centerline of the strip. The symmetry about the axial centerline was accomplished by placing the desired contour adjacent to its mirror image as shown in Fig. 17. The thinking here was that the axial symmetry might alleviate some of the uneven distortion produced in the initial rolling trial and the two foil strips could be separated using an axial splitting step after rolling. 


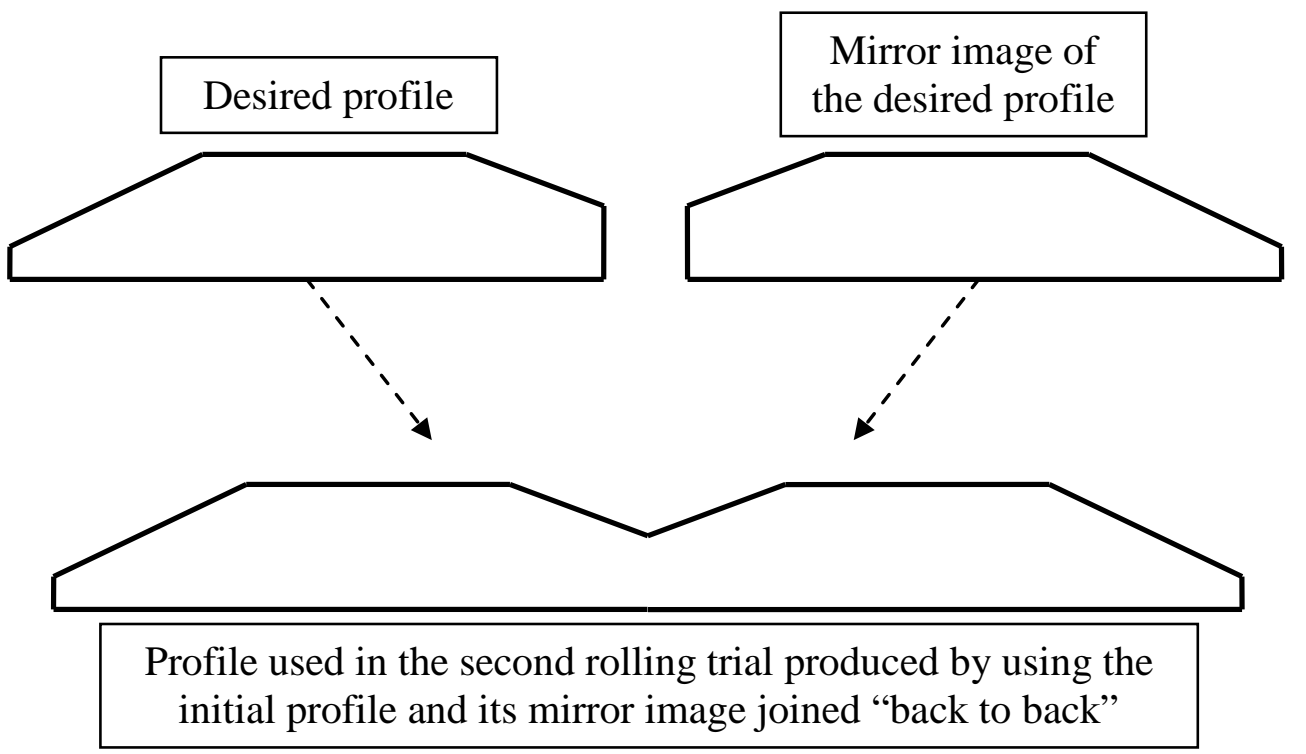

Fig. 17. Double strip symmetrical contoured rolling profile schematic used in the second contoured rolling trial by IRM.

A photograph of a surrogate sheet sample rolled in the second or "double strip symmetrical" contoured rolling trial is provided in Fig. 18. The photograph demonstrates that the added symmetry of the second attempt did not alleviate the uneven distortion experienced due to the varied thickness rolling. The sheet samples also tended to stick to the mill rolls regardless of lubrication condition.

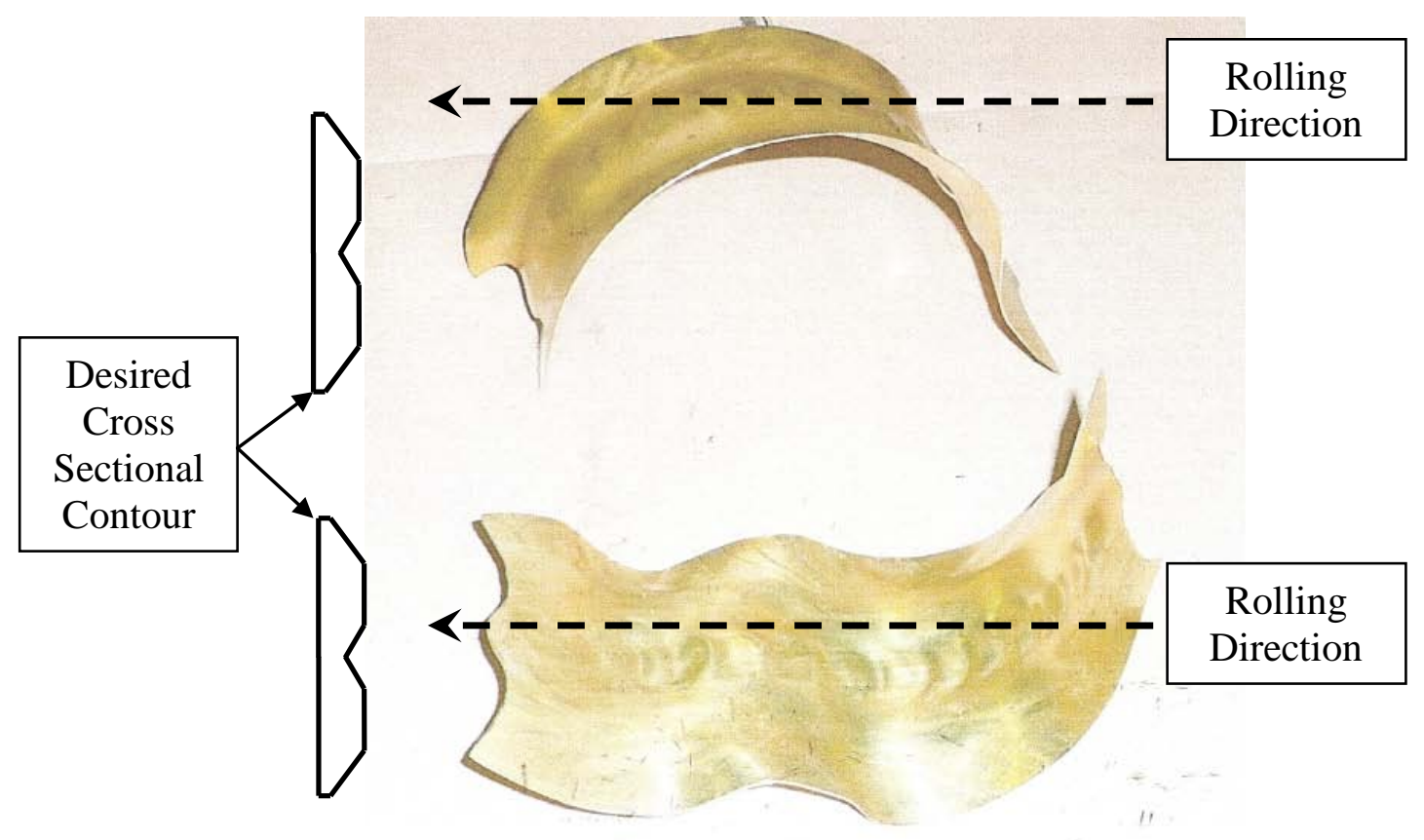

Fig. 18. Photograph “A” of the second contoured rolling attempt (photo provided by IRM). 


\subsection{CONTOURED ROLLING CONCLUSIONS}

The contoured rolling methods attempted in this study were deemed not to be feasible. The uneven material flow requirements of the varied thickness profile were thought to be too severe to be accommodated in a rolling process. Hot rolling under tension would likely be beneficial but is not believed to be sufficient to allow the contoured rolling method to be viable. In addition, adding the additional symmetry of top and bottom contouring rather than the top-only contouring attempted in this study (see Fig. 19 for description of contouring scenarios) is also not believed to be sufficient to improve the feasibility of the contoured rolling process.
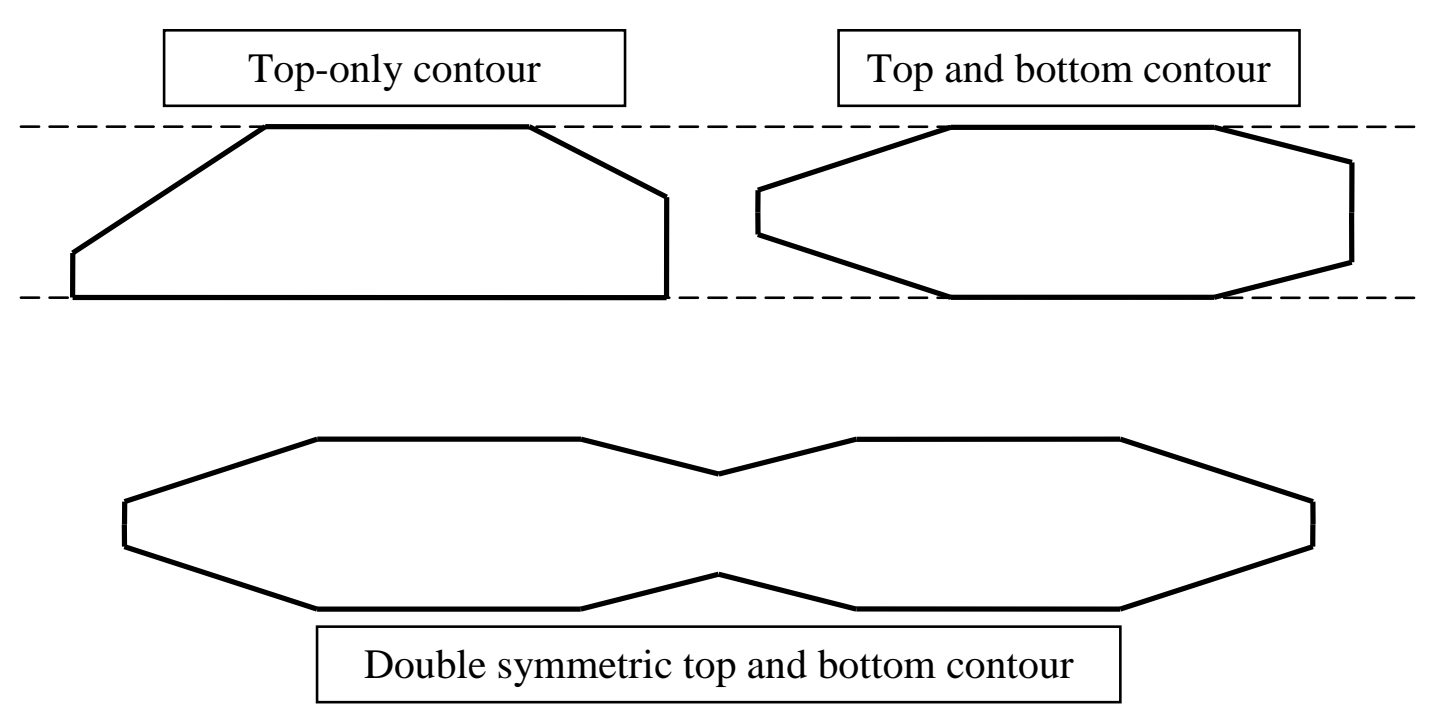

Fig. 19. Schematic of contouring scenarios.

\subsection{RECOMMENDATIONS}

The contoured rolling process was determined not to be feasible due to the uneven plastic flow requirements of the roll-forming process. The key issue is that the material in the thinnest sections of the profile has no where to go except to flow axially (in the rolling direction). In essence, the edges of the profile are forced to be longer than the middle, which produces stresses that the thin strip can not accommodate. It is possible that an incremental forging process may be feasible. In this incremental forging process the material could be allowed to flow in both the axial and width directions (the width direction corresponds to the radial direction when thinking in terms of the fuel configuration within the reactor core). It is recognized that growth of the foil during forming in the width dimension would necessitate edge trimming after forming, thus increasing scrap recycle or the waste fraction. 
A follow-on fuel foil contouring investigation via incremental forging is recommended. Issues such as die design, hot working, fuel foil blank symmetry, and scrap minimization would all be considered.

Planning for this incremental forging investigation is underway. A proposal including scope, cost, and schedule is being produced and will be submitted for consideration for FY 2011.

In an effort to document in an easily referencable and retrievable manner the work done by IRM in this contoured rolling investigation, the initial proposal provided by IRM at the beginning of this effort and the letter report from IRM documenting the results of the work are provided in Appendix B. 


\section{FUEL FABRICATION CAPABILITY}

Activities conducted in the fuel fabrication capability area consisted of multiple discussions among HFIR staff and staff members from Los Alamos National Laboratory, the Y-12 National Security Complex, the Idaho National Laboratory, and other research reactor fuel experts. A revision to the reference flow sheet presented in ref. 9 was drafted and is presented below as Fig. 20. 


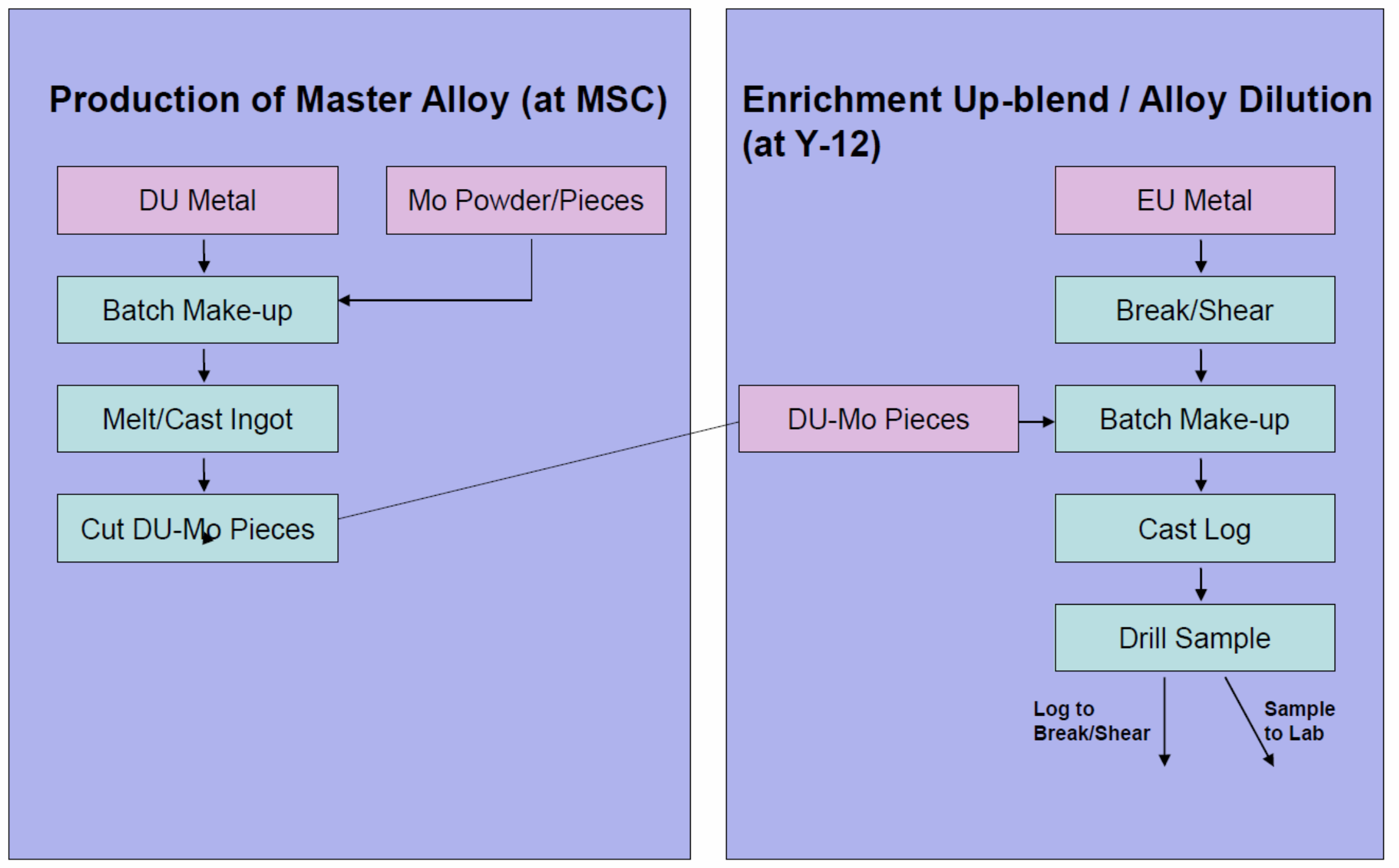

Fig. 20. Revised, proposed, LEU fuel fabrication flowstheet. 


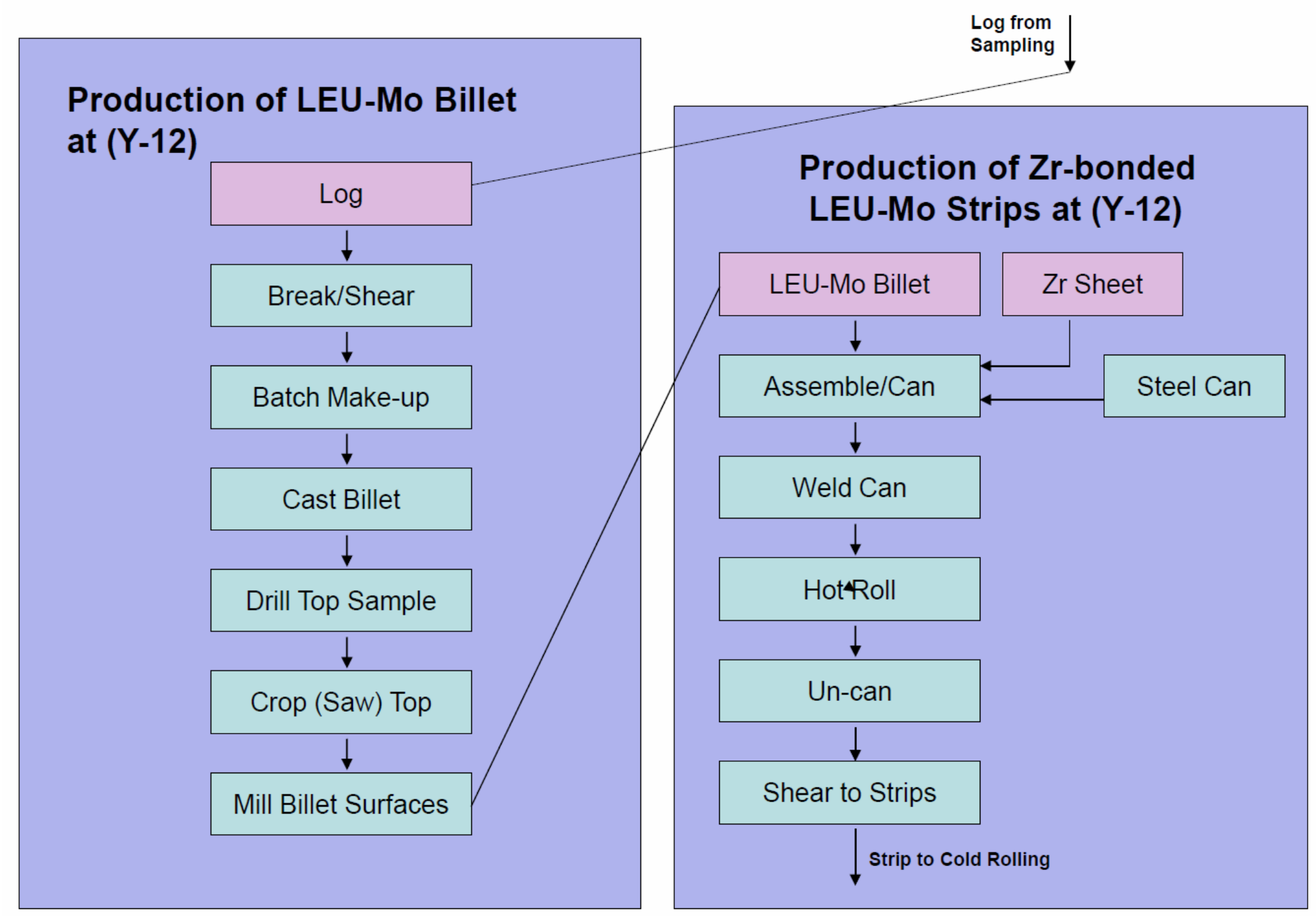

Fig. 20. Revised, proposed, LEU fuel fabrication flowstheet (continued) 


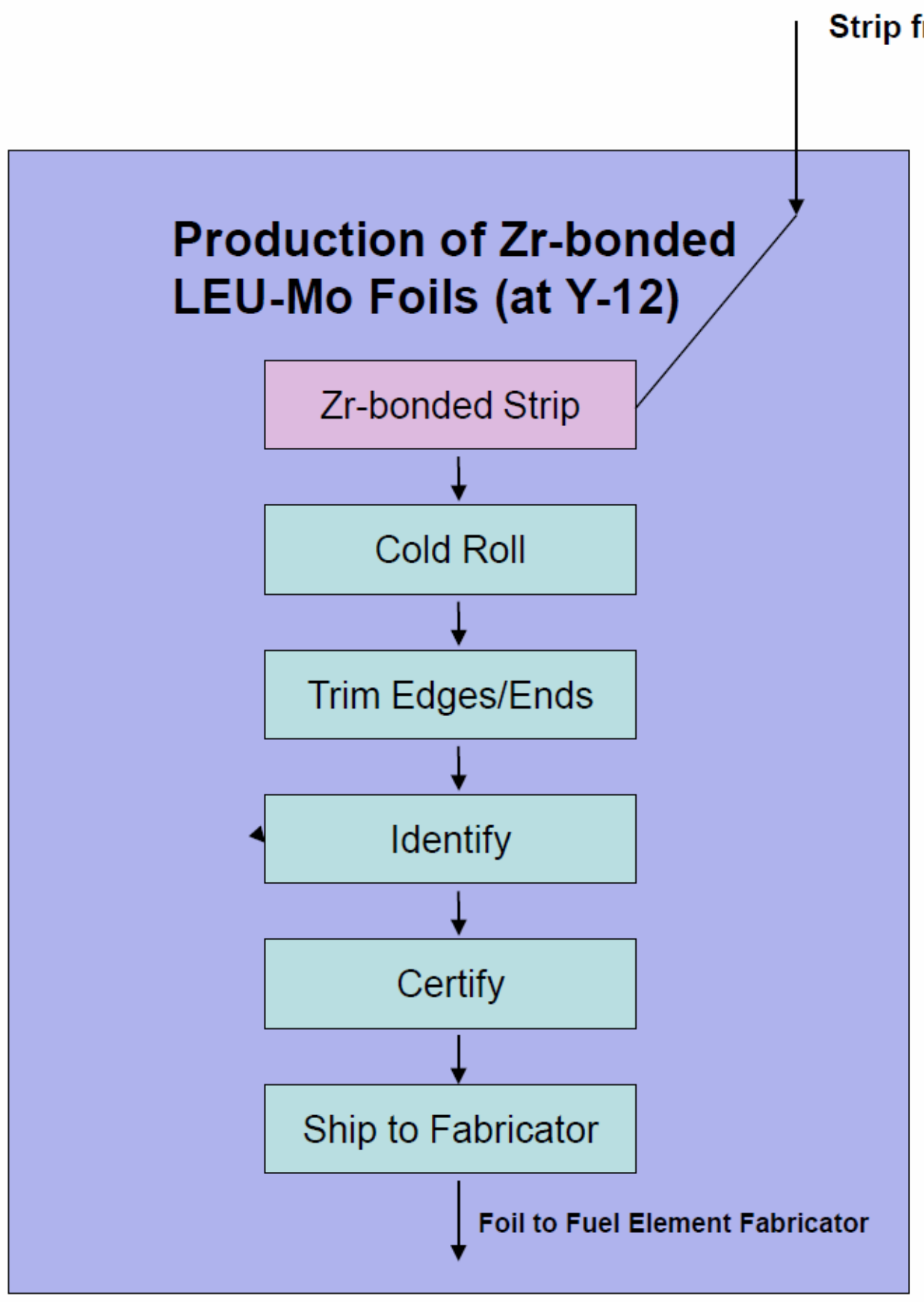

Fig. 20. Revised, proposed, LEU fuel fabrication flowstheet (continued) 


\section{STUDIES PLANNED FOR FY 2011}

The work plan for FY 2011 has been approved by the program office at ANL. Areas of study are presented in Table 4.1.

Table 5.1. ORNL staff activities proposed for FY 2011

\begin{tabular}{|c|c|}
\hline Subtask & Comments \\
\hline Conversion schedule & $\begin{array}{l}\text { Complete LEU impact study to update and maintain HFIR conversion } \\
\text { schedule integrated with conversion program schedule; Continue HFIR } \\
\text { conversion coordination and interface with conversion program. }\end{array}$ \\
\hline $\begin{array}{l}\text { Office of Science } \\
\text { participation }\end{array}$ & $\begin{array}{l}\text { Establish integrated DOE SC/ORNL LEU fuel conversion team and develop } \\
\text { safety design strategy }\end{array}$ \\
\hline Neutronics & $\begin{array}{l}\text { 1. Support of ANL peer review of ORNL analyses } \\
\text { 2. Confirm with researchers that any impacts on flux/spectra of neutron beams } \\
\text { are understood } \\
\text { 3. Assess any impacts on reactor vessel embrittlement monitoring } \\
\text { 4. Provide input for COMSOL TH analysis of optimized fuel e.g., power } \\
\text { profile without axial grading, power profile without burnable poison, and } \\
\text { sensitivity of power profile to radial grading }\end{array}$ \\
\hline Thermal hydraulics & $\begin{array}{l}\text { 1. Continue core multiphysics (TH/structural mechanics) analyses with } \\
\text { COMSOL } \\
\text { a. to develop and validate 3-D TH/structural mechanics model of HFIR fuel } \\
\text { elements } \\
\text { b. to provide input (e.g., hot spot factor, structural mechanics effects) to } \\
\text { support steady-state and transient analyses for SAR chapters } 4 \text { \& } 15 \text { including } \\
\text { integration with updated RELAP5 model } \\
\text { 2. Complete plant RELAP5 consolidated input model and documentation, } \\
\text { including preparations to apply COMSOL input }\end{array}$ \\
\hline RELAP5 plant model & $\begin{array}{l}\text { Complete plant RELAP5 consolidated input model and documentation, } \\
\text { including preparations to apply COMSOL input }\end{array}$ \\
\hline OSU Test loop & $\begin{array}{l}\text { Continue support of flow testing at Oregon State, including design of HFIR } \\
\text { test insert }\end{array}$ \\
\hline $\begin{array}{l}\text { Thermal deflection } \\
\text { testing }\end{array}$ & $\begin{array}{l}\text { Establish requirements for fuel plate deflection testing for thermal and } \\
\text { pressure effects }\end{array}$ \\
\hline $\begin{array}{l}\text { Fission product } \\
\text { release during } \\
\text { accident and } \\
\text { transport }\end{array}$ & $\begin{array}{l}\text { Develop methodology for revised fission product release and transport and } \\
\text { offsite dose analyses }\end{array}$ \\
\hline $\begin{array}{l}\text { Non-RELAP } \\
\text { transients }\end{array}$ & Scope SAR Chapter 15 revisions for non-RELAP-analyzed accidents \\
\hline Safeguards & Study safeguards and security issues \\
\hline Fuel development & Fuel Development activities, specified/coordinated by INL \\
\hline $\begin{array}{l}\text { Fuel fabrication } \\
\text { capability }\end{array}$ & Fuel Fabrication Capability tasks, specified/coordinated by Y-12 \\
\hline
\end{tabular}





\subsection{REFERENCES}

1. R. T. Primm, III, D. Chandler, J. D. Freels, T. Guida, G. Ilas, B. C. Jolly, J. H. Miller, and J. D. Sease, Design Study for a Low-Enriched Uranium Core for the High Flux Isotope Reactor, Annual Report for FY 2009, ORNL/TM-2009/313, February 2010.

2. Tracey Guida and R. T. Primm, III, Establishing a Cost Basis for Converting the High Flux Isotope Reactor from High Enriched to Low Enriched Uranium Fuel, ORNL/TM-2009/311, February 2010.

3. R. T. Primm, III, D. L. Pinkston, J. D. Sease, and D. G. Renfro, Establishing Specifications for Low Enriched Uranium Fuel Operations Conducted Outside the High Flux Isotope Reactor Site, ORNL/TM-2010/241, September 2010.

4. G. Ilas and R. T. Primm, III, Fuel Grading Study on a Low-Enriched Uranium Fuel Design for the High Flux Isotope Reactor, ORNL/TM-2009/223, initial issue November 26, 2009, revised and reissued as ORNL/TM-2009/223R1, March 2010.

5. G. Ilas and R. T. Primm, III, Low Enriched Uranium Fuel Design with Two-Dimensional Grading for the High Flux Isotope Reactor, ORNL/TM-2010/318, (expected publication 2011).

6. G. Ilas and R. T. Primm, III, "Methodology for Simulating the Irradiation of the Control Elements in HFIR”, Trans. Am. Nuc. Soc., Vol. 103, pp. 696-698, November 2010.

7. D. Chandler, R. T. Primm, III, and G. I. Maldonado, HFIR Post-Irradiation Curium Target Rod Nuclide Inventory Calculations, Trans. Am. Nuc. Soc., 102, 560, (2010).

8. H. A. McLain, HFIR Fuel Element Steady State Heat Transfer Analysis, Revised Version, ORNL/TM-1904, Oak Ridge National Laboratory, Oak Ridge, Tennessee, December 1967 as appended by T. E. Cole, L. F. Parsly, and W. E. Thomas, Revisions to the HFIR Steady State Heat Transfer Analysis Code, ORNL/CF-85/68, April 7, 1986.

9. J. D. Sease, R. T. Primm III, and J. H. Miller, Conceptual Process for the Manufacture of Lowenriched Uranium/Molybdenum Fuel for the High Flux Isotope Reactor, ORNL/TM-2007/39, September 2007. 



\section{APPENDIX A}

This appendix provides discussion of several technical areas of thermal hydraulics modeling. Two dimensional (2D) thermal and fluid flow methods development, three dimensional (3D) methods development, structural analysis methods development, and quality assurance concerns are included.

\section{A.1 2D Thermal-Hydraulics Methods Development}

The 2D methods development is performed to arrive at constraints on parameters used to create the full 3D model. Since a significant level of savings in computer resources can be obtained by working in 2D, one can arrive at the parametric constraints in a much shorter time than had one tried to find our limitations in the final 3D framework.

\section{A.1.1 Investigation of Turbulent Prandtl Number}

The new formulations of the turbulent Prandtl number used in COMSOL v4 are the Kays-Crawford, Extended Kays-Crawford, and User Defined. COMSOL versions 3.4 and earlier only provided for the "User Defined" option, which usually was represented as a constant such as 1.0 or 0.85 . The KaysCrawford turbulent Prandtl number is chosen by default. The COMSOL documentation states that this formulation of the turbulent Prandtl number is found to be sufficient for "most turbulent wall bounded flows except for liquid metals.”[ref. A.1] Formally it is expressed as

$P r_{T}=\left[\frac{1}{2 P r_{T \infty}}+\frac{0.3}{\sqrt{P r_{T \infty}}} \frac{C_{p} \eta_{T}}{k}-\left(0.3 \frac{C_{p} \eta_{T}}{k}\right)^{2}\left(1-e^{\frac{-k}{0.3 C_{p} \eta_{T} P r_{T \infty}}}\right)\right]^{-1}$,

where $P r_{T \infty}=0.85, k$ is the thermal conductivity of the fluid, $C_{p}$ is the specific heat of the fluid, and $\eta_{T}$ is the eddy viscosity. This equation is based on the idea that the mechanism for heat transfer in an eddy is by molecular diffusion only and "when compared with experiment it fits the available data reasonably well”. [ref. A.2]

The extended Kays-Crawford turbulent Prandtl number includes liquid metals by modifying the free stream turbulent Prandtl number

$P r_{T \infty}=0.85+\frac{100 k}{C_{p} \eta R e_{\infty}^{0.888}}$

where $R e_{\infty}$ is the free stream Reynolds number and $\eta$ is the dynamic viscosity of the fluid.

The "User defined" option gives the COMSOL user the freedom to define a value or expression for the turbulent Prandtl number. It is clear that the default input of Kays-Crawford turbulent Prandtl number is the correct input for the HFIR fuel element application.

\section{A.1.2 Investigation of Low-Reynolds Number k- $\varepsilon$ Turbulence Model}

A detailed discussion of the Low-Reynolds Number k- $\varepsilon$ Turbulence Model is included in the COMSOL conference paper referenced earlier (Exploiting New Features of COMSOL Version 4 on Conjugate Heat Transfer Problems). The COMSOL documentation describes this new feature to "yield high accuracy in the description of the flow and transport of heat and mass transport close to walls." One should undoubtedly be interested in obtaining high accuracy solutions near the HFIR fuel plate walls. In general, the application of the new Low-Reynolds Number k- $\varepsilon$ Turbulence Model upon the HFIR fuel plate has yielded wall temperatures lower than those predicted by the v3.5a wall function turbulence models. This is shown by Figure A.1 below whereby the 2D best-estimate HFIR fuel plate model has been modified to include the Low-Reynolds Number k- $\varepsilon$ Turbulence Model. This is compared to the previous solution obtained from COMSOL v3.5a wall functions (Fig. A.2) which predict the wall temperature to be 
considerably higher. While the curves are difficult to compare until overlaid upon each other, the LowReynolds number extension results tend to follow the expected wall temperature shape more accurately, while the overall temperature level is much lower. This is expected since the SSHTC is also expected to be conservatively high.

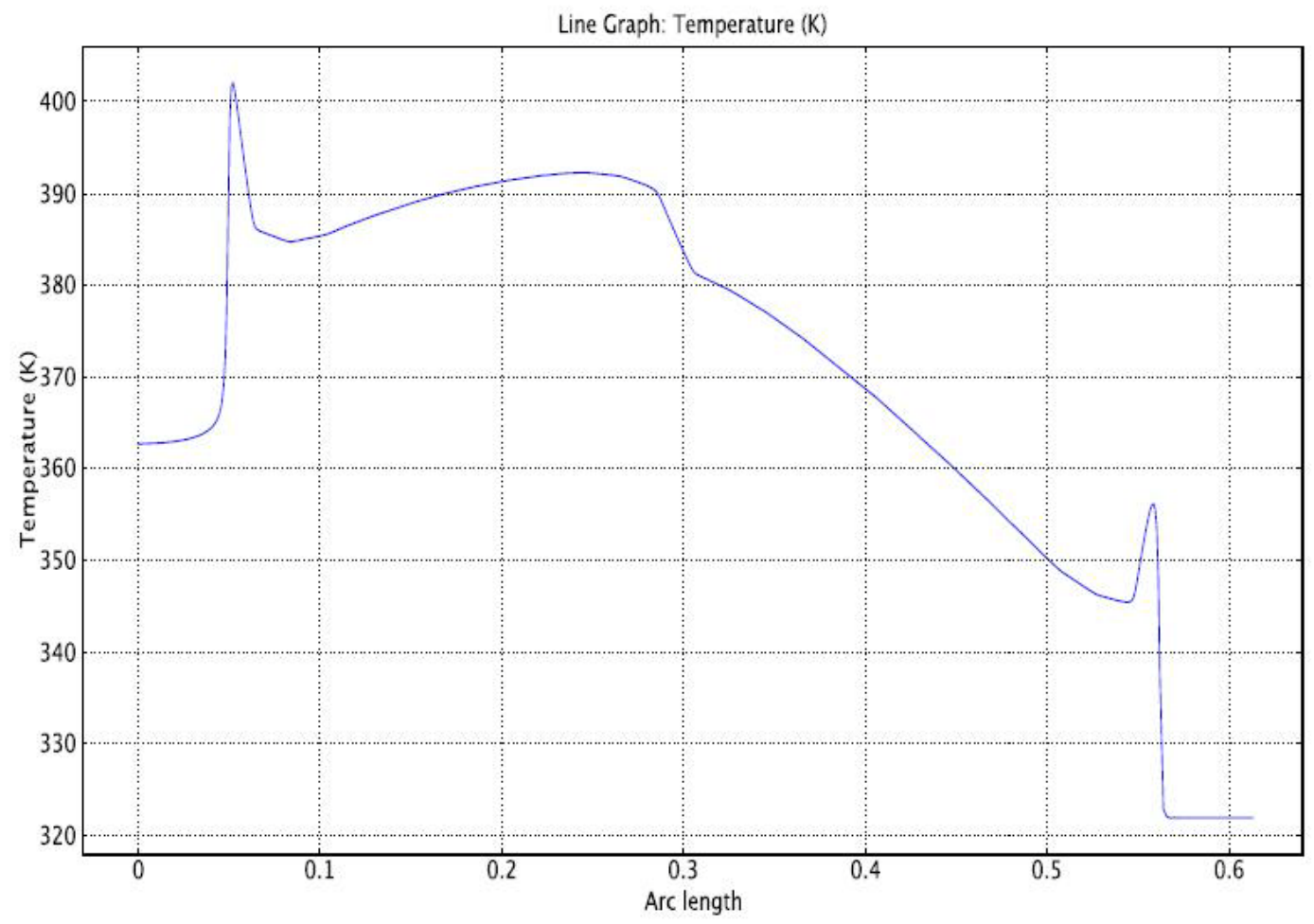

Figure A.1. COMSOL 4.0a Best-Estimate 2D Model, Low-Reynolds Number k- $\varepsilon$ Turbulence Model, HFIR Fuel Plate Wall Temperature.

\section{A.1.3 Investigation of Wall Offset Parameter used in the Traditional k- $\varepsilon$ Turbulence Model}

Detailed information about the difference in the wall temperature results between the "law-of-the-wall" (LOW) traditional turbulence models, which requires a specification of wall offset in the COMSOL code, and the new "Low-Reynolds Number" (LRN) extension to the turbulence model is also provided in the COMSOL conference paper (Exploiting New Features of COMSOL Version 4 on Conjugate Heat Transfer Problems). A goal is to perform the detailed 3D fuel-plate modeling using the more accurate LRN model; however, it may be that the less resource intensive LOW models are sufficient for some cases. In turns out that the LOW models used in v4+ series also corrected an over estimation of wall temperature that apparently existed in COMSOL v3.5a even if the wall offset is sufficiently small. 


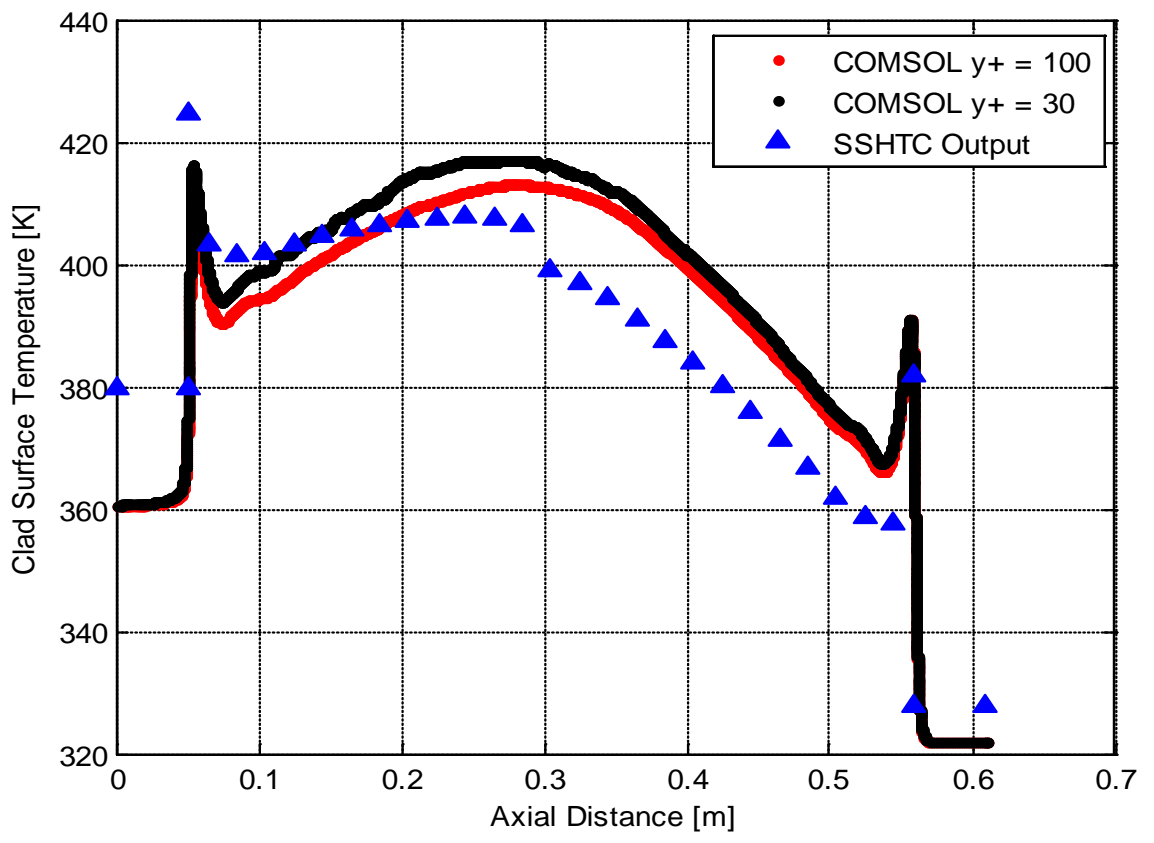

Fig. A.2. COMSOL 3.5a Best-Estimate 2D Model, Wall-Function k- $\varepsilon$ Turbulence Model, HFIR Fuel Plate Wall Temperature

\section{A.1.4 Investigation of Hot-Spot Modeling of HFIR Fuel with COMSOL}

A significant level of research has been carried out to investigate the best way for COMSOL to model the hot spots that will exist in the fuel due to manufacturing imperfections. Traditionally in HEU fuel, both non-bond and fuel-loading inconsistencies are accounted for in the hot-spot modeling. Several researchers have performed hot-spot modeling of HFIR fuel in the past and the efforts of their studies have been included in this study. At this point, no final conclusions have been made on the best methods to use, but there are no technical issues in implementation. The COMSOL model accommodates various sizes, shapes, and material property variations associated with the hot-spot modeling, and excellent results have been obtained. The expected reduction in hot-spot temperature is indeed indicated by the addition of axially-directed thermal conductivity. Even further reductions can be expected when the full 3D analysis is performed this coming year which adds thermal conduction dissipation in all directions except the direction of the hot spot normal to the wall toward the coolant. Details of the results of this study will be included in the annual report to be published later.

\section{A.1.5 Investigation of Axial Mesh Spacing and Overall Mesh Density Reduction Techniques}

The mesh density associated with the dominant direction of heat transfer (normal to the fuel-plate walls) is governed by the mesh requirements for the turbulence models. For the LOW models, this requires $30<$ $\mathrm{y}^{+}<100$. However, for the LRN models, an even smaller mesh density near the wall is required to capture the viscous sublayer velocity and temperature profile and is governed by the parameter $l_{c}{ }^{*}<1.0$, which is a similar measure to $\mathrm{y}^{+}$. Therefore, the issue of degrees of freedom and solution matrix size associated with mesh density becomes even more demanding with the LRN models.

Because the mesh density, hence problem size, is governed by the physics of the problem and the LRN models, the question of how dense the mesh requirements in the axial direction becomes even more important. The naïve approach will rely on the built-in mesh density recommendation of the COMSOL code mesh generator which is independent of the physics involved. Using these criteria, an analyst could 
misinterpret the requirements for the mesh density and conclude that the problem size would be overwhelming for the computer resources available.

It was felt by the current researchers that, because the flow is dominant in a single direction, a significant savings in mesh density could be achieved by a coarser mesh in the axial direction. It was already known from the preliminary 3D simulations performed last year, that one could solve a fairly coarse mesh in the axial direction and obtain a reasonable solution with sufficient mesh density normal to the wall to capture all boundary-layer affects. Further, it was known that an axial mesh spacing of approximately $10^{2}$ mesh lines would yield approximately $5 \times 10^{6}$ degrees of freedom (dof), or 5 Mdof, for a typical single-plate model of the HFIR fuel plate and requires about 40 GB of computer memory to solve in COMSOL on a single compute node of the cluster. The minimum axial mesh density requirements needed to provide accurate solutions given a best-estimate power profile of the HFIR fuel were not known. Therefore, the purpose of this part of the research was to determine this minimum axial mesh spacing requirement.

The details of the results of this study will be provided in the forthcoming annual report of the T-H research for the HFIR LEU conversion project. In summary, what one found was that there is very little constraint due to axial spacing requirements. In essence, what will drive the mesh spacing are the variations in the power profile. In simplified terms, whatever the spacing in the axial direction is for the power profile (the SSHTC presently uses 27 nodes in the axial direction), then the same axial spacing or greater should be used by COMSOL. A similar practice should be made in the span-wise or radial direction of the fuel plate regarding mesh spacing. The prospect of a curve-fitted, smooth power variation (to be performed in FY 2011) will provide even more flexibility in the COMSOL meshing requirements that should lead to an optimum level meshing. It is envisioned that more than a single fuel plate could be modeled on a single compute node of the cluster in a reasonable amount of time with this level of resolution.

\section{A.2. 3D Thermal-Hydraulics Model Development}

In preparing the models for the detailed 3D simulations, there are still a number of issues and parameters that cannot be investigated beforehand efficiently in 2D. These issues are discussed subsequently.

\section{A.2.1 Development of 3D Involute Geometry with CAD Packages}

Prior to the release of COMSOL-v4.1, there was no known method to create a smooth, single involute surface within the COMSOL internal CAD. A non-smooth, multi-surface involute geometry could be created with the COMSOL internal CAD by connecting multiple points to create the involute shaped line. Both the equation and point evaluations are available for the HFIR involute shape geometry through design drawings and approved calculations.

To remedy this problem, it was realized that if the geometry is first created with a professional 3D CAD package, such as SOLIDWORKS, then the surface would meet the desired characteristics of the geometry input into COMSOL. Indeed, SOLIDWORKS is a desirable package to interface to COMSOL because it includes a "live connection" which allows for changes on either side (SOLIDWORKS or COMSOL) to be instantly realized on the other side. A live connection then, allows for interactive design and analysis to take place. The idea being that a modern computing environment could be used to produce optimum designs of manufactured parts or components.

A professional designer, who is experienced with SOLIDWORKS, worked with us on this issue and was successful in creating the HFIR HEU involute plate. The model was imported into COMSOL, but was not successful in meshing the geometry. There appeared to be further issues in the translation that may or may not have been possible to correct, but after several iterations and attempts to fix this problem, no more time was spent on this task.

The official design software for HFIR is MICROSTATION. There is an ongoing project to convert a large fraction of the HFIR design drawings to 3D CAD with MICROSTATION. The HFIR fuel plates 
are certainly a part of that project and the design files can be imported into COMSOL. However, at present, the HFIR fuel plate drawings do not contain the internal fuel and filler regions. A task has been identified to generate the LEU counterpart fuel plate design in MICROSTATION.

\section{A.2.2 Development of 3D Involute Geometry with Native COMSOL CAD}

With the release of COMSOL-v4.1 (November 12, 2010, and patched with update 1 on November 26, 2010), a new feature, termed "parametric curves" and "geometric sweeps" has been included in the geometry creation portion of the code. With this new feature, it is now possible to describe and draw any $3 \mathrm{D}$ curve using a generalized equation as input, with free parameters that can vary over a range. So, for example, the HFIR involute curve shape can be input in equation form directly into COMSOL (no pointby-point input). Subsequently, given the generalized curve, a geometric sweep can be performed using the generalized parametric curve as a guide. This enables the HFIR involute shape to be drawn in 3D very precisely and with high accuracy. Furthermore, because the geometry is created natively within COMSOL, the internal mesh generation is performed consistently and without error. Therefore, this has eliminated the need to perform external CAD input from SOLIDWORKS or MICROSTATION (or any other CAD package for that matter).

If the reader may recall, it has always been an issue to also include the rounded (0.025” radius) entrance at the top, which is unique to the HFIR fuel to minimize pressure drop across the fuel element. This new feature also allows for the rounded top to be included in a straight-forward manner. Detailed results of the HFIR fuel plate geometry and mesh generation will be included in the T-H annual report.

\section{A.2.3 Investigation of 3D Fuel-Coolant Assembly Techniques}

In order to create a 3D model of the HFIR fuel plate and adjacent coolant channels, it is also important to include the entrance and exit regions. For a single channel, the fuel plate and adjacent coolant channel are geometrically uniform. Therefore, the geometry and mesh generation are fairly simple for this part of the model and can be created by first specifying the geometry/mesh in a cross-sectional plane, and then extruding axially to finish out the geometry/mesh.

The entrance and exit regions however are considerably more complex. Further, the side plates need to be coupled to the fuel and coolant to complete the model for a single channel. Eventually, the goal is to include multiple plates and flow channels to analyze complex accidents such as flow blockage and the propagation of a failed plate unto adjacent plates. For even the simplest situation of a single channel, a more complex method is required to generate the geometry and/or mesh with the internal tools available within COMSOL.

The simplest method of meshing in COMSOL is to create the entire geometry and then mesh the entire space using the "free mesh". This can be done, but will result in far too many finite elements than can be analyzed even for the available computing resources and distributed parallel processing that are now used for larger COMSOL problems.

In version 3.5a of COMSOL, an investigation was conducted of the feature of the code called "parts" and "assemblies". Using these tools, separate portions of the model geometry could be created and meshed. In order to create a continuity of mesh and boundary conditions between the parts, an "imprint” was required to be formed in order to couple the parts together for subsequent analysis. These advanced geometry and meshing methods were studied and demonstrated and found to work well for this problem. Indeed, the flow solution was obtained for the nominal HFIR operating condition to finalize the exercise.

Shortly after this point in the project, version 4+ of COMSOL was released. A completely new GUI was delivered with this new version of the code and a considerable amount of time was required to re-learn the code from many different perspectives. In this particular area, it was realized that the need for creation of separate "parts" and "assemblies" is no longer necessary. Indeed, this feature is a default mode now in the generation of the $3 \mathrm{D}$ objects. The concern of creating consistent mesh along adjacent surfaces 
between the parts via the "imprint" feature is automatic now. Therefore, the creation of the geometry and mesh has now become much simpler for the user in this new version of the code. This is just one of many new welcome features in the new version of COMSOL. Many of the details and examples of geometry and mesh for the 3D plate geometry will be included in the T-H annual report.

\section{A.2.4 Investigation of Periodic Boundary vs Extrusion Coupling Boundary Conditions}

An important question that has always existed during this project was the proper way to handle the boundary conditions that arise due to the periodicity that exists from the repetitive structure created by the involute-shaped plates and adjacent coolant channels arranged azimuthally to create the cylindrical shape

of the HFIR fuel elements. Last year this problem was studied and concluded that the COMSOL-supplied periodic boundary conditions were not sufficient for this problem, and that the more complex and difficult-to-implement "extrusion coupling" boundary conditions were necessary. The periodic boundary conditions (PDC) are a subset of the extrusion-coupling boundary conditions (ECBC) in COMSOL. The ECBC are a more general implementation of complex boundary conditions and provide a very powerful feature of the code such as the ability to map a 2D surface to a 3D surface, etc.

As a result of many contributing factors, as well as a nagging question about this issue, and also the difficulty in implementing the more general ECBC for this purpose, this question was investigated once again. The models used in the COMSOL conference paper cited earlier (Exploiting New Features of COMSOL Version 4 on Conjugate Heat Transfer Problems), provided an excellent testing ground to address this problem.

A thorough testing of this issue was performed. The primary question was not only whether the value of the conserved quantity across the boundary was made consistent, but also whether the derivative of this value, which contributes to the flux, was made consistent and conserved across the periodic boundary. Figure A.3 below represents the exit temperature plane of a typical HFIR-type fuel plate using the new LRN turbulence model at conditions not unlike HFIR operating conditions. The PDC was applied at an arbitrary point ( $25 \%$ and $75 \%$ of span left and right respectively at the view shown). This and many other tests were obtained, and the reader can easily verify that not only is the value preserved, but the flux across the boundary is also continuous. It is not clear at this point whether the implementation of the PDC is the same in v4.1 as it was in v3.5a which may have led to a different conclusion earlier. Nevertheless, the important aspect now is that only the implementation of the simpler PBC is necessary to create the models and perform the 3D analysis for the HFIR LEU conversion project. Additional details on this subject will be included in the T-H annual report. 


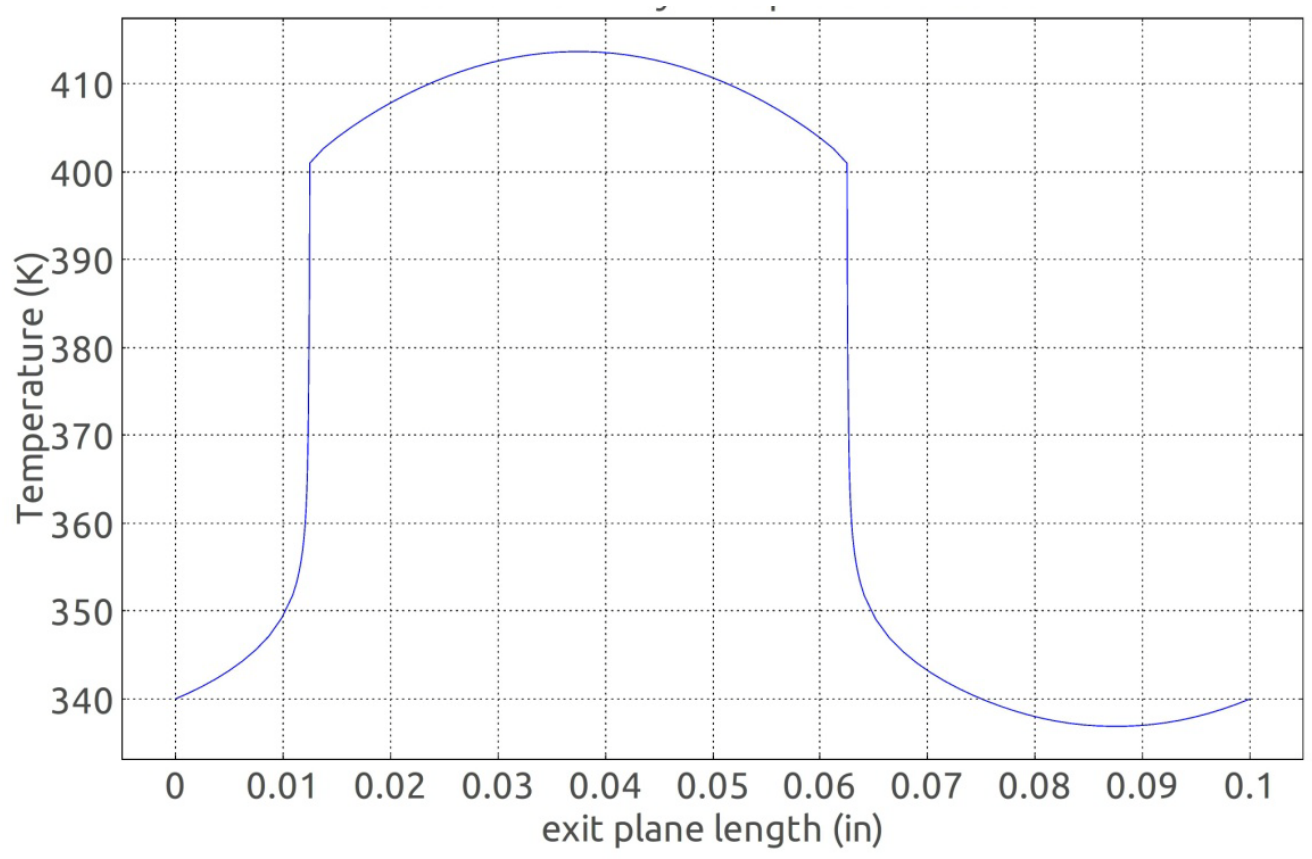

Fig. A.3. Demonstration of the applicability of the COMSOL periodic boundary condition applied to a representative HFIR fuel plate model at typical operating conditions.

\section{A.3. Structural Mechanics Methods Development}

This analysis project is only in the beginning stages of addressing the structural mechanics modeling and issues. Nevertheless, significant progress has been made in this area, and progress is expected to accelerate considerably now that an analysis team is formed.

\section{A.3.1 Fluid-Structure Interaction Methods Development}

The performance of this task has undergone a major shift in personnel and priority as this fiscal year has progressed. One graduate student started on the project in January, 2010 and left the project for full-time employment by the end of July, 2010. Several of the preliminary FSI results from this student were presented at LEU meetings. All of his work was preserved as is, and made available for a new student to take his place on the project.

For example, Figure A.4 shows a COMSOL velocity solution he obtained for flow over a flat plate typical of HFIR thin plate and flow conditions (flow left to right). This problem demonstrated the ability of COMSOL to obtain the FSI solution, including ALE adaptive meshing techniques, which are required to solve a problem of this type. Many questions remain unanswered regarding this solution, however. For example, why did the plate deflect in a preferred direction when all conditions should be symmetrical with respect to this problem? Therefore, no conclusions have been reached with any of these initial solutions at this point other than quality solutions can be produced from this software. 


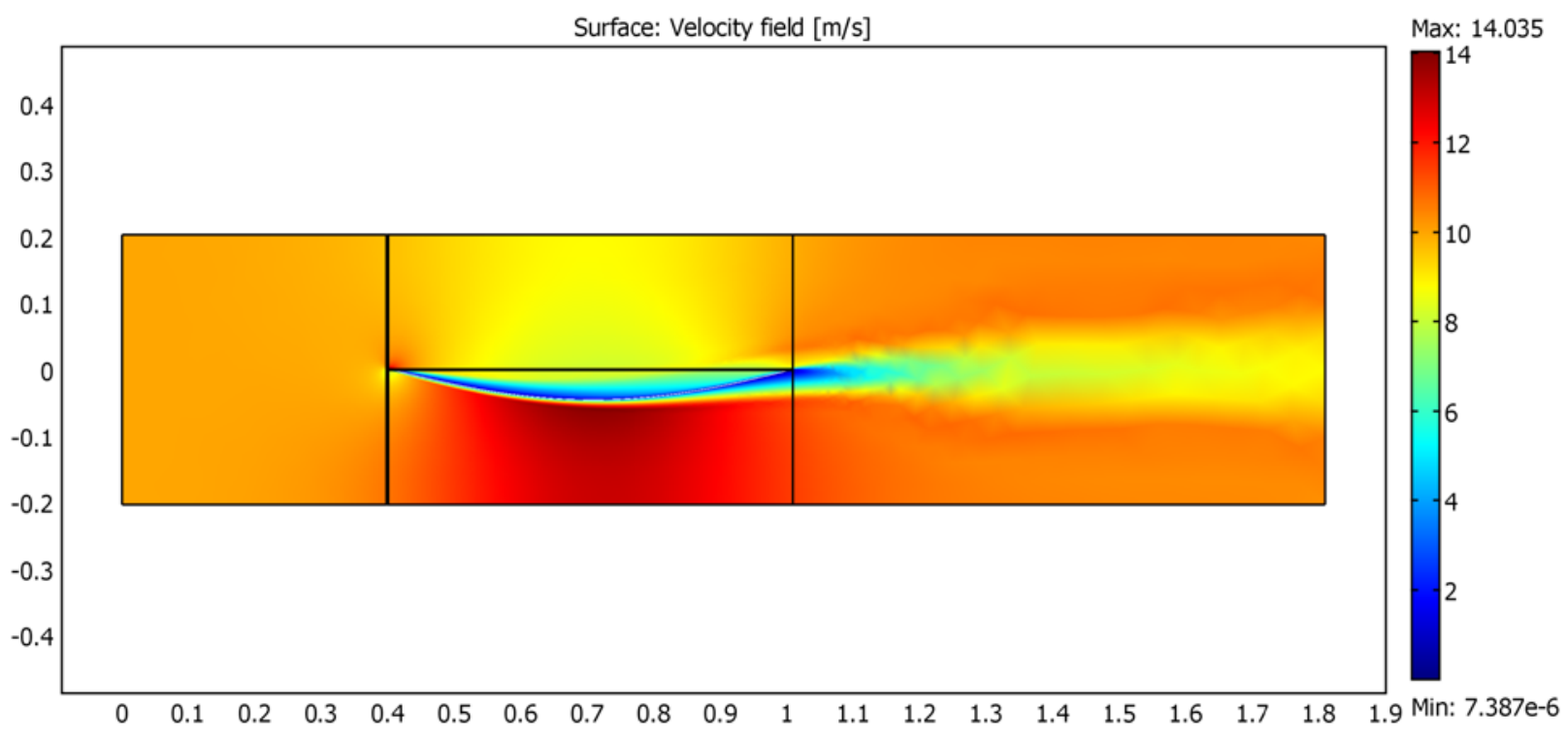

Fig. A.4. COMSOL velocity solution for a HFIR plate and HFIR-typical flow conditions.

Starting in late September, 2010, a new graduate student, Franklin Curtis, along with his major professor, Dr. Kivanc Ekici, joined the project under the existing contract with UTK-MABE. Since the first student left the project, it was recognized that additional expert assistance was needed on the analysis team. The subsequent addition of Dr. Ekici brings a wealth of knowledge in this technical area since his area of expertise is aeroelasticity which fits perfectly with the need for increased technical expertise in this area of the project. 
In addition to recovering the work from the previous student, the new team of Curtis and Ekici have focused their early involvement on performing validation cases that are related to the HFIR fuel-plate FSI problem. Both Curtis and Ekici are new users of COMSOL, so they have also been learning the code.

Two recent validation problems are noteworthy and reported here. First, an analytical solution for the eigen-frequencies of a flat plate from Analytical Methods in Vibrations, by Leonard Meirovitch provides a method for direct comparison with COMSOL numerically-obtained solution below in Table A.1. Note that a shell element was required for this problem which also pins all sides of the plate. This type of constraint is not available in the full 3D solid-mechanics model setup. An additional case was run where the mesh is refined that yielded eigen-frequencies with a maximum value of $0.55 \%$ in the difference for over 250 frequencies solved.

Table A.1. The comparison of the natural frequencies found using Meirovitch's analytical approach and the results found using COMSOL

\begin{tabular}{c|c|c}
\hline COMSOL & Meirovitch & \% Diff \\
\hline 0.051234825 & 0.0522765030 & 1.99 \\
\hline 0.10015778 & 0.1045530060 & 4.20 \\
\hline 0.178232023 & 0.1777401101 & 0.28 \\
\hline 0.271312196 & 0.2718378155 & 0.19 \\
\hline 0.397301688 & 0.3868461221 & 2.70 \\
\hline 0.514689659 & 0.5227650298 & 1.54 \\
\hline 0.691924526 & 0.6795945387 & 1.81 \\
\hline 0.857318985 & 0.8573346489 & 0.00 \\
\hline 1.055967529 & 1.0559853602 & 0.00 \\
\hline 1.280957977 & 1.2755466727 & 0.42 \\
\hline 1.511337648 & 1.5160185864 & 0.31 \\
\hline 1.776872295 & 1.7774011013 & 0.03 \\
\hline 2.060282156 & 2.0596942174 & 0.03 \\
\hline 2.386351312 & 2.3628979347 & 0.99 \\
\hline
\end{tabular}

For the second study, a cantilever-beam flat plate was investigated for the natural frequency and harmonics and known solutions compared to COMSOL with favorable results.

This more rigorous approach has been welcomed by the project team and the FSI technical area will be investigated with a more traditional approach to this type of problem solving. A new statement of work for CY 2011 has been generated which clearly identifies the FSI tasks to be completed which include a direct simulation and comparison to the OSU tests for the generic plate tests. More details in this technical area will be included in the detailed report.

\section{A.3.2 Thermal-Structure Interaction Methods Development}

An initial investigation of the thermal-structure interaction capability of COMSOL was applied to the 2D best-estimate model of the HFIR fuel plate. While no comparison with measured data of the HEU HFIR plate (ORNL/TM-2325) has been made yet, the model results follow physical intuition; that is, the greatest expansion of material is in the region of highest temperature. 
Figure A.5, below, shows the resultant fuel plate expansion which includes, as input, a best-estimate representation of the power profile as fitted by a cubic spline (smooth) representation of the power density. The $\mathrm{x}$ and $\mathrm{y}$ axes in Figure A.5 represent the fuel plate width and height respectively shown in a screen-expanded view where the $\mathrm{x}$ and $\mathrm{y}$ axis are not of equal scales. The color coding of the geometry indicates temperature $(\mathrm{K})$, and the solid lines indicate the initial position of the geometry prior to the thermal expansion.

From Figure A.5, one notices that the deformation is similar in shape to the power density profile. Of concern, are the large relative deformations near the upper and lower ends of the fuel plate caused by the peaks in power in that region. These deformations have steep altitude gradients with respect to the vertical axis. Significant energy could be extracted from the flow to feed eddies that reside downstream of these large gradient deformations should the computed results indeed hold to be true. Details of this finding will be included in the final report.

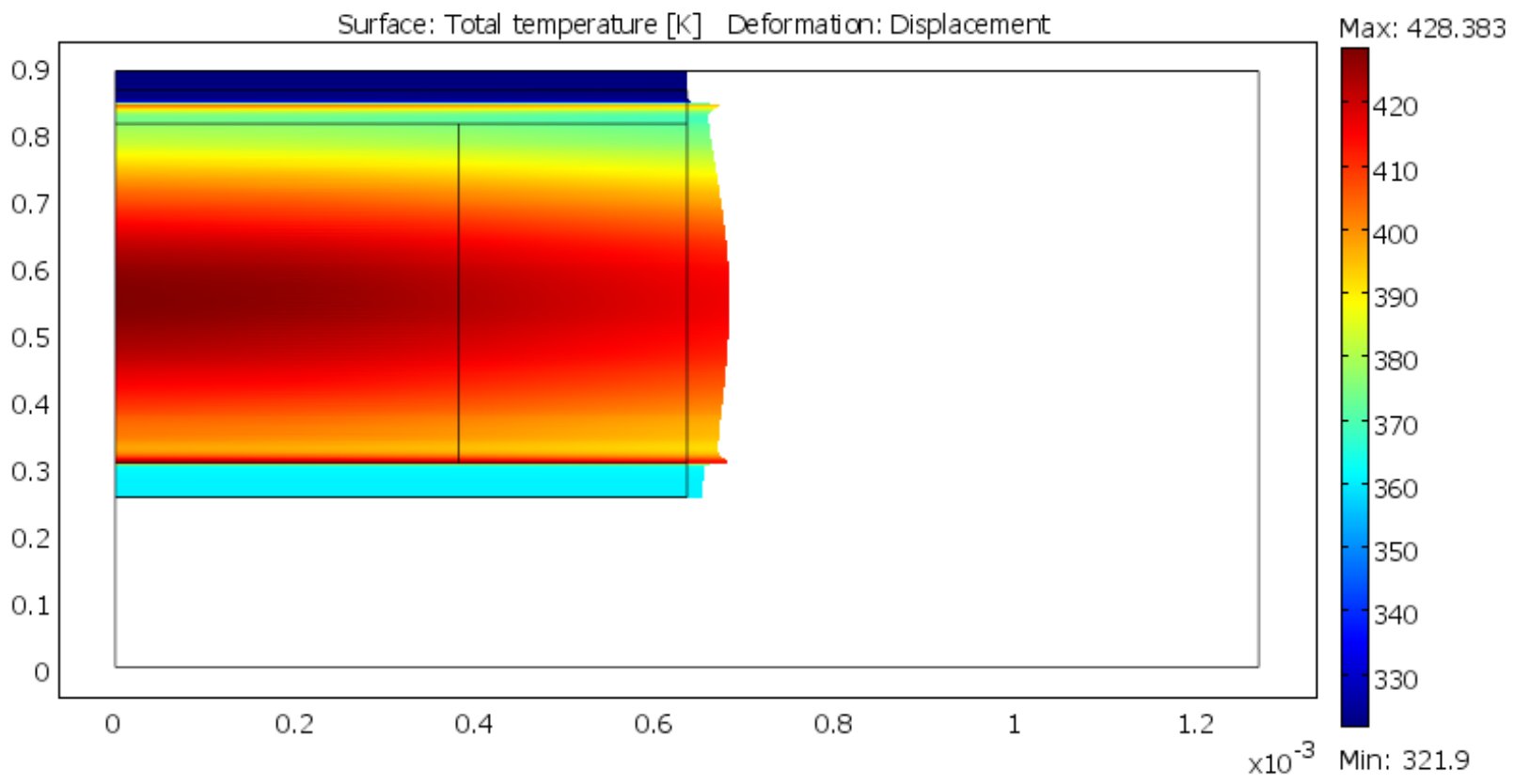

Fig. A.5. Preliminary 2D Model of the thermal swelling of the HFIR HEU fuel plate.

\section{A.4. Investigation of Oxide Growth Modeling in HFIR Fuel}

Oxide growth modeling techniques were investigated based on reports from the Advanced Neutron Source Reactor (ANSR) and the HFIR. The techniques used can be incorporated into the COMSOL modeling capabilities without a major problem. It was also determined that this topic would not become a $\mathrm{PhD}$ dissertation topic, so it is now a lower priority item in further development for the particular student involved. However, it is fully anticipated that the oxide growth effects will be incorporated into the multiphysics models developed in a straight-forward manner. 


\section{A.5. Software QA and Investigation of Distributed Parallel Processing}

Version 3.5a of COMSOL was accepted for nuclear-safety related calculations for HFIR on 07/17/2009. A draft nuclear-safety-related calculation C-HFIR-2010-040/R0 has been created using this version of the code and is currently in the check/review cycle for further processing and eventual approval. The calculation is essentially a translation of ORNL/TM-2010/018 from a report format to a formal calculation format. The main purpose of the calculation is to demonstrate that a COMSOL calculation could be prepared and accepted given the dramatically different form of computing documentation required. Recall COMSOL input is entirely generated from a graphical user interface (GUI), whereas, traditional legacy software uses a text-based input.

A task was started to qualify version 4.0 of COMSOL shortly after it was released during this fiscal year. It was soon realized that it was premature to qualify the v4+ series of COMSOL until such time as the documentation and model library includes all the example models from the v3+ series. In addition, the code development is very active for version 4 with releases of v4.0, v4.0a, v4.1, and an additional update patch for each release, already occurring in 2010. In addition, v4.2 is already planned for April 30, 2011. According to COMSOL developers, the code will have recovered all the previous capability and model library from v3.5a by the v4.2 release. The version 4 release has been a major change to the GUI as well as essential code architecture such that it has taken a considerable amount of time for the user base (over 60,000 licenses worldwide) to adjust to the changes [based on unofficial tallies taken at the COMSOL Conference, only 25\% of COMSOL users have transitioned to the new version 4 series]. The underlying changes to version 4 are very beneficial for the HFIR fuel-plate modeling, including: (1) the new Low-Reynolds number turbulence model, (2) general parametric curve geometry creation (involute plate), (3) improved periodic boundary conditions, and (4) distributed parallel processing capability. Therefore, the T-H analysis team on this project has already committed to the version 4 transition and have become accustomed to the new GUI and code features. At the appropriate time, the task of qualifying version v4+ to meet the ORNL/RRD/HFIR software QA requirements will be reintroduced.

As mentioned earlier, the new version 4 includes the capability to obtain COMSOL model solutions using modern distributed parallel processing (DPP) compute clusters. Specific COMSOL performance on HFIR models has been demonstrated and published for an early release of v4. This capability is still under investigation to determine the effectiveness of this new capability for the HFIR fuel element models. In addition, the HFIR computational resource (the cluster betty.ornl.gov) is being upgraded to provide additional compute nodes. The upgrade and new capability should provide an improved turnaround of results as the modeling effort matures.

\section{A.6. References}

1. COMSOL 3.5a Multiphysics Users Guide page 52.

2. Kays, William, Michael Crawford, and Bernhard Weigand. Convective Heat and Mass Transfer. New York, NY: McGraw Hill, 2005. 



\section{APPENDIX B}

\section{B.1 Proposal letter from IRM dated March 3, 2010 (2 pages)}

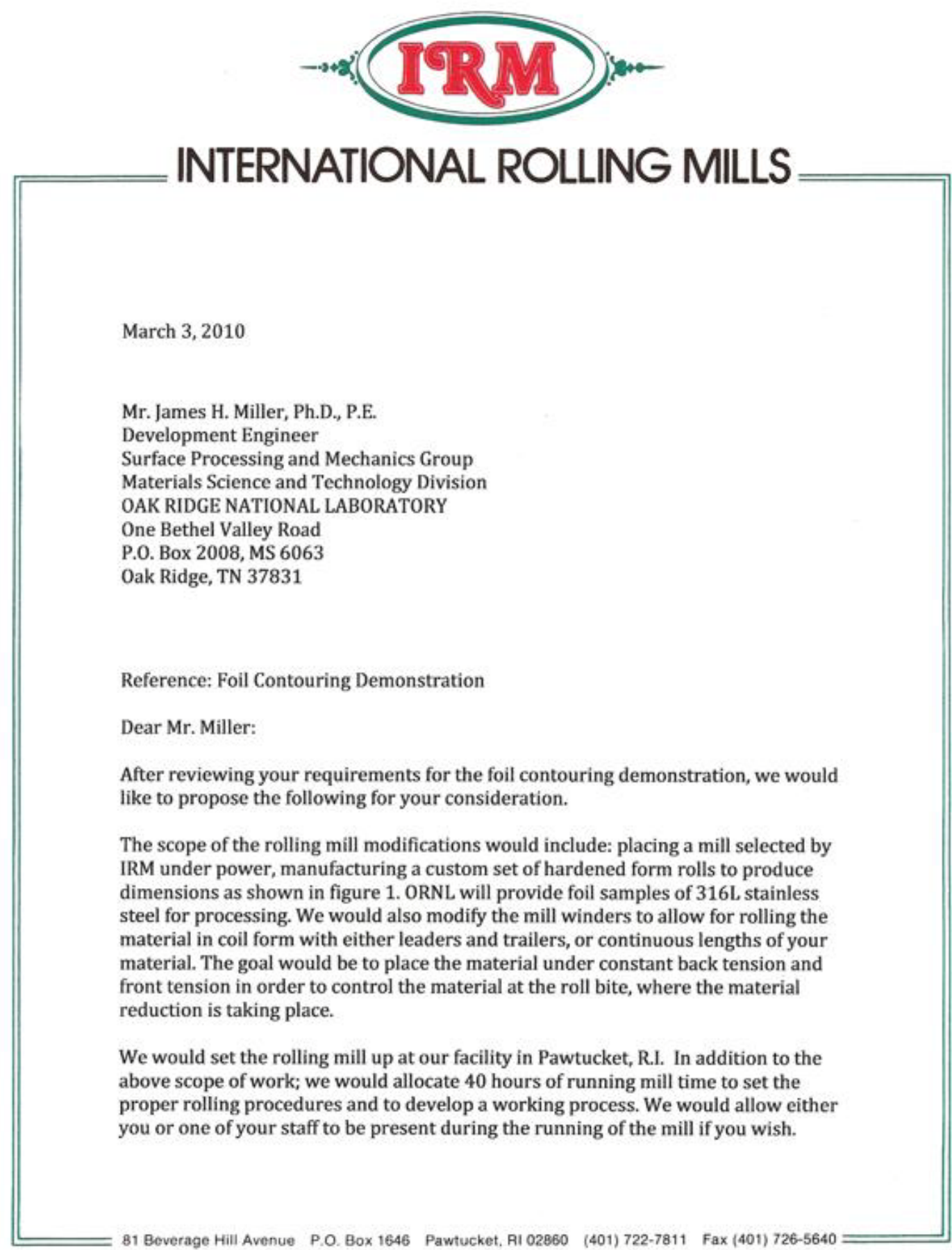




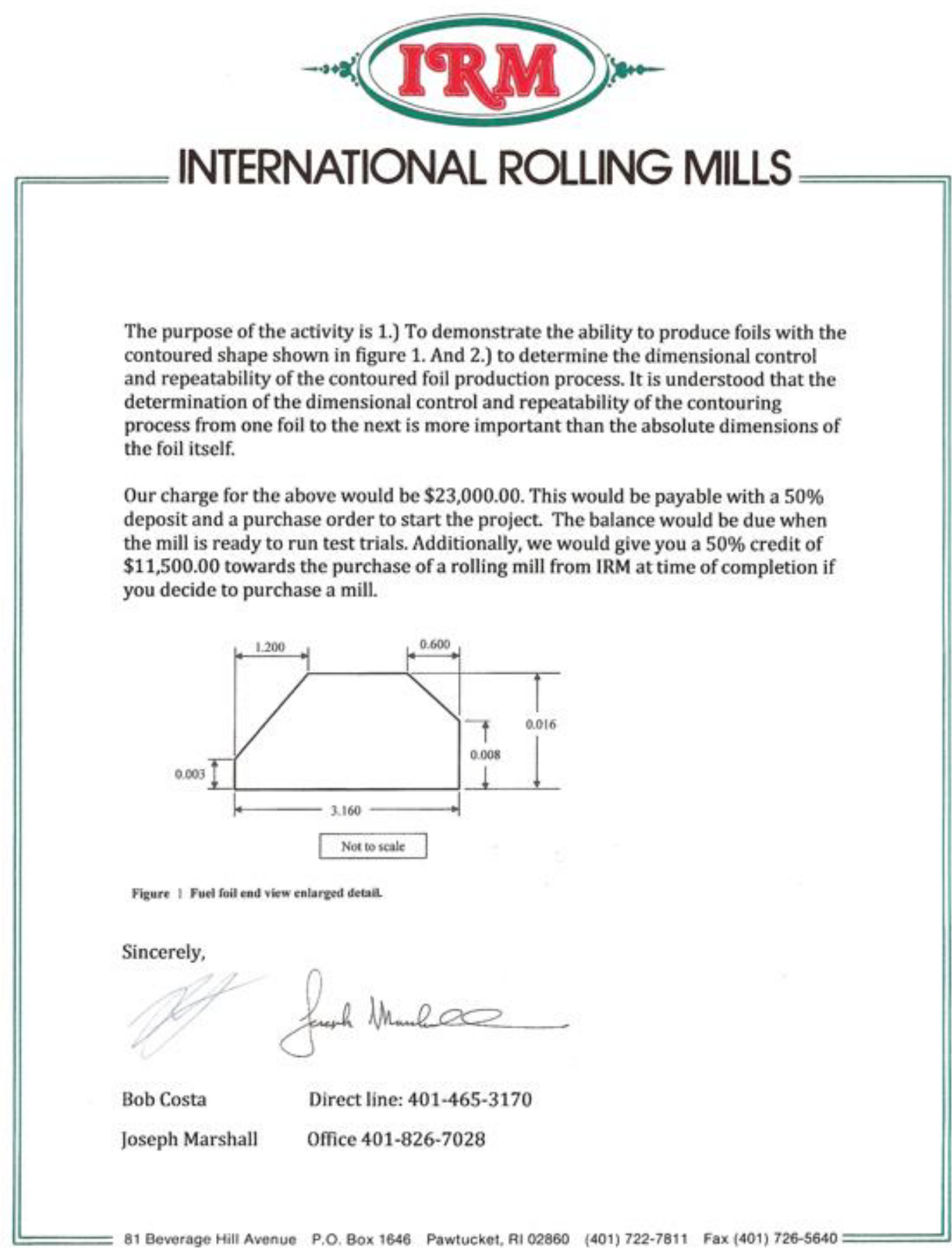

The purpose of the activity is 1.) To demonstrate the ability to produce foils with the contoured shape shown in figure 1. And 2.) to determine the dimensional contro process from one foil to the next is more important than the absolute dimensions of (1, 500.00 towards the purchase of a rolling mill from IRM at time of completion if

Figure | Fued foil end view enlarged detal

Sincerely,

Bob Costa

Joseph Marshal 
B.2 Proof of Concept letter from IRM dated April 21, 2010 (1 page)

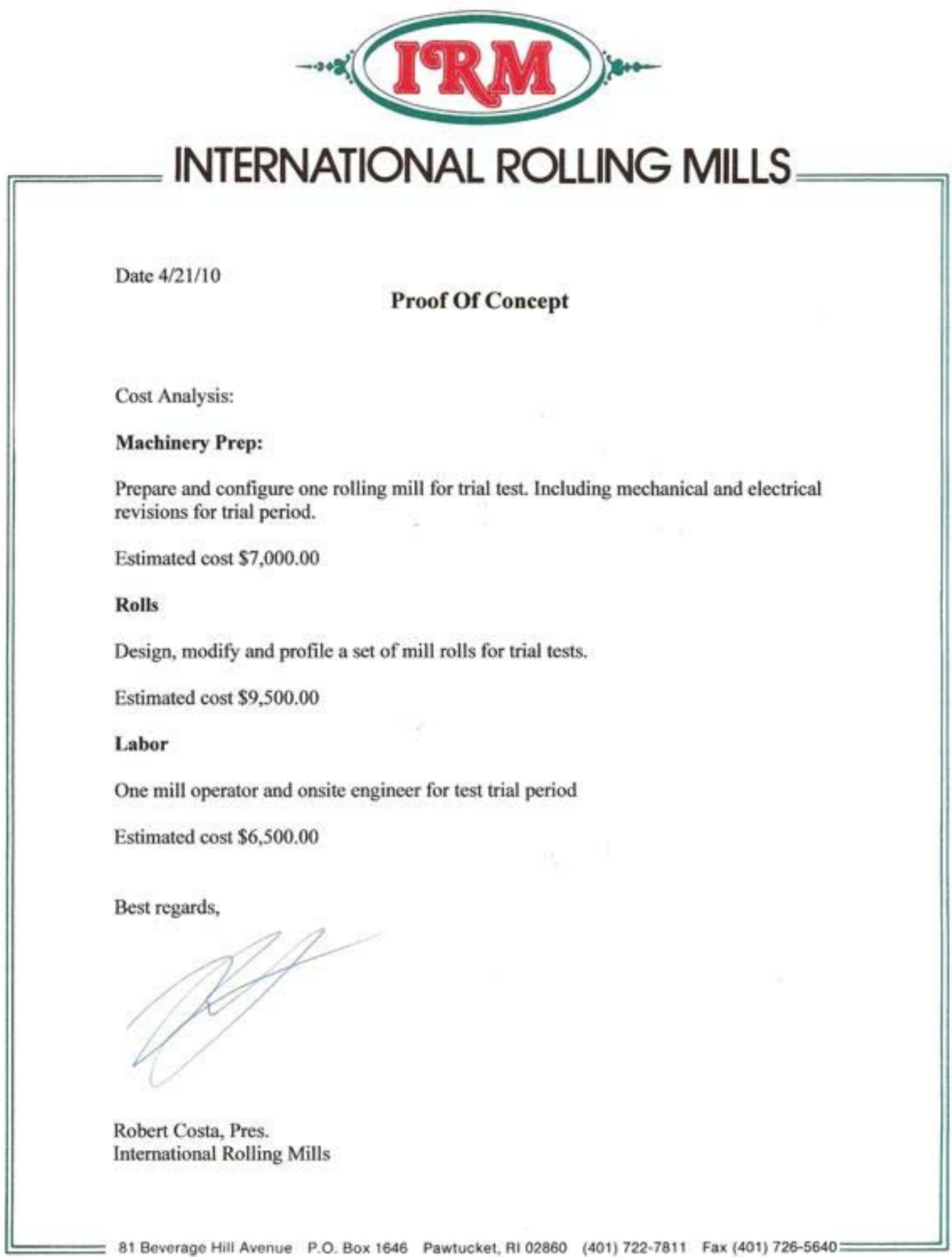




\section{B.3 Foil contouring results letter from IRM dated November 16, 2010 (7 pages)}

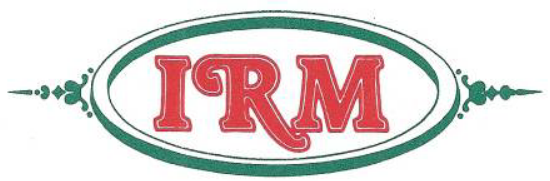

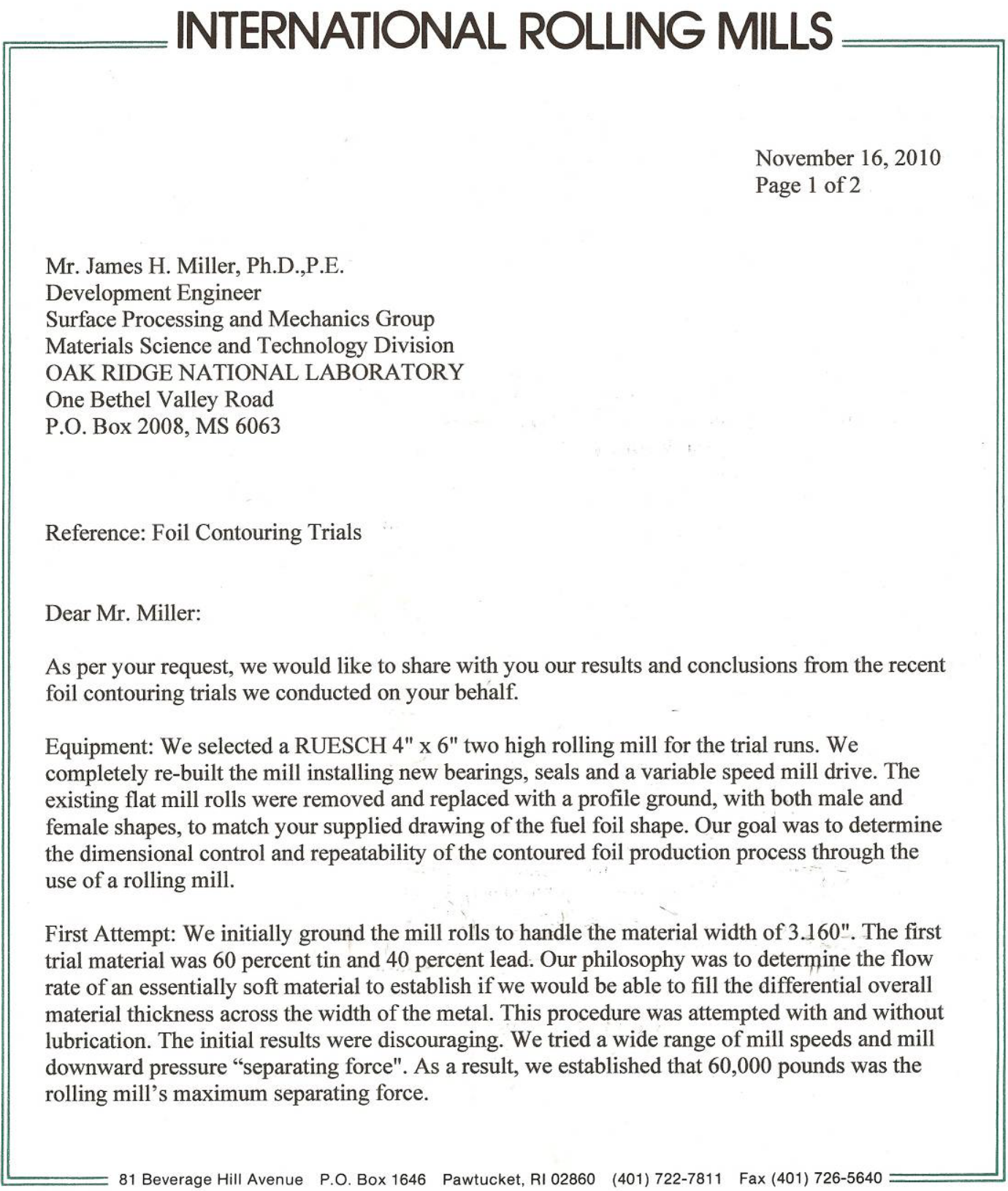




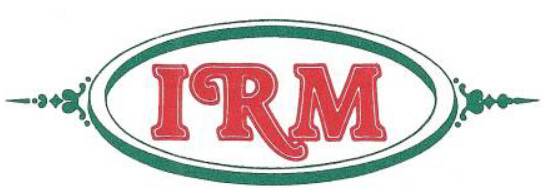

INTERNATIONAL ROLLING MILLS

Mr. James H. Miller, Ph.D.,P.E.

Development Engineer
November 16,2010

Page 2 of 2

Second Attempt: We removed the form rolls from the rolling mill and had them re-ground essentially splitting the overall profile into two sides. For this trial we used a quarter hard, $70 / 30$-brass alloy. The initial passes through the rolling mill looked promising. We found however, as we came down to the desired gage, the material was picking up in the center of the strip as it was passing between the rolls. The addition of lubrication caused little change in the movement of the metal.

Conclusions: Based on our two different trial runs, we have reached the conclusion that a more desirable method to produce your contour would be to use a hydraulic press with specific tooling to forge the part. With a progressive tool the material could be struck multiple times in which the metal is entrapped in the tool. We currently have a 1100 ton capacity hydraulic platen press in inventory which we believe would be well suited for the trials. We would be happy to discuss this possible option with you.

Sincerely,

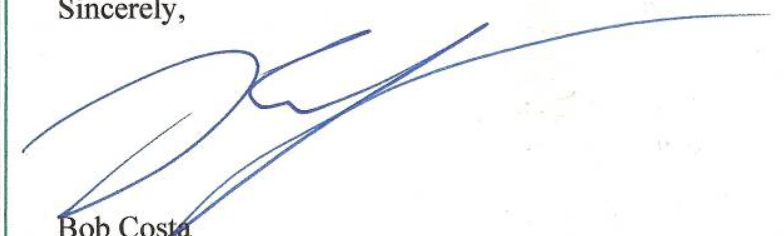

President, International Rolling Mills

Direct Line: 401-465-3170

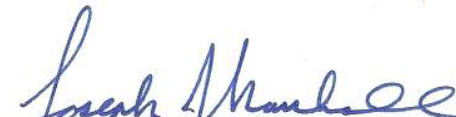

Joseph Marshall

Senior Engineer

Office: $401-826-7028$ 

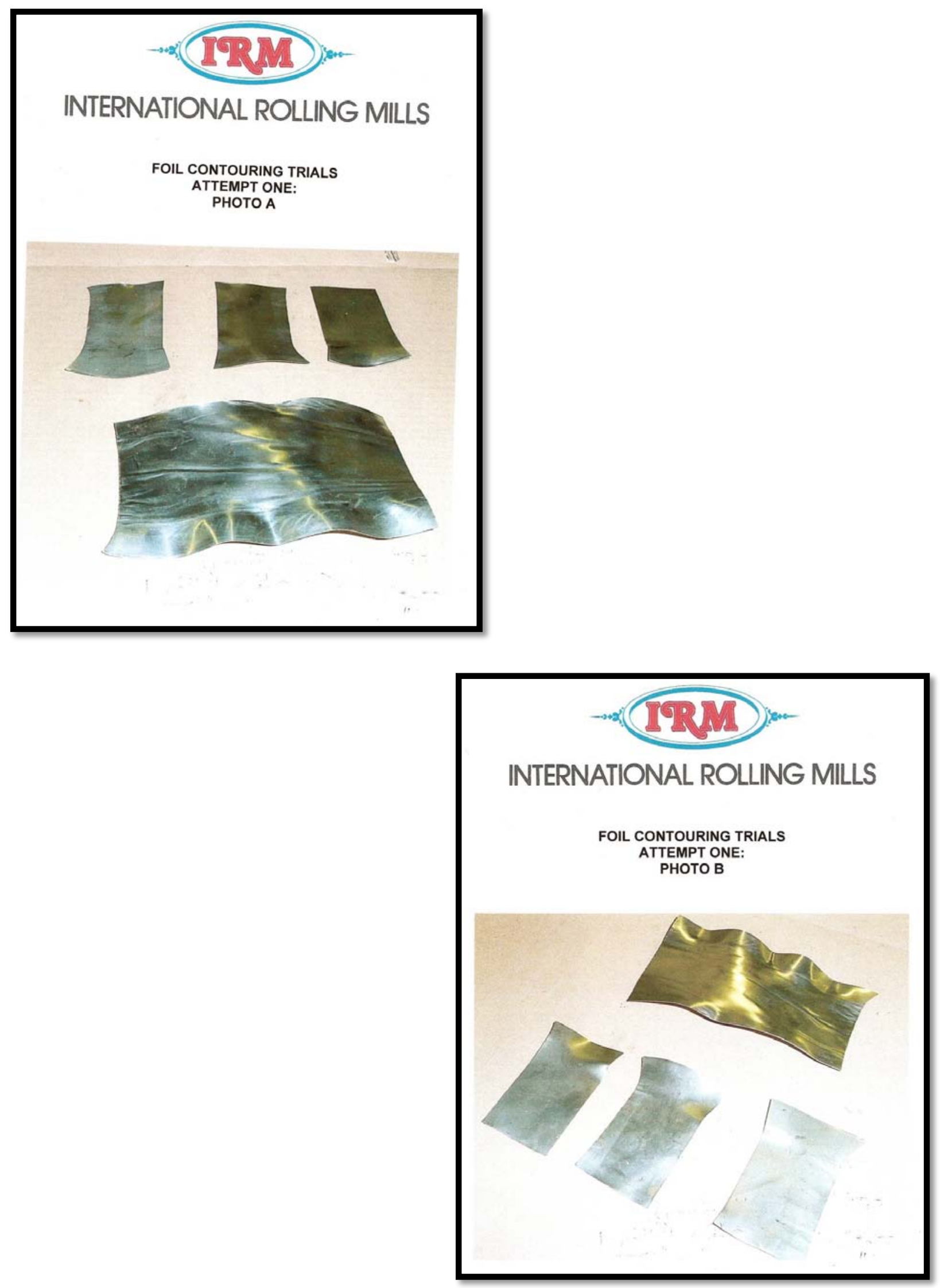

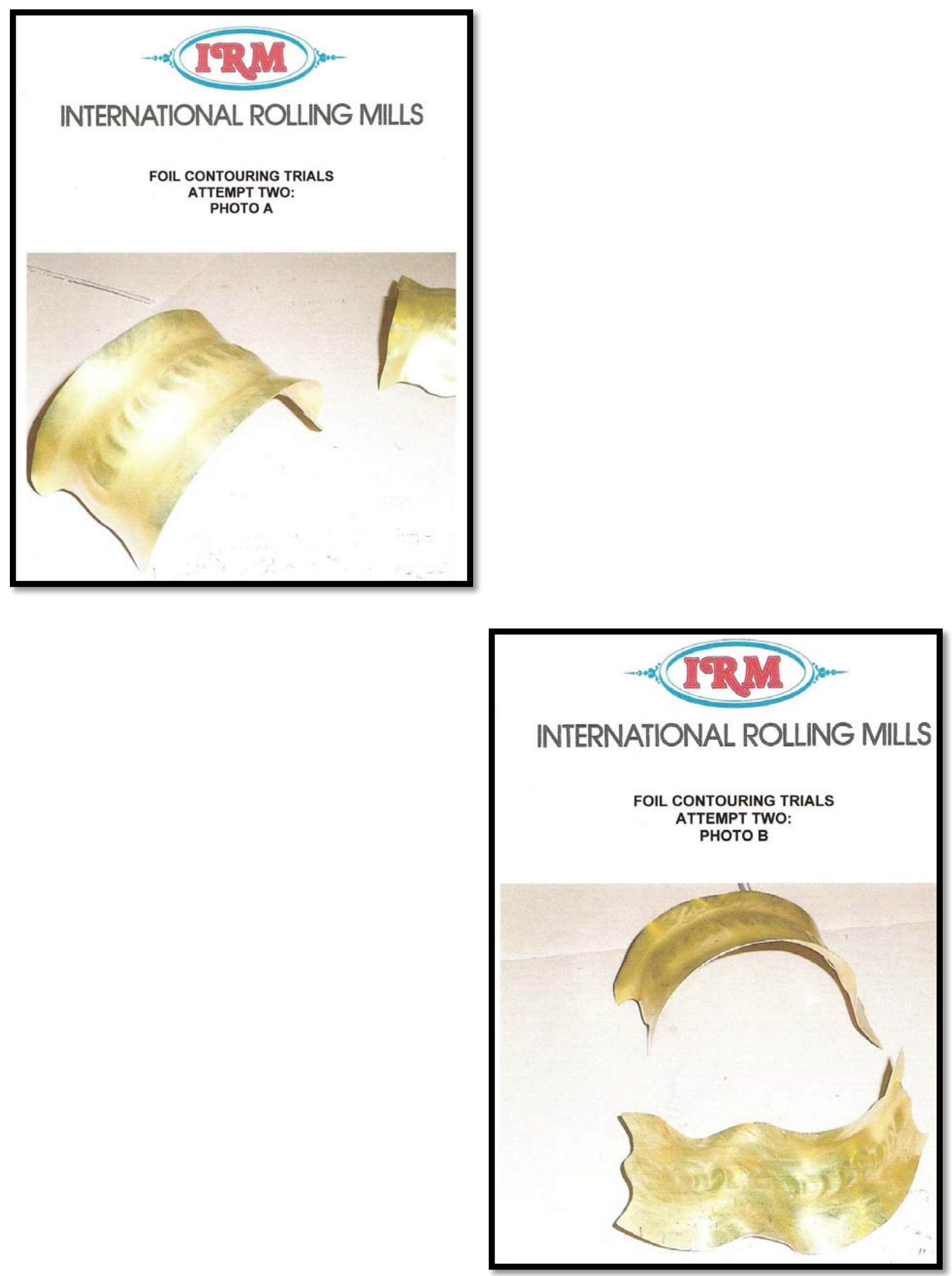


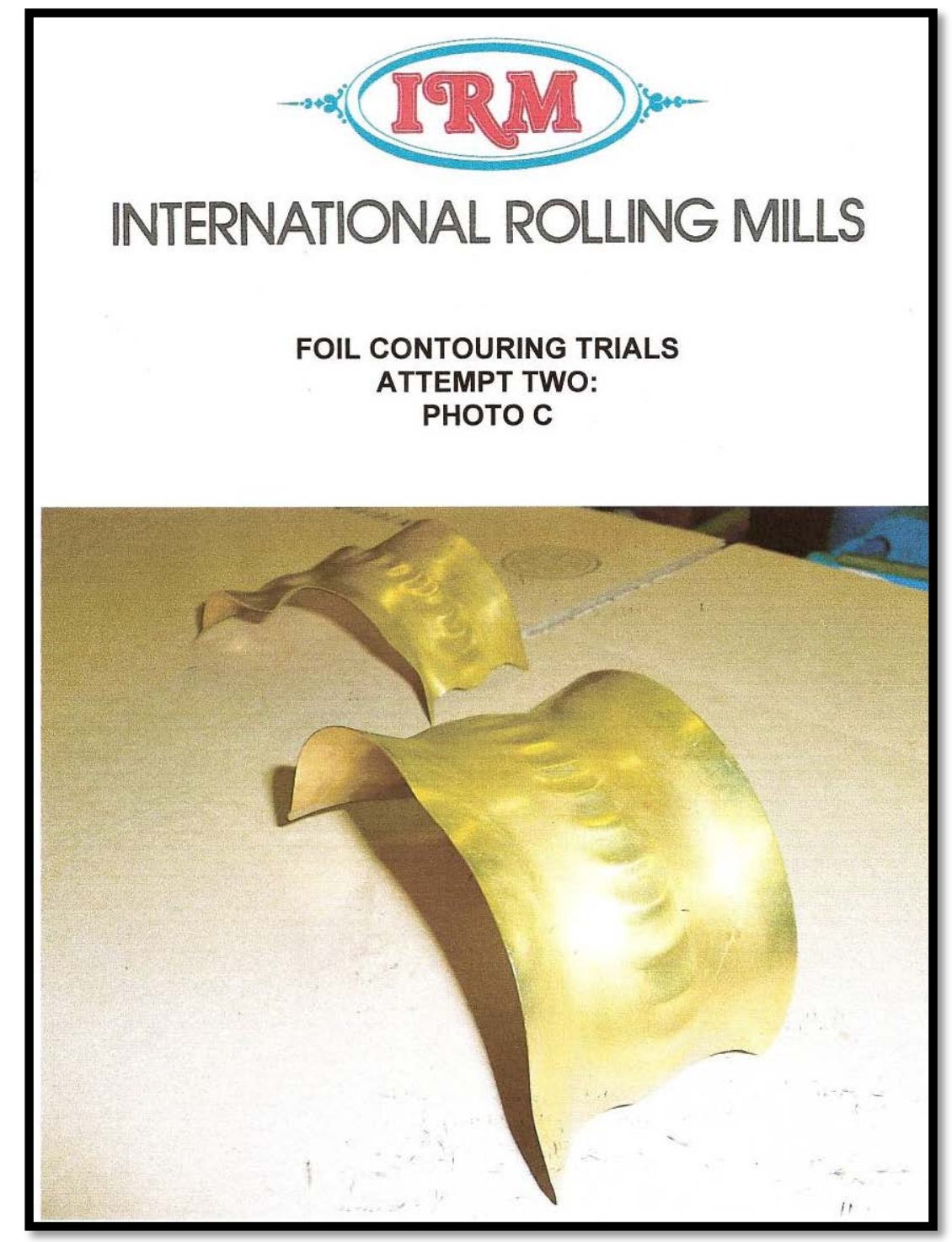




\section{INTERNAL DISTRIBUTION}

1. K. J. Beierschmitt (beierschmitt@ornl.gov)

2. G. I. Bell (bellgi@ornl.gov)

3. J. L. Binder (binderjl@ornl.gov)

4. S. E. Burnette (burnettese@ornl.gov)

5. D. H. Cook (dhc@ornl.gov)

6. B. S. Cowell (cowellbs@ornl.gov)

7. R. A. Crone (cronera@ornl.gov)

8. R. J. Ellis (ellisrj@ornl.gov)

9. J. D. Freels (freelsjd@ornl.gov)

10. J. C. Gehin (gehinjc@ornl.gov)

11. S. R. Greene (srg@ornl.gov)

12. A. S. Icenhour (icenhouras@ornl.gov)

13. G. Ilas (ilasg@ornl.gov)

14. B. C. Jolly (jollybc@ornl.gov)
15. J. H. Miller (millerjh2@ornl.gov)

16. L.J. Ott (ottlj@ornl.gov)

17. C. V. Parks (parkscv@ornl.gov)

18. R. T. Primm III (primmrtiii@ornl.gov)

19. D. G. Renfro (renfrodg@ornl.gov)

20. J. E. Rushton (rushtonje@ornl.gov)

21. L. J. Satkowiak (satkowiaklj@ornl.gov)

22. J. D. Sease (seasejd@ornl.gov)

23. K. A. Smith (smithka@ornl.gov)

24. R. L. Snipes (snipesrl@ornl.gov)

25. W. J. Toth (tothwj@ornl.gov)

26. S. J. Zinkle (zinklesj@ornl.gov)

27. ORNL Laboratory Records (hamrindr@ornl.gov)

\section{EXTERNAL DISTRIBUTION}

28. A. Adams, U.S. Nuclear Regulatory Commission, One White Flint North, 11555 Rockville Pike, Rockville, Maryland 20852-2738 (axa@nrc.gov)

29. R. A. Butler, Director, Research Reactor Center, 1513 Research Park Drive, Columbia, MO 65211 (ButlerRa@missouri.edu)

30. G. S. Chang, Idaho National Laboratory, P.O. Box 1625, Idaho Falls, ID 83415-3885 (gray.chang@inl.gov)

31. J. Chamberlin, NA-212, U.S. Department of Energy, 1000 Independence Avenue SW, Washington, DC 20585 (jeffry.chamberlin@nnsa.doe.gov)

32. D. Chong, NA-212, U.S. Department of Energy, 1000 Independence Avenue SW, Washington, DC 20585 (Daniel.Chong@nnse.doe.gov)

33. Bruce DeWald, (bruce.dewald@nuclearassociates.com).

34. D. Diamond, Brookhaven National Laboratory, P.O. Box 5000, Upton, NY 11973-5000 (diamond@bnl.gov)

35. M. D. DeHart, Idaho National Laboratory, P. O. Box 1625, Idaho Falls, Idaho 83415-8370 (Mark.DeHart@inl.gov)

36. Phillip Finck, Associate Laboratory Director - Nuclear Science \& Technology, INL, P.O. Box 1625, MS 3860, Idaho Falls, ID 83415-3860 (Phillip.Finck@inl.gov)

37. D. Kutikkad, Assistant Reactor Manager-Physics, University of Missouri Research Reactor Facility, Columbia, MO 65211 (kutikkadk@missouri.edu)

38. C. Landers, NA-212, U.S. Department of Energy, 1000 Independence Avenue SW, Washington, DC 20585 (Christopher.landers@nnsa.doe.gov)

39. J. Matos, Argonne National Laboratory, 9700 S. Cass Avenue, Argonne, IL 60439 (jim.matos@anl.gov)

40. C. McKibben, University of Missouri Research Reactor Facility, Columbia, MO 65211 (mckibben@missouri.edu)

41. John Dwight, Idaho National Laboratory, P.O. Box 1625, Idaho Falls, ID 83415-3750 (John.Dwight@inl.gov)

42. T. Newton, MIT Nuclear Reactor Laboratory, 138 Albany St., Cambridge, MA 02139 (tnewton@mit.edu)

43. W. Richards, NIST Center for Neutron Research, 100 Bureau Drive, Stop 8561, Gaithersburg, MD 208998561 (wade.richards@nist.gov)

44. J. Roglans, Argonne National Laboratory, 9700 S. Cass Avenue, Argonne, IL 60439 (roglans@anl.gov)

45. Paul Roth, Idaho National Laboratory, P.O. Box 6188, Idaho Falls, ID 83415 (Paul.Roth@inl.gov)

46. P. Staples, NA-212, U.S. Department of Energy, 1000 Independence Avenue SW, Washington, DC 20585 (Parrish.Staples@nnsa.doe.gov)

47. John G.Stevens, Argonne National Laboratory, 9700 S. Cass Avenue, Argonne, IL 60439 (johnstevens@anl.gov)

48. Daniel M. Wachs, MFC 791 B-147, Idaho National Laboratory, P.O. Box 6188, Idaho Falls, ID 83415 (Daniel.Wachs@inl.gov) 
49. R. E. Williams, NIST Center for Neutron Research, 100 Bureau Drive, Stop 8560, Gaithersburg, MD 208998560 (robert.williams@nist.gov)

50. Sean O’Kelly, NIST Center for Neutron Research, 100 Bureau Drive, Stop 8560, Gaithersburg, MD 208998560 (sean.okelly@nist.gov)

51. W. C. Richardson, BWXT Technology, Inc., 2016 Mount Athos Rd., Lynchburg, VA 24504 (WCRichardson@bwxt.com)

52. Eric C Woolstenhulme, P.O. Box 1625, Idaho Falls, ID 83415-3750 (Eric.Woolstenhulme@inl.gov)

53. Pedro Mantano, Office of Basic Energy Sciences, U.S. Department of Energy, 1000 Independence Avenue SW, Washington, DC 20585 (pedro.montano@science.doe.gov).

54. Carol Sohn, of Basic Energy Sciences, U.S. Department of Energy (carol.sohn@pnso.science.doe.gov).

55. Johnny O. Moore, U. S. Department of Energy, (moorejo@ornl.gov)

56. Les Foyto, Research Reactor Center, 1513 Research Park Drive, Columbia, MO 65211 (foytol@missouri.edu)

57. Lloyd Jollay, Y-12 National Security Complex,( jollayl@y12.doe.gov)

58. David Rosine, U. S. Department of Energy, (rosinedb@ornl.gov)

59. Doug Reed, U. S. Department of Energy, (reeddr@ornl.gov)

60. Gary Solbrekken, University of Missouri, Columbia, MO 65211 (solbrekkeng@missouri.edu)

61. David McDaniel, Idaho National Laboratory, P.O. Box 6188, Idaho Falls, ID 83415 (David.McDaniel@inl.gov) 